\title{
Biological and Biochemical Transformation of Nutrients in Agricultural Soils of Yucatan, Mexico
}

\author{
Dissertation \\ to obtain the $\mathrm{Ph}$. D. degree \\ in the International Ph. D. Program for Agricultural Sciences in Göttingen \\ (IPAG) \\ at the Faculty of Agricultural Sciences, \\ Georg-August-University Göttingen, Germany
}

presented by

Adriana J. Campos G.

born in Carúpano, Venezuela

Göttingen, January 2008 
D7

1. Supervisor: Professor Dr. Holm Tiessen

2. Co-supervisor: Professor Dr. Juan Jimenez Osornio

3. Co-Supervisor: PD Dr. Martin Worbes

Date of Examination: $31^{\text {st }}$ January 2008. 


\section{TABLE OF CONTENT}

LIST OF ABBREVIATIONS ...........................................................................................v

\section{BIOLOGICAL AND BIOCHEMICAL TRANSFORMATION OF NUTRIENTS IN}

AGRICULTURAL SOILS OF YUCATAN, MEXICO.........................................................1

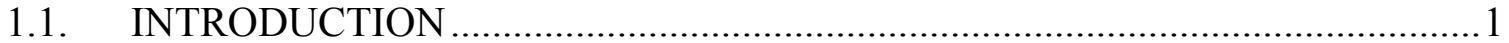

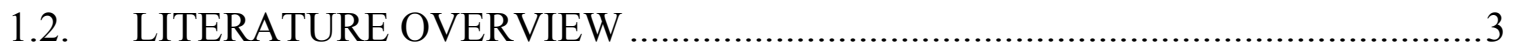

1.2.1. Geology, Land Use Systems and Soil Fertility in the Yucatan Peninsula.................... 3

1.2.2. Influence of water content on the soil biological processes ..................................6

1.2.3. Litter decomposition and the role of the soil fauna on the decomposition process....... 8

1.2.4. Soil biological and biochemical processes and its role in nutrient cycling ................. 12

1.2.5. Soil Microbial Biomass ........................................................................................ 14

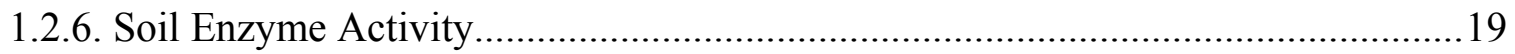

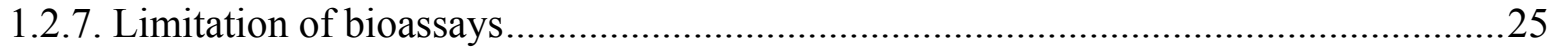

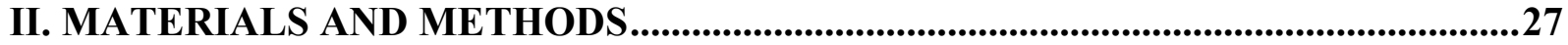

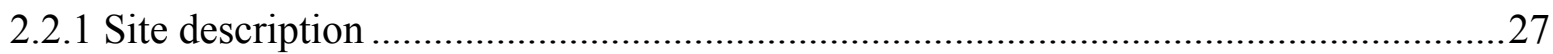

2.2.2 Land Use Systems and Plot selection ...............................................................28

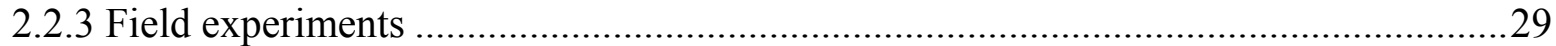

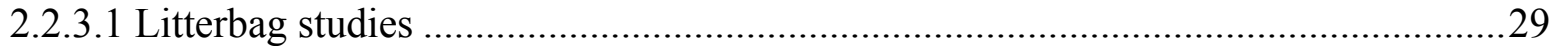

2.2.4. Soil Sampling and Laboratory Analyses .............................................................29

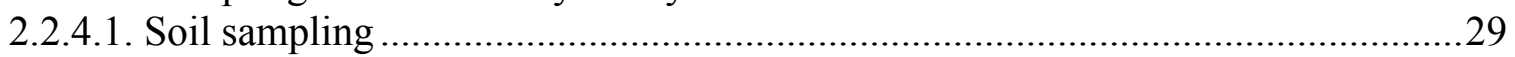

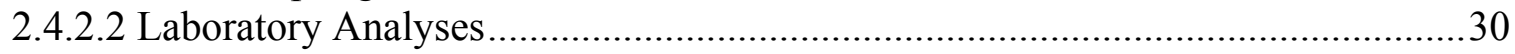

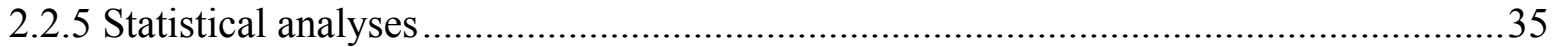

III. LITTER DECOMPOSITION, SOIL FAUNA, MICROBIAL BIOMASS, AND

ENZYME ACTIVITY INVOLVED IN THE C -CYCLE IN KARSTIC SOILS OF

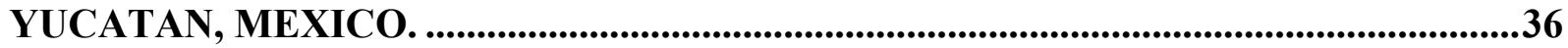

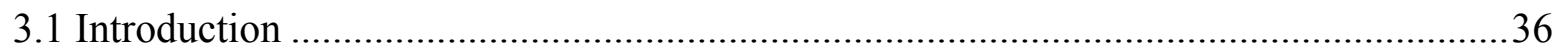

III.A. Soil Biological, Microbial and Biochemical Characteristics under Field Conditions.

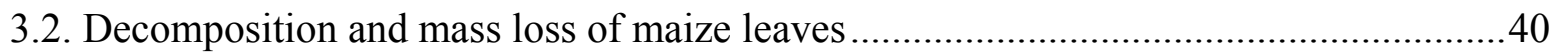

3.3. Soil Fauna abundance and their relation to observations of litter mass loss .................44

3.4. Soil fauna abundance and their functional role in different land use at Yucatan, Mexico

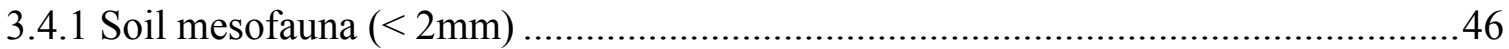

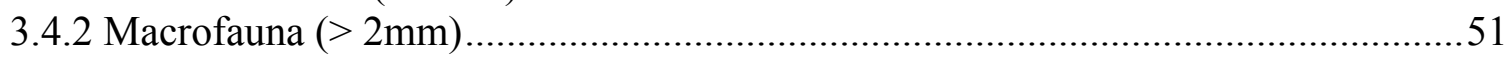

3.5. Microbial biomass nitrogen during the dry and rainy season..................................54

3.6. The activity of $\beta$-glucosidase during the dry and rainy season .................................57 


\section{III.B. Soil Microbial and Biochemical Characteristics upon wetting and Laboratory}

incubation.

3.7 Response of the soil microbial activity (soil respiration) after artificial wetting .62

3.7.a) $\mathrm{CO}_{2}$ evolution

3.7.b) $\mathrm{CO}_{2}$ evolved during eighteen days incubation: Differential activity of bacteria and

fungi....

3.7.c) $\mathrm{CO}_{2}$ evolved during thirty-nine days: Influence of the soil moisture on the microbial activity

3.8. Microbial biomass nitrogen upon wetting at the end of the incubation experiment ..70

3.9. $\beta$-Glucosidase activity upon artificial wetting at the end of the incubation experiment.

3.10 Synthesis: Effect of seasonal field and simulated laboratory moisture conditions on microbial biomass and activity and soil enzymes .78

IV. SOIL ENZYMES INVOLVED IN N AND P MINERALIZATION IN KARTIC

SOILS OF YUCATAN, MEXICO.

4.1 Introduction .81

IV.A. Soil enzyme activities under field conditions.

4.2 Acid phosphatase activity during the dry and rainy season.

4.3 Alkaline phosphatase activity during the dry and rainy season................................87

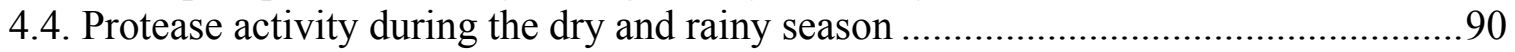

IV.B. Soil biochemical characteristics upon wetting and laboratory incubation. ................93

4.5. Acid Phosphatase activity upon artificial wetting ...........................................93

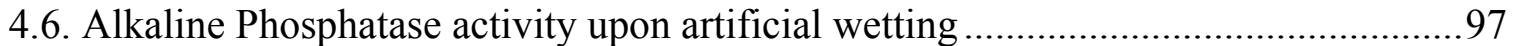

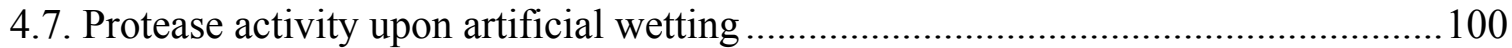

4.8 Synthesis: Effects of moisture conditions on enzymes involved in the $\mathrm{N}$ and $\mathrm{P}$ cycle -

Potential effect on nutrient availability and comparison to microbial activities................104

V. GENERAL CONCLUSIONS. ......................................................................................106

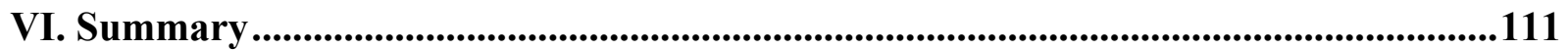

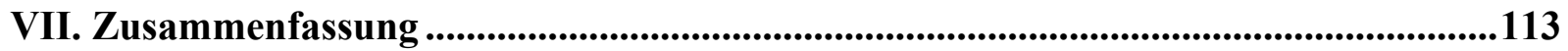

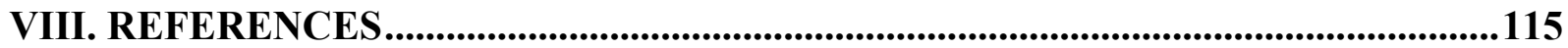

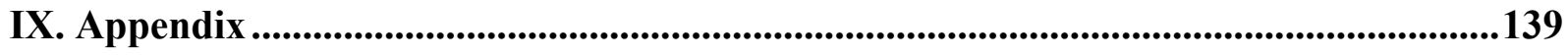

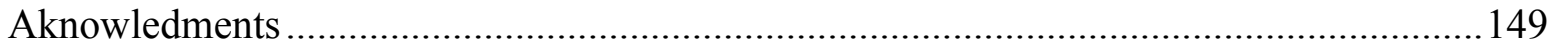

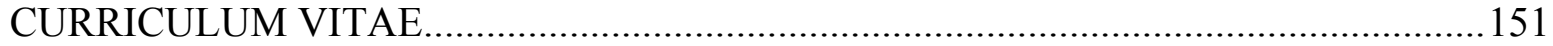




\section{LIST OF TABLES}

Table 2. 1. Main characteristics of soils in the different land use systems (these samples were taken at the same plots as were sampled for this thesis).

Table 3.1. a. Abundance of the soil fauna (ind. $\mathrm{m}^{-2}$ ) in the black soils under different landuse during the dry and rainy season. Classification according to body width of the mesh sizes pores (medium: $<250 \mu \mathrm{m}$ and big: $1000 \mu \mathrm{m}$ ).

Table 3.1. b. Abundance of the soil fauna (ind. $\mathrm{m}^{-2}$ ) in the red soils under different landuse during the dry and rainy season. Classification according to body width of the mesh sizes pores (medium: $<250 \mu \mathrm{m}$ and big: $1000 \mu \mathrm{m}$ ).

Table 3.3. a. Abundance of the most important decomposer groups (ind. $\mathrm{m}^{-2}$ ) in the black soils under different land uses during the dry and rainy season. ...................................................5 Table 3.3. b. Abundance of the most important decomposer groups (ind. $\mathrm{m}^{-2}$ ) in the red soils under different land uses during the dry and rainy season.

Table 3.4. a. Microbial biomass $\mathrm{N}$ ( $\mathrm{mg} \mathrm{N} \mathrm{kg}^{-1}$ dry soil) in the black soils under different land uses during the dry and rainy season.

Table 3.4. b. Microbial biomass $\mathrm{N}$ ( $\mathrm{mg} \mathrm{N} \mathrm{kg}^{-1}$ dry soil) in the red soils under different land uses during the dry and rainy season.

Table 3.5. a. $\beta$-glucosidase activity ( $\mathrm{mg} \mathrm{PNP} \mathrm{kg}^{-1}$ dry soil $\mathrm{h}^{-1}$ ) in black soils under different land uses during the dry and rainy season.

Table 3.5. b. $\beta$-glucosidase activity (mg PNP kg ${ }^{-1}$ dry soil h$\left.{ }^{-1}\right)$ in red soils under different land uses during the dry and rainy season.

Table 3.6. a. Cumulative $\mathrm{CO}_{2}-\mathrm{C}\left(\mathrm{mg} \mathrm{CO}_{2} \mathrm{~kg}^{-1}\right.$ soil) emission during 18 days of the black soils in 4 treatments: $1 / 2 \mathrm{FC}, \mathrm{FC}$, with $\mathrm{Str}$, and control under different land uses. .66 Table 3.6. b. Cumulative $\mathrm{CO}_{2}-\mathrm{C}\left(\mathrm{mg} \mathrm{CO} \mathrm{kg}^{-1}\right.$ soil) emission during 18 days of the red soils in 4 treatments: $1 / 2 \mathrm{FC}, \mathrm{FC}$, with $\mathrm{Str}$, and control under different land uses.

Table 3.7. a. Cumulative $\mathrm{CO}_{2}-\mathrm{C}$ ( $\mathrm{mg} \mathrm{CO}_{2} \mathrm{~kg}^{-1}$ soil) emission during 39 days of the black soils in 3 treatments: $1 / 2 \mathrm{FC}, \mathrm{FC}$ and control under different land uses.

Table 3.7. b. Cumulative $\mathrm{CO}_{2}-\mathrm{C}\left(\mathrm{mg} \mathrm{CO}_{2} \mathrm{~kg}^{-1}\right.$ soil) emission during 39 days of the red soils in 3 treatments: $1 / 2 \mathrm{FC}, \mathrm{FC}$ and control under different land uses.

Table 3.8. a. Microbial Biomass $\mathrm{N}$ by artificial wetting of black soils under different land uses (mg N kg ${ }^{-1}$ dry soil).

Table 3.8. b. Microbial Biomass $\mathrm{N}$ by artificial wetting of red soils under different land uses (mg N kg${ }^{-1}$ dry soil).

Table 3.8. c. Pearson's correlation coefficients of microbial biomass nitrogen upon artificial wetting with moisture content, organic $\mathrm{C}$, microbial activity $\left(\mathrm{CO}_{2}-\mathrm{C}\right)$ and nitrate.

Table 3.9. a. $\beta$-glucosidase activity by artificial wetting of black soils under different land uses (mg PNP kg ${ }^{-1}$ dry soil ${ }^{-1}$ ). 75

Table 3.9. b. $\beta$-glucosidase activity by artificial wetting of red soils under different land uses (mg PNP kg ${ }^{-1}$ dry soil $\mathrm{h}^{-1}$ ). 
Table 3.9. c. Pearson's correlation coefficients of $\beta$-glucosidase upon artificial wetting with moisture content, microbial activity $(\mathrm{CO} 2-\mathrm{C})$ and organic $\mathrm{C}$.

Table 4.1. a. Acid phosphatase activity (mg PNP kg-1 dry soil $\mathrm{h}^{-1}$ ) in black soils under different land uses during the dry and rainy season.

Table 4.1. b. Acid phosphatase activity (mg PNP kg-1 dry soil h $\mathrm{h}^{-1}$ ) in red soils under different

land uses during the dry and rainy season. ...

Table 4.1. c. Pearson's correlation coefficients of the acid phosphatase activity (acP) during the dry and rainy season with moisture content, inorganic $\mathrm{P}$ and organic $\mathrm{P}$.

Table 4.2. a. Alkaline phosphatase activity ( $\mathrm{mg} \mathrm{PNP} \mathrm{kg}^{-1}$ dry soil $\left.\mathrm{h}^{-1}\right)$ in black soils under different land uses during the dry and rainy season.

Table 4.2. b. Alkaline phosphatase activity (mg PNP kg-1 dry soil $\mathrm{h}^{-1}$ ) in red soils under different land uses during the dry and rainy season.

Table 4.2. c. Pearson's correlation coefficients of alkaline phosphatase activity (alP) during the dry and rainy season with moisture content and microbial activity $\left(\mathrm{CO}_{2}-\mathrm{C}\right)$.

Table 4.3. a. Protease activity $\left(\mathrm{mg} \mathrm{NH}_{4}{ }^{+} \mathrm{kg}^{-1}\right.$ dry soil $\left.\mathrm{h}^{-1}\right)$ in black soils under different land uses during the dry and rainy season.

Table 4.3. b. Protease activity $\left(\mathrm{mg} \mathrm{NH}_{4}{ }^{+} \mathrm{kg}^{-1}\right.$ dry soil h$\left.{ }^{-1}\right)$ in red soils under different land uses during the dry and rainy season. 91

Table 4.3. c. Pearson's correlation coefficients of protease activity during the rainy and dry season with moisture content, microbial biomass $\mathrm{N}$, total $\mathrm{N}$, organic $\mathrm{C}$ and microbial activity $\left(\mathrm{C}-\mathrm{CO}_{2}\right)$

Table 4.4 a. Acid phosphatase activity (mg PNP kg ${ }^{-1}$ dry soil $\mathrm{h}^{-1}$ ) in black soils under different land uses by artificial wetting.

Table 4.4 b. Acid phosphatase activity (mg PNP kg-1 dry soil h $\left.\mathrm{h}^{-1}\right)$ in red soils under different land uses by artificial wetting.

Table 4.4 c. Pearson's correlation coefficients of acid phosphatase activity (acP) after artificial wetting with organic $\mathrm{C}$, microbial activity $\left(\mathrm{C}-\mathrm{CO}_{2}\right)$ and phosphate.

Table 4.5. a. Alkaline phosphatase activity by artificial wetting of black soils under different land uses (mg PNP kg-1 dry soil $\mathbf{h}^{-1}$ ).

Table 4.5. b. Alkaline phosphatase activity by artificial wetting of red soils under different land uses (mg PNP kg-1 dry soil $\mathrm{h}^{-1}$ ).

Table 4.5. c. Pearson's correlation coefficients of alkaline phosphatase activity (alP) after artificial wetting with determined parameters.

Table 4.6. a. Protease activity by artificial wetting of black soils under different land uses (mg $\mathrm{NH}_{4}{ }^{+} \mathrm{kg}^{-1}$ dry soil $\mathrm{h}^{-1}$ ).

Table 4.6. b. Protease activity by artificial wetting of red soils under different land uses (mg $\mathrm{NH}_{4}{ }^{+} \mathrm{kg}^{-1}$ dry soil $\mathrm{h}^{-1}$ ).

Table 4.6. c. Pearson's correlation coefficients of protease activity after artificial wetting with determined parameters.. 


\section{LIST OF ABBREVIATIONS}

\begin{tabular}{|c|c|}
\hline ANOVA & analysis of variances \\
\hline $\mathrm{C}_{\text {mic }}$ & microbial biomass carbon \\
\hline $\mathrm{C}_{\mathrm{t}}$ & total carbon \\
\hline DAI & day after incubation \\
\hline FAO & Food and Agriculture Organization of the United Nations \\
\hline $\mathrm{FC}$ & field capacity \\
\hline Inc. & $\begin{array}{l}\text { abbreviation of incorporated, used in the name of U.S. companies that } \\
\text { are legally established }\end{array}$ \\
\hline ind. $m^{2}$ & individual per square meter \\
\hline $\mathrm{N}_{\text {mic }}$ & microbial biomass nitrogen \\
\hline $\mathrm{N}_{\mathrm{t}}$ & total nitrogen \\
\hline$P_{i}$ available & available inorganic phosphorus \\
\hline PNP & p-nitrophenol \\
\hline $\mathrm{P}_{\mathrm{o}}-\mathrm{HCO}_{3}$ & organic phosphorus extracted with sodium bicarbonate at $\mathrm{pH} 8.5$ \\
\hline$P_{t}$ & total phosphorus \\
\hline PWP & permanent wilting point \\
\hline SOM & soil organic matter \\
\hline SPSS & $\begin{array}{l}\text { software for statistical analysis of data and name of the producer } \\
\text { company }\end{array}$ \\
\hline Str & streptomycin \\
\hline
\end{tabular}




\section{BIOLOGICAL AND BIOCHEMICAL TRANSFORMATION OF NUTRIENTS IN AGRICULTURAL SOILS OF YUCATAN, MEXICO.}

\subsection{INTRODUCTION}

The soils of the Yucatan Peninsula in Mexico, which are subject to diverse kinds of agricultural practices, have shown over time a decline in their fertility (Perez et al. 1981, Zech et al. 1991, Weisbach et al. 2002, Aguila Alcantara 2007). The climate of the region (semiarid) with scarce rainfall, rain in a concentrated short period, and a high mean temperature (26 ${ }^{\circ} \mathrm{C}$ ), play an important role in the soil processes and nutrient cycling. In addition, the high heterogeneity of the soils, where some of them present high organic matter content, does not allow a good diffusion of nutrients and limits their availability to the plants (Shang and Tiessen 2003).

Generally, in semi-arid ecosystems some nutrients are limiting and available to plant in short pulses following precipitation (Schwinning and Sala 2004, James and Richards 2006, 2007). Studies have shown that water input stimulates nutrient mineralization from accumulated organic mater (Austin et al. 2004). However, in a study carried out by Shang and Tiessen (2003) in Yucatan the hydrophobic characteristics of some soil types with high organic matter content was observed, which affects water retention and consequently limits nutrient release.

Several studies have been carried out in some land use systems of the region, such as the physical, (Estrada 2000) chemical, (Zech et al. 1991, Aguila 2007) and ecophysiological (Bejamin 2000) characteristics of the soils. However, there are no studies regarding to biological and biochemical processes, which are very important for the understanding of the soil functioning. Biological processes are the centre of any ecological functions of a soil (Dick 1994), because biotic activity can be influenced by soil degradation, the transformation of organic matter and soil structure (Garcia et al. 1994).

Studies on biological processes of the soils have been based on the measurements of several variables: microbial biomass, respiration, and enzyme activities and, to understand their 
structure and functioning it is also evaluated the soil fauna (structure of communities, abundance and diversity). This thesis is focussed on the evaluation of the soil's biological and biochemical characteristics involved in the nutrients transformation processes, which may contribute to understand the complexity of these soils and to improve their management. Therefore, the principal objectives of this study are summarized in the following points:

- Characterize biological and biochemical processes involved in the nutrients supply during two seasons of the year (dry and rainy) in calcareous soils under three different land uses in Yucatan, Mexico.

- Evaluate the role of biological and biochemical processes in the nutrients availability through incubation study under two contrasting moisture conditions (FC and $1 / 2 \mathrm{FC}$ ) in these soils with different managements from Yucatan.

- Assess the link between soil's biological and biochemical parameters to determine those possible indicators or processes that are affected by changes in the seasons (natural regime) and/or moisture condition (artificial regime), in different agricultural soils from this region. 


\subsection{LITERATURE OVERVIEW}

\subsubsection{Geology, Land Use Systems and Soil Fertility in the Yucatan Peninsula}

The Yucatan Peninsula is constituted by an extensive and deep limestone and dolomite platform that emerged to the surface gradually in a northerly direction from the sea-bottom 25 to 6 million years ago in the Tertiary and Quaternary Period (Duch 1991). The peninsula was formed from whatever shallow-water coastal drift materials happened to lie on the hard crust immediately prior to uplift (Duch 1991).

Limestone as parent material and the limited weathering explain the shallowness and stoniness of the Yucatan soils. The substratum is of calcareous origin, of which the carbonates represent 95\% (Pool 1986), and it is composed of calcium $\left(\mathrm{CaCO}_{3}\right)$ and calcium-magnesium carbonate $\left(\mathrm{CaMg}\left(\mathrm{CO}_{3}\right)_{2}\right.$, dolomite) (Wilson 1980). The permeability of the soils in Yucatan is high and this characteristic does not permit the formation of superficial water, hampering the formation of rivers. The filtration of water led to a karstified subterranean network of water bodies (Wilson 1980). These caverns occasionally breach to the surface and create natural wells that are known as "Cenotes". These are holes of different sizes, which are a result of the dissolution of $\mathrm{CaCO}_{3}$ (Hernandez X., 1959).

The majority of the state presents an undulated and low relief. Only in the south some major elevations can be found due to a folding of the limestone platform in the Tertiary. The solid limestone is locally called Chaltun with a calcareous, friable, and whitish layer underneath, known as Sahkab, which is able to store infiltrated water. Limestone on the soil surface is easily cracked and penetrated by plant roots, which explains the abundance of stones (Duch 1994).

The Yucatan soils present a mosaic of different characteristics: there is a great morphological variation, factors as colour, localization, depth, fertility, water, content of stone (Duch 1991, 1994). The differences in colour are associated principally to the content of organic matter, which give the basic coloration of black, red-brown and red, with high (black soils) or low stone content (red soils). These differences might originate the distinguishing characteristics in the biological and chemical properties. 
Since pre-Columbian times, different agricultural and forestry practices have been developed, modified, and carried out by the Mayan population in the peninsula. At present, the traditional shifting cultivation (milpa) in co-existence with secondary forestry, and homegardens (solares), are the land use systems where the families can self-satisfy their basic necessities, with essential products for their diet as for example maize, which is the principal nutritional source, fruits, and vegetables.

Currently, the milpa system is developed in one third of the soil in Yucatan (Moya et al. 2003). The most important crop of the milpa is maize (Zea mays) followed by squash (Cucurbita pepo and C. moschata) and beans (Phaseolus vulgaris and P.lunatus). In parts of the milpa small patches are used for horticultural species like chillies (Capsicum annum), tomatoes (Lycopersicum esculentum), watermelon (Citrullus lanatus), jícama (Pachyrrhizus erosus), manioc (Manihot eculenta), sweet potatoes (Ipomea batatas), xcucut makal (Xanthosoma yucatanense) and cucumber (Cucumis sativus) (Hernandez X. et al. 1994).

The milpa has different cycles; the first task for the farmer is to select a suitable area and to evaluate the soil, relief, and existing vegetation. The farm worker clears a piece of forest sized between one and two hectares using the slash-and-burn method. The burning takes place at the end of the dry season during the month of March or April, when the slashed vegetation has dried and the beginning of the rain is forthcoming. Normally the milpa system has a short period of cultivation, around two years with long periods of fallow (15-25 years) but now with the increase in the population, changes in the land tenure and limited allocation; the fallow periods have been reduced (20-7 years) and the soils cannot recover its fertility between milpa cycles (Teran and Rasmussen 1992, Benjamin 2000, Weissbach et al. 2002).

Homegardens in Yucatan have been described as other important agricultural system for the Yucatecan families (Benjamin 2000). This system is composed of intimate, multi-story combinations of various trees and crops, in association with domestic animals and around homesteads (Anderson 1993). Despite the fact that the solares are less than one hectare in size, they have a great diversity of species and present three to four vertical floristic strata (Benjamin 2000). The principal function of the homegarden is food production; also to 
generate secondary products (medicinal plants, seasonings, utensils, firewood, etc). Dominance of species in a vegetation analysis of solares in Yucatan was found by Xuluc (1995), among them: Annona squamosa, Apoplanesia panniculata, Brosimum alicastrum, Cedrela odorata, Citrus auratium, Cordia dodecandra, Ehretia tinifolia, Manilkara zapota, Melicoccus bijugatus, Musa paradisiacal, Spondia purpurea, and Talisia olivaeformis. RicoGray et al. (1990; quoted in Benjamin 2000) observed that due to modernization and developing processes, there is a tendency to changes in the structure and functions of the solares.

Several studies have been focussed on the fertility and quality in agricultural soils, and have shown a decline in the soil fertility of the peninsula (Perez et al. 1981, Zech et al. 1991, Weissbach et al. 2002). Zech et al. (1991) observed that some nutrient (P, N, Mn, and Zn) might be deficient. However, Weisbach et al. (2002) who studied the soil fertility in milpa systems with several fallow periods concluded that the nutrient status of the Yucatan soils is higher in comparison to other semiarid tropical soils, and have a rapid capacity of fertility regeneration but low productivity. In addition, Shang and Tiessen (2003) found a high organic

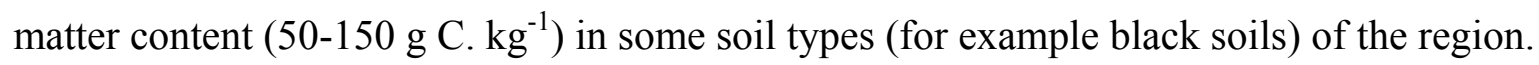

As the peninsula receives low amount of precipitation this might be a reason for their low soil productivity. Generally in semi-arid regions, water, soil nutrients, and plant productivity, typically go through periods of high and low pulses (Schwinning and Sala 2004, James and Richards 2006, 2007). Short periods of high resource abundance are triggered by rainfall events, which despite the overall scarcity of rain, can saturate the resource demand of some biological processes for some time (Schwinning and Sala 2004). Rainfall input into a dry soil triggers a cascade of biogeochemical and biological transformations, which can vary in time from hours to years. For example, the liberation of nitrogen by microorganisms residing on the soil surface takes only hours (Cui and Caldwell 1997) and the demographic responses of primary decomposers and consumers that unfold can take years (Osfeld and Keesing 2000). 
It is known that the soil biological processes are water dependent, because the soil microbial activity is influenced by moisture conditions and, consequently the dynamic of nutrient transformation is affected. Both carbon $(\mathrm{C})$ and nitrogen $(\mathrm{N})$ mineralization rates increase for a few days following the rewetting of a dry soil (Fierer and Schimel 2002). Water may enhance $\mathrm{C}$ mineralization and stimulate microbial activity by acting as a solvent for organic substrates derived from litter. In addition, phosphorus (P) diffusion occurs in water-filled pore spaces in the soil, and their availability to the plants by the moisture is also affected (Misra and Tyler 1999). Higher moisture content allows these substances to diffuse through a greater proportion of the soil pore volume, making them more available to microorganisms and consequently high nutrients mineralization. However, in soils with high organic matter content, the drought, wetting and rewetting might be different and therefore have different effects on the mineralization processes and in nutrients availability.

Soil fertility is related to microbial characteristics (enzyme activities, microbial biomass, microbial turnover, and microbial population), soil physicochemical properties ( $\mathrm{pH}$, organic $\mathrm{C}$ content, and nutrient availability), vegetational response (plant biomass or yield and nutrient uptake), and climatological conditions (temperature and rainfall). Quantitative data on the chemical and physiological processes in the Yucatecan land uses are few. Most of the studies are focused on the structure, system inventory, species composition, diversity, and socioeconomic aspects. Studies about litter decomposition and chemical characteristic have been reported, but information on the biological and biochemical dynamic and transformation of nutrients in the land uses in Yucatan are not well documented.

\subsubsection{Influence of water content on the soil biological processes}

Soil water content regulates biological processes and ecological interactions involved in nutrient cycling. It affects the rate and pathways for microbial transformations of $\mathrm{N}$ and $\mathrm{C}$ (Skopp et al. 1990, Amador and Jones 1997, Amador et al. 2005). In most soils, C mineralization increases with the increase of soil moisture content until saturation is reached (Skopp et al. 1990, Amador and Jones 1997). Water may enhance the microbial activity because the organic substances derived from litter can spread through the soil pores and thus can be available for the microorganisms. The water content also regulates grazing and predation by the soil microfauna (Elliot et al. 1980, Goerres et al. 1999, Savin et al. 2001); 
where a greater connectivity of pore spaces may benefit microbivorous fauna by increasing their access to the microbial habitat (Hassink et al. 1993, Marinissen and deRuiter 1993).

Many studies have reported the moisture effect on soil; litter and humus respiration amongst others, but moisture has been expressed in several terms. Commonly, it has been described in three forms: gravitational, capillary, and hygroscopic. Moisture has been also expressed gravimetrically as a percentage of moisture content, such as water holding capacity or oven dry weight, rather than in terms of the physical force with which water is held in the soil (Orchard and Cook 1983). Birch (1958) first showed its importance by demonstrating that soils with frequent wetting and drying cycles exhibit a pronounced increase in the magnitude of $\mathrm{N}$ mineralization that follows a wetting episode. Since then, many studies have focussed on the influence of drying and rewetting on the microbial biomass, microbial activity, and decomposition of the SOM and most have demonstrated an increased rate of $\mathrm{CO}_{2}$, evolution, microbial biomass, microbial activity, and enzyme activities after rewetting compared to soil kept moist or dried soils (Sorensen 1974, Lund and Goeksoyr 1980, Bloem et al. 1992, Magid et al. 1999, Li and Sarah 2003, Sardans and Pañuelas 2005, Amador et al. 2005). Dry-wet cycles generally cause an increase in decomposition of the SOM because more decomposable organic substrate becomes available for the microbial attack upon drying and rewetting (Sorensen 1974). These substrates are partially obtained from a portion of the killed microorganisms and also of the organic compound occluded in the aggregates (Van Gestel et al. 1991).

Other factors that may influence the increase or decrease of the microbial biomass by drying, wetting and rewetting, are the inherent properties of the soil microbial populations. Soil organisms are not homogeneous; they differ in type, age, physiological, and metabolic rate (Van Gestel et al. 1993). Several groupings based on physiological differences have been proposed (Van Gestel et al. 1993), and depending of the physiological state have been classified in "zymogenous" (bacteria and fungi) and "autochthonous" (Paul and Clark 1989). The physiological state of soil organisms may influence their response to desiccation. For example, some studies have reported that older cells, in a resting or sporulated state, are more resistant to drying than younger cells (Soulides and Allison 1961, quoted in Van Gestel et al. 
1993). Other factors that could prevent the lethal effect against desiccations are the location in the micro-aggregates or the metabolic inactivity of microbial cells (Van Gestel et al. 1993).

Moisture may also affect the contribution of the soil fauna to crop nutrition. Amador et al. (2005) showed that the moisture status affects $\mathrm{C}$ and $\mathrm{N}$ dynamics due to its influences on biogeochemical transformations in soils; there was a positive response of the $\mathrm{C}$ mineralization to increased moisture indicating that this process is limited by either water availability and/or physical factors associated with the connectivity of water-filled pores in the burrows. In addition, studies have shown the effect of soil moisture on the soil enzyme activity; these have reported a considerable sensitivity to a slight decrease in water availability. Decreases in soil enzyme activity during drought periods have been shown by several studies (Li and Sarah 2003, Sardans and Pañuelas 2005). For example, it has been reported that proteases are very sensitive to dry seasons (low activity), whereas alkaline phosphatase and $\beta$-glucosidase are less sensitive to change in the soil moisture (Wick et al. 1998). Therefore, the decrease in the activity of enzymes involved in the recycling of $\mathrm{P}, \mathrm{N}$, and $\mathrm{C}$ will affect, in the long term, soil nutrient availability, reducing the nutrient supply to the plants (Mayor et al. 1994, Sardans and Pañuelas 2005).

\subsubsection{Litter decomposition and the role of the soil fauna on the decomposition process}

A study carried out by Swift et al. (1979) has shown that nutrients cycling in litter decomposition are an important process in terrestrial ecosystems. Litter decomposition influences primary productivity, net ecosystem $\mathrm{C}$ storage, and humus formation in the soil (Xu et al. 2006). Plant nutrients are released from litter by both physical leaching and breakdown of structural organic components by soil organisms (Frankland 1998). Decomposing litter has been studied in many plant species, ecosystem types, and environmental gradients (Berg and McClaugherty 2003, Heim and Frey 2004, Emmett et al. 2004, Xu et al. 2006, Chacón and Dezzeo 2007). Because different patterns were observed in the dynamics of elements in various ecosystems, it has been proposed that the decomposition process and nutrient dynamics depended to a large extent on the interaction between the substrate, biota and environment (Swift et al. 1979), and nutrient availability to decomposers (Staaf et al. 1982). 
Litter decomposition involves two simultaneous and fundamental processes: the first is the mineralization and humification of lignin, cellulose and other compounds by a succession of organisms; which is represented by the adjusting composition and interaction of biological communities involved in biodegradation (Frankland 1998); the second is the leaching of soluble compounds whose $\mathrm{C}$ and $\mathrm{N}$ are progressively mineralised or immobilized. After physical fragmentation to particulate organic matter, the first stage of biochemical alteration involves the decomposition of $\mathrm{C}$ input (chiefly cellulose and lignin biopolymers present in plant litter) into smaller molecules. Principally microorganisms and their extracellular enzymes mediate this process (Jastrow et al. 2007).

The rate of decomposition can be expressed as a function of the concentration of one or more of the substrates being degraded and has been experimentally found well described by firstorder rate kinetics (Paul and Clark 1989). In first-order reactions the rate of transformation of a substrate is proportional to the substrate concentration. Additionally, the decomposition rate has been found to depend on plant $\mathrm{N}$, lignin, polyphenol, and carbohydrate composition (Paul and Clark 1989). It is also controlled by the abiotic temperature and moisture (Paul and Clark 1989). Bargali et al. (1993) proposed that in a wet tropical climate, temperature and moisture are less constraining, and the decomposition rate depends primarily on soil and humus properties and litter quality. However, Vanlauwe et al. (1995) proposed that under tropical conditions, rainfall could be expected to be the determinant climatological factor that influences the decomposition and nutrient release process.

Decomposition in terrestrial ecosystems is commonly studied using the litterbag method, which consists of enclosing plant material of known mass and chemical composition in a screened container (Wider and Lang 1982). Although the method may underestimate actual decomposition, it is assumed that the results of litterbag studies will reflect trends characteristic of unconfined decomposition litter, and as such allow for comparisons among species, sites, and experimental manipulations (Wider and Lang 1982). In general, depending of the objective of the study, two analytical approaches are used: to compare treatment (species and site) means by some parametric statistical procedure or to obtain mathematical descriptions of the data that characterize the observed over time (Wider et al. 1982). In the present research, the use the litterbags is aimed at describing the loss of mass over time. This 
approach can be of considerable value for obtaining insight into the biology of the decomposition process mediated by the soil fauna through the differentiation of mesh sizes.

Few studies have focused on the relation between the structure of communities and the functioning of ecosystems (Hector et al. 1999, Huston et al. 2000). As previously mentioned, litter decomposition depends on the interaction between substrate, biota, and environment. Therefore, the whole study of litter decomposition through mass loss by litterbags and soil fauna (abundance and diversity) is important to understand the role of these soil organisms within organic matter decomposition and nutrient dynamics in soils.

Soil fauna plays a regulating role in mineral cycling in decomposition processes; their impacts on nutrient conversion and litter decomposition have been verified (Seastedt 1984, Ingham et al. 1985, 1986, Kuikman et al. 1990, Wolters and Joergensen 1992, Wolters 2000). Both, qualitative and quantitative differences between soil fauna and their effect on nutrient mineralization have been described. This has led to their classification into functional groups. These are group of organisms, which have, irrespective of their taxonomical origin, a similar function in the process of mineralization (Moore et al. 1988). Among the most common are: size-, habitat- and food-classification.

In the present study the classification is based on the body width of the animals, since this should reflect the scales at which they affect soil processes. In the literature, three groups are generally identified: microfauna comprise nematodes, protozoa, and other less common groups. They live in water-filled and water films in the soil matrix, and represent a diverse assemblage of trophic groups, with fungal-, bacterial- and plant-feeding species as the most abundant. Mesofauna comprises, among other groups, collembola, mites, and enchytraeids, which are largely found in air-filled pores. This group is a mixture of species with various trophic relationships. Macrofauna comprises, among other, millipedes, woodlice, beetles, snails, and earthworms. They have body sizes large enough to disrupt the physical structure of the soil through their feeding and/or burrowing activities (Verhoef and Brussaard 1990). Here meso- and macro-fauna were identified. 
According to González et al. (2001), soil fauna can influence soil processes via two main pathways: directly, by physically modifying the litter and soil environments, and indirectly, through interactions with the microbial community. Soil fauna and microbial interactions are diverse. First, microarthropods can modify the surface area of organic substrates and affect microbial colonization and use; second, soil fauna can feed on microbes altering the microbial biomass and turnover rates. The microbial-faunal interaction may be modified by several external factors, as for example collembolans influence the nutrient availability to mycorrhiza (Lussenhop 1996), while temperature, moisture, and environmental chemicals may have synergistic or antagonistic influences on the interaction between microorganisms and mesofauna (Foerster et al. 1995).

Several studies have been published about the abundance and role of the soil fauna in different ecosystems at different latitudes (Swift et al. 1979, Romanyà et al. 2000, González et al. 2001). They have reported that the relative abundance of various soil fauna groups changes with the latitude. For example soil macrofauna are more abundant in the tropics than they are in temperate regions, whereas soil microfauna are often more common in temperate regions. Newell (1984) pointed, that the macrofauna are important in the mixing of soil organic and mineral materials. These organisms eat relatively large amounts of litter compared to microbes, although they consume the microflora adhering to these substrates.

In tropical ecosystems, the abundance and activity of soil fauna may explain the occurrence of litter on the floor. However, among the numerous factors that may affect the fauna activity, soil stoniness could have a strong influence (as for example one of the soil types in this study). As summarized by Poesen and Lavee (1994) rock fragments can modify the microclimate of the forest floor by intercepting water and by altering the infiltration rate. Consequently, changes in microclimatic conditions may affect the distribution and activity of soil organisms. Additionally, rock fragments may affect the activity of soil fauna by changing the characteristics of the soil habitat and by limiting the circulation of the soil fauna through the soil. 
An important feature of the soil fauna population is their variability through seasonal changes, which modifies the soil microclimatic conditions. Various studies have been aimed at quantifying the effects of soil moisture on the activity of soil animals. Depending on the soil fauna group, the moisture has influence on their abundance and activity. For instance, Verhoef and Brussaard (1990) reported that those organisms which live in water-filled pores and water films around soil particles (as protozoa and nematode) are sensitive to cycles of drought and rain, whereas, Lavelle et al. (2001) pointed that climatic conditions rarely limit the activities of macroinvertebrates. In addition, several studies have reported that agricultural management can also influence the soil biota, thus affecting decomposition (Fromm et al. 1993, Filser et al. 1999, 2002). Agricultural practices influence the species abundance and functioning of the soil fauna community (Filser et al. 1995). Some studies have reported that agricultural practices had a stronger influence on $\mathrm{C}$ and $\mathrm{N}$ turnover, due to the mesofauna influences of $\mathrm{C}$ and $\mathrm{N}$ turnover in soil before and after management conversion (Fromm et al. 1993, Mebes and Filser 1998, Filser 2002). The finding by Ke et al. (2005) supports this assumption. They indicated that mesofauna significantly accelerated mass loss, litter, $\mathrm{N}$ and $\mathrm{C}$ content in the soil from the integrated system, and concluded that farming systems influenced the decomposition through affecting both microflora and mesofauna.

\subsubsection{Soil biological and biochemical processes and its role in nutrient cycling}

In the soils, the transformation of organic matter for the liberation of nutrients easily available to the plants is carried out by a wide number of organisms, where many biological and biochemical processes are involved (organic matter decomposition and mineralization of nutrients). This transformation has been classified in two phases (Jastrow et al. 2007). Firstly, the residues of plants are fragmented into particulate organic matter and decomposed into smaller molecules. In this stage, decomposers assimilate many elements that are used for their growth and decomposed when these organisms turnover. Secondly, the decomposition phase is followed by a series of chemical reactions that produce new molecules releases during the process. Although, there are abiotic factors involved in these reactions (such as temperature and precipitation), both phases of the transformation are largely biologically driven, where microorganisms and their extracellular enzymes are the principal mediators (Jastrow et al. 2007). 
Both, the influences of the environment and agricultural managements on the SOM transformation are commonly studied; for that, soil biological and biochemical indicators are commonly used (Doormaar et al. 1984, Friedel et al. 1996, Chander et al. 1997, Magid et al. 1999, Piao et al. 2000). Biological and biochemical properties reflect slight changes in the soil in the presence of any degrading agent (Nannipieri et al. 1990) and modifications in the soil environment (Dick 1994). These properties are capable of reflecting the actual flux of organic matter and essential elements in soils, and their transference between the different pools of soil (Nannipieri et al. 2003).

The use of the microbial and biochemical characteristics as indicators of changes in the soil properties, is due to their role in the cycling of $\mathrm{C}, \mathrm{N}$ and $\mathrm{P}$. Various methods are used to determine microbial activity (basal respiration, substrate induced respiration, $\mathrm{N}$ mineralization, ATP content, specific enzyme activities, and others). Amongst the parameters most frequently used are: the microbial biomass $\mathrm{C}$, which is considered to be the most reliable, followed by the dehydrogenase activity and $\mathrm{N}$ mineralization capacity. Also, distinctive characteristics of the soil to measure their functioning are the extracellular enzyme activities as for example: phosphatase, $\beta$-glucosidase and urease activity used among the specific parameters to represent the $\mathrm{P}, \mathrm{C}$, and $\mathrm{N}$ cycles, respectively.

Extracellular enzymes are associated with soil colloids and maintain their activity under severe environmental conditions. However, Nannipieri et al. (2002) showed that measure of enzyme activities involved the contribution of both intracellular and extracellular, up to date there are no techniques that can distinguish between them, consequently, it cannot be known which reaction is mediated by the microbes. However, some ratios have been proposed to have an idea of the location of the measured enzyme activities. For instance, Landi et al. (2000) proposed the relation between enzyme activity and the microbial biomass. Indeed, the use of the ratios between several enzyme activities and other measurements of activities has been emphasized to provide information on microbial activity in the soil. 


\subsubsection{Soil Microbial Biomass}

The microbial biomass is composed of bacteria, fungi, actinomycetes, algae, protozoa, and some nematode; it is a part of the living or active living or active SOM, which plays an important role in the developing and functioning of terrestrial ecosystems (Smith et al., 1993). This living compartment is approximately $4 \%$ of the total soil organic $C$, including plant roots (5-10\%), macroorganisms (soil fauna 15-30\%), and microorganisms (60-80\%) (Jenkinson and Ladd 1981). As active fraction, microbial biomass changes continually and responds much more rapidly to changes in the environment than total organic matter. Therefore, microbial biomass has been reported as an important indicator in the soil studies because, it is sensitive to environmental stress and changes in agricultural managements (Brookes 1995, Jordan et al. 1995, Friedel et al. 1996, Trasar Cepeda et al. 1998).

Soil microorganisms play a critical role in the retention and release of nutrients; the microbial biomass acts as both a sink and a source of labile nutrients, capable of supplying a significant proportion of the nutrients used by plants (Jenkinson and Ladd 1981, Marumoto et al. 1982, Bonde et al. 1988). In many cases, the interaction between plants and soil microorganisms is both competitive and mutualistic (Harte and Kinzig 1993). Some studies have reported that the size and activity of the microbial biomass is regulated by the quantity and quality of vegetal material (Van Veen et al. 1989), soil moisture content (Insam 1990, Van Gestel et al. 1996), soil temperature (Joergensen et al. 1990), soil pH (Powlson and Jenkinson 1976), management practices (Ocio and Brookes 1990, Mueller et al. 1992), soil structure and texture (Amato and Ladd 1992).

Regarding management practices, positive effect on microbial biomass has been showed by Moore et al. (2000), who studied rotation systems compared with the continuous corn and soybean systems. The highest microbial biomass $\mathrm{C}$ and biomass $\mathrm{N}$ were found in the multicropping systems of 4-year rotations, and the lowest values were found in continuous corn and soybean systems. They attributed the increase in the microbial biomass to several reasons, amongst them, enhanced soil structure, root density, and greater amounts of crop residues and proportion of easily decomposable organic compounds that return to the soil. Management of the microbial community through residue placement has great influence for the organic matter and nutrients in agroecosystems, especially under dry land conditions (Moore et al. 2000). The 
incorporation of residues into the soil creates a favourable environment for microbial activity in the soil and increases the microbial biomass. Organic substances supplied to the soil, via residues and waste from animals and plant production, are used as an energy and nutrient source for microorganisms (Singh and Singh 1993). In dry land farming systems soil moisture can be conserved through reduced tillage.

On the other hand, some information is available on seasonal responses of microbial biomass in soils under different types of management (McGill et al. 1986, DeLuca and Keemey 1994, Chander et al. 1997) or different moisture regimes (Dash and Guru 1980, Salinas Garcia et al. 1997). In general, it has been reported that changes in soil moisture status can markedly affect the magnitude of the soil microbial biomass because many soil microorganisms are known to be intolerant to low soil moisture contents (Reid 1980), low microbial biomass is associated to low moisture conditions. However, in a study developed in karstic areas, it was found that the moisture influence occurs only significantly at high temperatures when the fluctuation in soil moisture is high (Piao et al. 2000). The marked seasonal changes in the microbial biomass were ascribed to its higher turnover rates at warmer atmospheric temperatures, which were promoted by fluctuations in soil moisture $>20{ }^{\circ} \mathrm{C}$.

Many studies have found that abrupt changes in soil moisture stimulate the turnover of microbial biomass in soils (McGill et al. 1986, Ross 1987, Wardle and Parkinson 1990, Van Gestel et al. 1993). Rewetting of dry soil may kill soil microbes through osmotic stress (Kieft et al. 1987). For instance, Van Gestel et al. (1991, 1993) report increased C and $\mathrm{N}$ mineralization when dry soils are remoistened, with a large portion of the $\mathrm{C}$ mineralization derived from dead organic matter. An increase in soil carbohydrates during a drying-wetting cycle in semi arid areas has not been well described, but is likely to be caused by the decomposition of the organic matter accumulated during the dry period (Gallardo and Schlesinger 1995). The rapid flush of decomposition after wetting the soils may be due to a persistent pool of enzymes capable of tolerating extended periods of desiccation, as shown by Peterjohn (1991) for denitrifying enzymes.

To measure metabolic processes $\mathrm{CO}_{2}$ evolution is normally used, as this reflects the catabolic degradation under aerobic conditions. Since more than $90 \%$ of the energy in the soil flows 
through microorganisms, the microbial biomass is another of the measurements normally employed. Several methods have been proposed for the determination of microbial biomass in soils (Horwath and Paul 1994, Joergensen 1995). In general, they can be grouped into direct and indirect methods. The direct methods involve microscopic procedures, including plate counting, estimation of bio-volume, and culture methods. The indirect methods involve techniques including fumigation-incubation (FI) and fumigation-extraction (FE), estimation of cell components such as ATP, phospholipids, catalase, and dehydrogenase activities, and substrate-induced activity of microorganisms. Amongst them, the FI and FE methods are widely used for estimation of microbial biomass $\mathrm{C}\left(\mathrm{C}_{\mathrm{mic}}\right)$ and biomass $\mathrm{N}\left(\mathrm{N}_{\text {mic }}\right)$. In the present study, the FE method was selected for the soil fumigation-extraction, and to estimate the $\mathrm{N}$ in the extracts the ninhydrin-reactive $\mathrm{N}$ method (Joergensen and Brookes 1990) was employed.

Studies on the microbial biomass $\mathrm{C}$ and microbial biomass $\mathrm{N}$ have been widely carried out. These have shown that the turnover time for $\mathrm{N}$ immobilized in the microbial biomass was found to be about ten times faster than that derived from plant material (Smith and Paul 1990). Therefore, the determination of $\mathrm{N}_{\text {mic }}$ is important for the quantification of $\mathrm{N}$ dynamics in agricultural ecosystems because it controls soil inorganic $\mathrm{N}$ availability and loss. The present research is particularly focussed on seasonal responses of $\mathrm{N}_{\text {mic }}$ in karstic soils under different land uses, which describes changes in $\mathrm{N}_{\text {mic }}$ occurred during the dry and the rainy season as well as the response under artificial wetting at contrasting moisture conditions.

\subsubsection{Bacteria and Fungi}

The nutrients released during the decomposition processes play a significant role in nutrient cycling, energy flow, and primary, secondary, and decomposer production. Fungi and bacteria, as the primary decomposers, are responsible for decomposing $90 \%$ of all plant biomass; catabolizing substrates, and releasing mineral nutrients (Swift et al. 1979). Both fungi and bacteria readily degrade cellulose. Lignin, however, is more recalcitrant, and its complete degradation is restricted to a select group of fungi (Conesa et al. 2002, ten Have and Teunissen 2001).

A study performed by Paul and Clark (1989) has reflected that soil bacteria are responsible for some of the most specific biogenic transformations in elemental cycles. For instance, in the $\mathrm{N}$ 
cycle, many bacteria are involved in ammonification, but other $\mathrm{N}$ transformations are carried out by taxonomically narrow groups of microorganisms. As for example the heterotrophic nitrification, is in part carried out by Arthrobacter and actinomycetes. Other genera are included in the $\mathrm{NO}_{2}^{-}$reduction (Mycobacterium, Clostridium) and denitrification (Pseudomonas, Bacillus, Thiobacillus) (Payne 1981).

The role of the bacteria in the P cycle appears somewhat less specialized. Although there are no microbial mediated gaseous fluxes of $\mathrm{P}$, a wide range of bacteria (Pseudomona, Bacillus) are involved in the solubilization of inorganic P. As a group, bacteria are important in the short-term immobilization of $\mathrm{P}$ and mineralization of organic P. Somewhat more specialized group of bacteria are involved in the transformation of metals, sulphur and methane (Beare et al. 1995).

On the other hand, fungi are a major component of the soil biomass (Hawksworth 1991) and are considered important to regulate ecosystem processes (Wainwright 1992). The important role of many fungi, including the ectotrophic mycorrizal species in the ammonification of organic $\mathrm{N}$ is well established (Beare et al. 1995). Though autotrophic nitrification by bacteria is often assumed to dominate, the heterotrophic activities of fungi may account for a significant proportion of the nitrification in acid forest soils (Schimel et al. 1984). Fungi attack a wide range of cellulose and lignin compounds, many studies suggested that fungi tend to be the dominant microorganisms when plant litter is left on the soil surface (Holland and Coleman 1987, Beare et al. 1992). However, some researches have suggested that bacteria contribute more than fungi to the mineralization of organic C in soils (Nakas and Klein 1980).

Agricultural management brings about changes in the soil environment, which alter microbial communities, their activity and associated processes of decomposition and nutrient cycling (Stamatiadis et al. 1990). Changes in the soil surface due to tillage, for example, can create more aerobic conditions, which could modify the relative dominance of bacteria and fungi and consequently alter the decomposition process. Generally, fungal biomass is found to be greater than bacterial biomass in agricultural soils (Anderson and Domsch 1975, Sakamoto and Oba 1994, West 1986, Zelles et al. 1995), although bacterial dominance has also been reported (Bloem et al. 1994, Hassink et al. 1993, Neher and Campbell 1994). Many authors have 
attributed a major fungal biomass in forest soils due to their capacity to degrade substances more complex such as for example lignin. On the other hand, it is also known that environmental factors control the microbial biomass. For instance, soil moisture has been often demonstrated to exert an important effect on the magnitude of the microbial biomass (Bottner 1985, Kieft et al. 1987, Wardle and Parkinson 1990). Therefore, drying-rewetting cycles also result in substantial modifications of the microorganisms' population, as for example, most bacteria, which are sensitive to drought periods.

In order to predict microbial response to soil management and soil moisture changes and have a better understanding of their functional importance, it is necessary to effectively separate the activities of the microbial groups like bacteria and fungi, which can differ in their role in the ecosystem functions (Stamatiadis et al. 1990). Differentiation in the activity of fungi and bacteria has been attempted through the use of selective microbial biocides (Anderson and Domsch 1973). A current approach for measuring the potential activity of bacteria and fungi in soil is to quantify the contribution of these groups to substrate (glucose)-induced soil respiration after selective inhibition of bacteria by streptomycin sulphate (Str) and of fungi by cycloheximide, based on the method of Anderson and Domsch (1973, 1975). Both are inhibitors of protein synthesis, Str causes misreading of messenger RNA, while cycloheximide inhibits the peptidyl transferase activity of the eukaryotic $60 \mathrm{~S}$ ribosomal subunit (Stryer 1988). The advantages of this method are that is practical and it does not require sophisticated machinery to do the estimations. However, some authors (Badaluco et al. 1994, Alphei et al. 1995) have reported problems with the use of biocides to estimate the relative contribution from different microbial populations to nutrient cycling in soil due to, (1) variable biocide effects on non-target microorganisms (especially Str), (2) sorption of the biocides to surfaces of the soil particles, (3) concentrations of inhibitors to prove a sufficient inhibition to microbial growth and (4) the manner how the inhibitors are added to soil (in aqueous solution or in powder). Although all these arguments can have valid reasons, in the present research this method was only used to estimate the contribution of bacteria to the soil respiration. The method was carried out and some modifications were done to reach one of the objectives of the study. 


\subsubsection{Soil Enzyme Activity}

Enzyme activities are involved in processes important to soil function such as organic matter decomposition and synthesis, nutrient cycling, and decomposition of xenobiotics (AcostaMartinez et al. 2007). As major decomposers, soil microbes are unable to assimilate large and complex organic polymers. Instead, extracellular enzymes conduct the initial breakdown of organic polymers. While some soil enzymes may be produced constitutively, many are substrate inducible, and will thus vary with resource availability (Burns 1982). Due to its diverse chemical composition, SOM may, to some extent, determine microbial production of extracellular enzymes. Factors like, quantity and quality of SOM or microbial biomass are important in regulating some extracellular soil enzymes. The quality of SOM or the composition of microbial community may be the critical factor influencing the relative production of soil enzymes (Sinsabaugh et al. 1991, Waldrop et al. 2000). Indeed, soil enzyme activity has been identified as a sensitive indicator of soil quality because of its association with SOM and the soil microbial community (Dick 1984, Dick et al. 1996).

Soil enzymes catalyse all biochemical transformations and could indicate the biochemical potential and possible resilience to environmental stress and perturbations (Zhang et al. 2006). Measurements of soil enzymatic activities have been extensively conducted to indicate biological activity and soil quality (Bandick and Dick 1999, Kandeler et al. 2000, Badiane et al. 2001), to offer information about changes produced by land uses on biogeochemical cycling of the terrestrial ecosystems (Kandeler et al. 1996, Wick et al. 2000) and can also give indications on the extent of specific processes involved in governing soil fertility (Senthilkumar et al. 1997).

The overall activity of a single enzyme may depend on enzymes in different locations, including intracellular enzymes from viable proliferating cells, and accumulated or extracellular enzymes stabilized in clay minerals and/or complexed with humic colloids (Burns 1982, Tabatabai 1994, Nannipieri et al. 2002). Even though an assessment of several enzyme activities is needed in order to provide a better idea of the status of soil processes as affected by management, there are particular enzyme activities, which are involved in key reactions of important metabolic processes of soils (organic matter decomposition, nutrient cycling) that have been shown to be sensitive to management and require a simple assay 
procedures. For example, $\beta$-glucosidase activity is involved in the final step of cellulose degradation that provides simple sugars for microorganisms in soils, and it has shown to be sensitive to agricultural practices (Acosta-Martinez et al.1999, Bandick and Dick 1999). Alkaline and acid phosphatase activities catalyse the hydrolysis of both organic P esters and anhydrides of phosphoric acid into inorganic P (Schmidt and Laskowski 1961, AcostaMartinez et al. 2007).

It has been established that soil enzyme activities respond more quickly to changes in crop management practices or environmental conditions than do characteristics such as total SOM (Brookes 1995). Management practices (crop rotation, mulching, tillage, burning, and application of fertilizers and pesticides) may have diverse effects on various enzymes of soil (Ladd 1985, Dick et al. 1987, Tabatabai 1994). It has shown, that enzyme activities have strongly declined under intensive agronomic use and cultivated soil with poor input of vegetal residues (Bolton et al. 1985, Dick 1992, Caravaca et al. 2002). Other studies have shown the effects of burning on the microbial biomass and enzyme activities (Eivazi and Bayan 1996, Dick et al. 1988, Ajwa et al. 1999, Boerner et al. 2005). These have found that long-term burning alters the rate of organic matter turnover and therefore, affect microbial biomass and the production of enzymes. However, Senthilkumar et al. (1997) reported a positive effect on soil enzyme activities (amylase, cellulase, invertase and phosphatase) in plots over a 2-year period after fire in grasslands in southern India.

On other hand, patterns in the change of soil enzyme activities with seasonal variation have also been documented. Seasonal fluctuation in enzyme activity plays an important role because according with the seasonal variations change the quantity and quality of substrates upon which they act and are responsible for altering the rate of various soil processes (Rao and Tarafdar 1992). Two commonly predicted outcomes of seasonal variation are changes in temperature and altered rainfall patterns. Altered rainfall patterns including increased incidence of summer drought, are also predicted especially in temperate regions (Sowerby et al. 2005). However, the seasonal patterns of activity have varied among enzymes, soil properties, and ecosystem types. The key to understanding seasonality in enzyme activity may be in the factors that regulate various enzymes systems (Boerner et al. 2005), for example those enzymes like phosphatase are regulated by microclimate and soil chemical factors, 
whereas lignocelluloses degrading enzymes like glucosidase are more regulated by substrate availability (Sinsabaugh et al. 1992, 1993). A study carried by Skujin (1976) showed that seasonal variations in enzymatic activities were generally small; once the enzymes become stabilized in the soil, they manifest resistance to moisture, temperature and to various environmental changes. In addition, Shi et al. (2006) have shown that the association between soil enzyme activity and SOM was not obscured by the seasonal fluctuation in soil enzyme activities caused by temperature and moisture. Conversely, work developed by Dormaar et al. (1984) reported significant fluctuation over the seasonal changes in enzyme activities under different vegetation types, regions, and managements.

\subsubsection{Acid and alkaline phosphatase}

Phosphatases catalyse the hydrolysis of phosphate esters and are enzymes with relatively broad specificity, capable of acting on a number of different structurally related substrates, but at widely different rates (Alef et al. 1995). The rate of $\mathrm{P}$ mineralization depends on microbial activity (Tarafdar et al. 1988) and on the activity of free phosphatases (Dalal 1977), which is controlled by the solution P concentration (McGill and Cole 1981). Nannipieri et al. (1978) and McGill and Cole (1981) suggested that high P concentrations in soil inhibit phosphatase activity. Phosphatases are produced by microorganisms (Tarafdar and Chhonkar 1979), plants (Tarafdar and Jungk 1987), and mycorrhizae (Leprince and Quiquampoix 1996) and are stabilized in soils by sorption to organic mineral complexes (Nannipieri et al. 1996). According to their optimum $\mathrm{pH}$, phosphatases are classified as acid and alkaline phosphatases. Both acid and alkaline phosphatases are supposed to play an important role in plant nutrition, because their activity in the ectorhizosphere is high (Alef et al. 1995).

Phosphatases measured in soils reflect the activity of enzymes bound to soil colloids and humic substances, free phosphatases in the soil solution, and phosphatases associated with leaving and dead plant or microbial cells (Skujins 1976, Nannipieri et al. 1990, Kraemer and Green 2000). These enzyme activities have been suggested as potential components of groups of indices to assess soil quality (Kennedy and Papendick 1995, Staddon et al. 1998). Since, these are related to soil and vegetation conditions (Herbien and Neal 1990), respond to changes in management (Adams 1992, Clarholm 1993), and can be related to seasonal 
changes in soil temperature and moisture (Harrison 1983, Dormaar et al. 1984, Speir and Cowling 1991).

Tillage and crop-residue management practices may lead to significant changes in biological, chemical and biochemical properties of soils and alter the composition, distribution, and activities of enzymes (Dick 1984, Magnan and Lynch 1986). A study by Dick (1984) indicated that the activities of acid phosphatase, alkaline phosphatase, were significantly greater in soils from no-tillage plots as compared with those from conventional tillage plots. Management practices that minimize the addition of organic amendments to soils, diminish the potential for enzyme activity, which could affect the ability of soils to cycle and provide nutrients for plant growth. Dick et al. (1988) have shown that this soil enzyme activity is sensitive in discriminating between long-term residue practices, but is not a consistent index for evaluating the short-term fertility status of a soil in relation to crop yield.

Phosphatase activity and seasonal changes have been widely studied (Harrison and Pearce 1979, Rastin et al. 1988, Kraemer and Green 2000, Wick et al. 2002) however, seasonal changes in phosphatase activity patterns did not always show the same trend. A study carried out by Harrison and Pearce (1979), showed a high variation of phosphatase activity in $0-5 \mathrm{~cm}$ soils of woodland soils in England, however, it was not significantly affected by the season due to their variability. Also, Rastin et al. (1988) and Wick et al. (2002) didn't show a significant relationship between seasonal variations in soil moisture content with phosphatases. The lack of significant changes is attributed to stabilization with clays minerals and colloids (Busto and Perez-Mateos 1995).

Studies have also shown the effects of soils characteristic on the soil enzyme. For instance, Acosta-Martinez and Tabatabai (2000) reported the sensitivity to soil $\mathrm{pH}$. With the exception of the acid phosphatase, they reported a significant increase in the enzyme activities, including the alkaline phosphatase, with the soil $\mathrm{pH}$ due to the stimulation of the microbial population activity and diversity, resulting in an increase in the soil enzyme activities. Another characteristic, which has been reported to have influence on the enzyme activity, is the texture. Phosphatases have been positively and significantly correlated with clay, silt, the mean weight diameter of the soil particles, the geometric mean diameter of the soil particles, the equivalent 
$\mathrm{CaCO}_{3}$, and the Olsen available phosphorus, amongst others, in contrast, the soil phosphatase exhibited a significant negative correlation with sand (Sinegani et al. 2006).

\subsubsection{2 $\beta$-Glucosidase}

Cellulase is an enzyme complex, which hydrolyses cellulose to glucose. It is formed from at least three different types of enzymes, all of which are required to decompose crystalline cellulose: exo- $\beta$-1.4-glucanase, endo- $\beta$-1.4-glucanase and $\beta$-glucosidase or cellobiase. $\beta$ glucosidase catalyses the hydrolysis of cellobiose and cellodextrins formed by the action of endo- and exo-glucanase, to glucose, it is the rate-limiting enzyme in the microbial degradation of cellulose to glucose (Shewale 1982). $\beta$-glucosidase plays a crucial role in largescale sacharification by removing cellobiose, since both exo- and endo-glucanases are inhibited by cellobiose. $\beta$-glucosidase has been detected in microorganisms, plants, and animals (Shewalle 1982, Esen 1993). However, the main producers of $\beta$-glucosidase are thought to be mucoraceous fungi such as Actinomucor sp. and Mortirella sp. (Hayano et al. 1985).

Studies have reported that $\beta$-glucosidase is rarely substrate limited and is synthesised by soil microorganisms in response to the presence of suitable substrates (Turner et al. 2002). This enzyme activity has been significantly correlated with microbial biomass, suggesting to Kiss et al. (1970, quoted in Boehme et al. 2004) that the activity of extracellular immobilised enzymes was not important. However, other studies have shown a significant relationship between $\beta$-glucosidase activity and clay content, which may reflect the potential for enzyme immobilisation in the soil and therefore, the dominance of immobilised extracellular enzymes (Busto and Perez-Mateos 2000, Turner et al. 2002). Probably, this enzyme, which is physically protected from degradation, remains active for a long time and is evenly distributed in the soil (Boehme et al. 2004).

$\beta$-glucosidase activity has been found to be sensitive to soil management (Dick et al. 1996, Bergstrom et al. 1998, Bandick and Dick 1999) and has been proposed as a soil quality indicator (Wick et al. 1998, Ndiaye et al. 2000). $\beta$-glucosidase activity can detect changes in soil management within relatively short time periods (1-3 years) and it is relatively stable throughout the seasonal changes (Bandick and Dick 1999, Ndiaye et al. 2000). Wick et al. 
(1998) measured different microbiological indicators in Nigerian tropical soils subjected to contrasting management, and found that the most affected variables were the microbial biomass, $\beta$-glucosidase, and alkaline phosphatase activities. A subsequent study stated $\beta$ glucosidase as an indicator due to their sensitive to change in the managements (de la Paz Jimenez et al. 2002), in fallow plots and pasture soils (Turner et al. 2002).

Seasonal variations in $\beta$-glucosidase have been studied by several authors (Kiss et al. 1975, Eivazi and Tabatabai 1990, Wick et al. 2002). For example, Kiss et al. (1975) reported an increase in the activity throughout spring to a maximum in the summer months and the decline in autumn. Wick et al. (2002) found increases in the activity during the mid rainy seasons in forest soils, whereas in degraded site the variation was less pronounced. However, the temporal fluctuation was not correlated to moisture. Fluctuation in the $\beta$-glucosidase activity due to different soil moisture conditions are attributed to the rewetting of the soil thus causing a breakdown of aggregates and this increases the accessibility of soil enzymes to their substrates (Eivazi and Tabatabai 1990). Also, temporal changes in $\beta$-glucosidase activity are related to the availability of vegetal residues that increase or decrease depending on the season.

\subsubsection{Proteases}

Proteolysis plays an important role in the organic $\mathrm{N}$ cycle of soil. Through ammonification and nitrification the $\mathrm{N}$ can be available to the plant thus maintaining the soil fertility. Proteins often comprise one-third of total soil N (Bremner 1949, quoted in Asmar et al. 1994). Protease activity is considered to be important in the production of oligopeptides from proteins, resulting in the subsequent release of low-molecular-weight compounds, which are assimilated by macroorganisms. This enzyme catalyses the hydrolysis of proteins to polypeptides, and oligopeptides to amino acids (Payne 1980). Several studies have stated that protease is an enzyme of the $\mathrm{N}$ cycle, which has great importance in semiarid climates (Garcia et al. 1997, Bastida et al. 2006b).

The intrinsic characteristics of the protease are not well understood, because there are associations with molecules of different sizes and structures, and also because they have several substrate specifities. Protease activities have been detected in microorganisms, plants, 
and animals (Loll and Bollag 1983). In soil, proteases are present in living and active cells, in dead cells, as free enzymes, and adsorbed to organic or inorganic mineral particles. Consequently, its origin has not been clearly defined and therefore widely discussed. For instance, Badalucco et al (1996) reported high activity of protease in the rhizosphere and attributed their origin to the interface soil-plant root. However, Hayano (1996) concluded that the contribution of protease by plant root is smaller in comparison to other soil enzymes. Other authors attributed the origin to bacteria (Law 1980, Hayano and Watanabe 1990).

Little information about seasonal changes on protease activity has been carried out. In general, low activity has been found in dry periods, attributing it to the restriction of proteolysis (Watabane and Hayano 1996). Ladd (1978) showed that the protease activity in the field varied with the season. Wick et al. (2002), reported high fluctuation of protease during the cropping season, and there was a decrease in the activity during the dry season. However, minor fluctuations have been recorded in the field with changes in the seasons and over the year, Speir et al. (1980) found few significant differences in the protease activity of planted and fallow soils. On the other hand, Bonmati et al. (1991), showed a significant correlation of the protease with the organic matter, as result of the increase in the extracellular activity. Agricultural practices that contribute to improve the organic matter content would raise the activity of this enzyme. However the quality of the organic matter is also considered important to increase the activity of the protease. Wick et al (2002) reported the influence of different managements on the protease and pointed that the quality was the major control factor in enhancement the protease activity.

\subsubsection{Limitation of bioassays}

Normally the selection of indicators to evaluate soil quality and fertility includes physical (texture, rooting depth, bulk density, water retention capacity), chemical ( $\mathrm{pH}$, total C, electrical conductivity, nutrient level) and biological ( $\mathrm{C}$ and $\mathrm{N}$ microbial biomass, potentially mineralizable N, soil respiration) properties (Doran and Parkin 1996). In general, the physicalchemical parameters are of little use since, are altered only when soils undergo a really drastic change (Filip 2002). On the contrary, biological and biochemical parameters are sensitive to slight modification (Nannipieri et al. 1990). Considering a wide number of biological and biochemical properties involved in the functioning of the soil, several levels have been 
identified (Visser and Parkinson 1992). Amongst them are those related to the cycles of nutrients ( $\mathrm{C}, \mathrm{N}, \mathrm{P}$, and $\mathrm{S})$, especially as linked to the transformation of the organic matter in the soil, as well as properties associated to the size, diversity and activity of microbial biomass and the activity of the soil hydrolytic enzymes.

The majority of the studies used biochemical properties that reflect the activity of microbial processes (general biochemical parameter) or hydrolytic enzymes (specific biochemical parameters). These properties reflect the actual flux of organic matter and essential elements in soil, and their transfer between individual pools, as well as between the soil and other parts of the environment. However, the lack of standard methods for many microbiological indicators makes it difficult to compare between different studies. On the other hand, soil enzymes are studied by measuring of the potential activity under controlled incubation conditions, which ensure the most favourable rates of catalytic substrate conversion (Nannipieri 1994). Drawbacks of enzyme activity measurements are that the methods cannot distinguish between intracellular and extracellular enzymes (Nannipieri 1994). However, the study of several soil enzyme activities as well as microbial biomass is considered be reliably combination to study soil biochemical processes (Gil-Sotres et al. 2005). 


\section{MATERIALS AND METHODS}

\subsubsection{Site description}

The study sites were located in Xmatkuil and Hocaba near Merida in the Yucatan Peninsula, Mexico at $20^{\circ} 49^{\prime} \mathrm{N} 89^{\circ} 15^{\prime} \mathrm{W}$. (Duch 1988). According to the classification of Köppen, the climate is characterized as Aw with dry and rainy season of little precipitation. The annual temperature is $26^{\circ} \mathrm{C}$ and the annual precipitation between 1000-1200 mm (INEGI 1995). Between $70 \%$ and $80 \%$ of the total rain falls within the rainy season, which lasts from May until October. The wettest month is September; the driest months are March and April (Teran and Rasmussen 1992).

The parental material consists primarily of consolidated marine sediments forming limestone and dolomite. Due to weathering, the calcareous materials have developed a karstic landscape, characterized by mounds and plains (Andrist 2003). Yucatan comprises a high diversity of soils. In this study, two principal groups are identified, which according to the Mayan knowledge are recognized as: Boxlu'um (black Rendzinas) to designate the soils that are found on the mounds and K'ankab (Rendzinas or Terra Rossa) to designate the soils located on the plains (Estrada 2000). Boxlu'um and K'ankab soils are known in the FAO classification as Lithosol and Luvisol, respectively. Generally, the mound soils are shallow, with a high content of stone and gravel, and are brown to black in colour due to their high organic matter content. The plain soils are deeper $(>20 \mathrm{~cm})$, have low gravel content, and more horizons number than the soils in slightly elevated areas, and are of red colour (Estrada 2000).

Soils from the plains have lower sand and aggregate content than the soils on the elevated areas, where the aggregates are more stable (Estrada 2000). Organic C is higher on the mounds $(133 \mathrm{~g}$. kg-1 $)$ than in the plain $\left(61{\mathrm{~g} . ~ \mathrm{~kg}^{-1}}^{-1}\right.$ (Weisbach 2002). The carbonate content is correlated with the amount of calcareous gravel and stones on the mound soils (Estrada 2000). The exchangeable bases are strongly related to the calcium content in the soil, which represent high percentage in both mound and plain soils (Fitzpatrick 1996). 
The soils at the study sites have high $\mathrm{C}$ and $\mathrm{N}$ contents, especially those located on the mound, high concentration of organic and inorganic available $\mathrm{P}$. The $\mathrm{pH}$ is slightly alkaline and base saturation is high with the exception of Potassium that is low (Table 2.1).

Table 2. 1. Main characteristics of soils in the different land use systems (these samples were taken at the same plots as were sampled for this thesis).

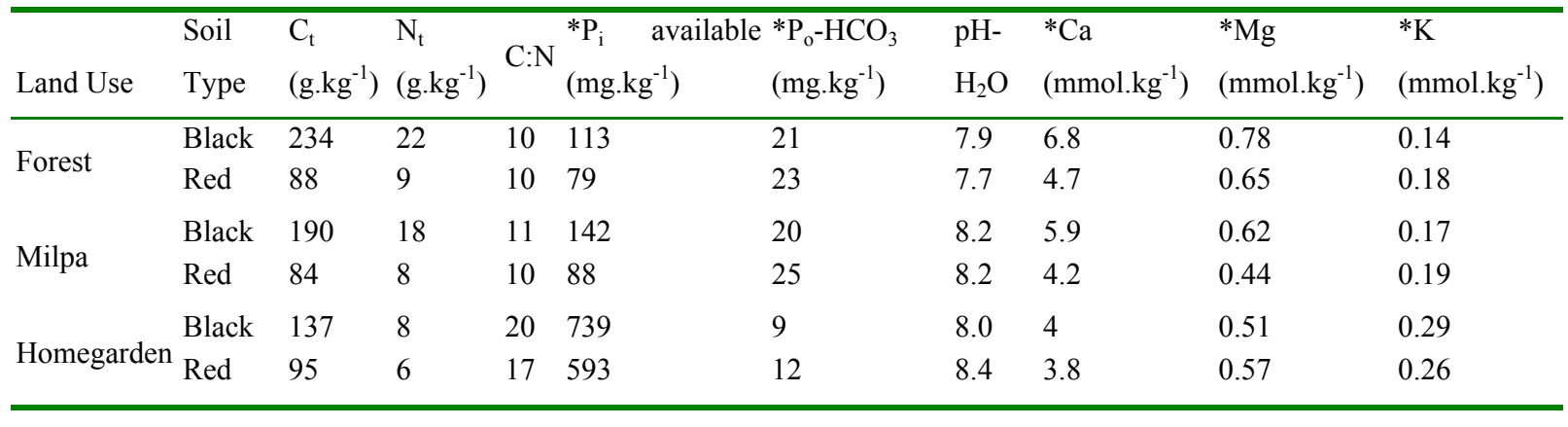

$\mathrm{C}_{\mathrm{t}}$ : Total Carbon

$\mathrm{N}_{\mathrm{t}}$ : Total Nitrogen

$\mathrm{P}_{\mathrm{i}}$ available: Available Inorganic Phosphorus (it is the sum of: $\mathrm{P}$ resin, $\mathrm{Pi}-\mathrm{HCO}_{3}, \mathrm{Pi}-\mathrm{NaOH}$ )

$\mathrm{P}_{\mathrm{o}}-\mathrm{HCO}_{3}$ : Organic Phosphorus extracted with sodium bicarbonate at $\mathrm{pH} 8.5$

* Source: Aguila Alcantara(2007)

\subsubsection{Land Use Systems and Plot selection}

Three land use systems were selected: forest, milpa (shifting cultivation), and homegardens. Forest and milpa plots were located in Xmatkuil and the homegardens were located in Hocaba. The forests were sampled in 25-30 years old plots and comprised mainly deciduous trees of 15-20 $\mathrm{m}$ height (selva baja caducifolia) and some spinous leguminous species (Flores and Espejel 1994). The milpa systems were 2 years old and were a mixed cropping of maize, pumpkin (Cucurbita moschata), and bean (Phaseolus vulgaris L). In the homegardens, a great variety of species was found, with a multi-strata vegetation of native trees, shrubs, and spices. The principal species observed were: Achiote (Bixa orellana), Guava (Psidium guajava), Agave (Agave furcroydes Lemaire), Lime (Citrus aurantifolia), Sweet Orange (Citrus sinensis), Sour Orange (Citrus aurantium L), Sapote (Manikara zapota), Saramuyo (Annona squamosa), Siricote (Cordia dodecandra), Banana (Musa paradisiaca). 


\subsubsection{Field experiments}

\subsubsection{Litterbag studies}

Litterbag studies with maize leaves were conducted from December 2004 to August 2005 both at one forest site and one milpa plot. Homegardens were excluded due to frequent cleansing. Two different mesh sizes were used, $250 \mu \mathrm{m}$ and $1000 \mu \mathrm{m}$ to study the impact of soil fauna on litter decomposition. Fresh maize leaves were collected in November 2004 from one milpa plot near Xmatkuil. Maize leaves were selected as reference material to guarantee similar conditions (litter quality) at each site. Fifty medium mesh bags (250 $\mu \mathrm{m}$ mesh size) and fifty large mesh bags (1000 $\mu \mathrm{m}$ mesh size) of $20 \times 20 \mathrm{~cm}$ size were filled with 7-10 g maize leaves previously dried at $40{ }^{\circ} \mathrm{C}$. The exact weight of the leaf material in each bag was recorded. After filling, the bags were marked with metallic tags and then the bags were closed by sewing with nylon yarn. Ten sets of bags were used, i.e. five from each mesh size and five by each soil type and land use combination previously mentioned. Bags were placed on the soil surface randomly stratified according to the soil colour. Bags were recollected at five intervals, unevenly divided over a period of seven and half months. Thirty days after the initial time, the first collection took place, and then at the 75, 135, 180, and 225 days after incubation (DAI). At the retrieval dates five litterbags from each soil type (red and black), and study site (milpa and forest) for each mesh size were removed, enclosed in plastic bags, and transported to the laboratory. Then, the bags were checked for holes made by animals and from penetration by roots or fungal hyphae. No holes made by animals and from penetration by root or fungal hyphae were found. The litter was dried at $65{ }^{\circ} \mathrm{C}$ and weighed. The weight was recorded and the decomposition is measured as the mass loss of litter from litterbags.

\subsubsection{Soil Sampling and Laboratory Analyses}

\subsubsection{Soil sampling}

Soil sampling was done twice, once during the dry season (December 2004, January 2005) and once during the rainy season (September 2005). The sampling was randomly stratified according to the soil type. Within each land use three plots of each 40 x $60 \mathrm{~m}$ were randomly selected. Within each plots five samples of each soil type were taken from the top $10 \mathrm{~cm}$ in an area of $25 \mathrm{~cm}^{2}$. Before sampling the litter was removed. The soils were sieved $(<2 \mathrm{~mm})$ to 
remove the roots and sealed in plastic bags for the transport to Germany. The samples taken during the rainy season were kept field moist at $4{ }^{\circ} \mathrm{C}$ until further analysis.

\subsubsection{Laboratory Analyses}

\subsection{Nutrient determination of maize leaves}

Leaf samples of maize were analysed for total $\mathrm{C}\left(\mathrm{C}_{\mathrm{t}}\right)$, total $\mathrm{N}\left(\mathrm{N}_{\mathrm{t}}\right)$, and total phosphorus $\left(\mathrm{P}_{\mathrm{t}}\right)$. Total N was measured by dry combustion with CHNS analyser (Model VARIO EL III, Elementar Analysensysteme $\mathrm{GmbH}$, Hanau, Germany). $\mathrm{P}_{\mathrm{t}}$ was determined by digestion with $\mathrm{HNO}_{3}$ at $200{ }^{\circ} \mathrm{C}$ for twelve hours, and then $\mathrm{P}$ was colorimetric determined using the Vanadium - Molybdate method according to the methodology described by Methods for Soil and Plant Analysis, Association of Official Analytical Chemist (1970).

\subsection{Soil Physical Analyses}

\subsubsection{2. a Permanent Wilting Point}

The permanent wilting point (PWP) was carried out by the centrifuge method as is described by Methods of Soil Analysis (Part 1, 1986). All analyses were performed in duplicate. About 10-15 gram of soils was placed into a beaker. The soils samples were saturated with distilled water and it was left for overnight. Then, moist soils were placed in centrifuge tubes (previously weighed), which have in the bottom little pores to allow the water drainage. The bottom of the centrifuge tube was covered with Whatman No. 2 filter paper. The soils were left for the percolation of water for a period of approximately 30 minutes. Duplicate samples were put opposite each other in the centrifuge head to keep it balanced. The loaded samples were brought to a speed of 5000 revolutions per minute and maintained for 15 minutes. This procedure was carried out two times. Then, the samples were brought to a speed of 15000 revolutions per minute and maintained for approximately 1 hour. The centrifuge tubes were weighed and the samples were centrifuged at the same revolution one hour more until obtain a constant weight. This procedure was repeated about six. The final weight was recorded. Then, the centrifuge tubes were left overnight in the oven at $60{ }^{\circ} \mathrm{C}$. The weight of the dried sample was recorded and the PWP was calculated as:

$$
\operatorname{PWP}(\%)=\frac{\text { moist sample weight }- \text { dried soil sample weight }\left(\text { at } 60^{\circ} \mathrm{C}\right)}{\text { dried sample weight }} \times 100
$$




\subsubsection{2.b Field Capacity}

Field capacity (FC 1) was determined at first based on the water percolation principle according as is described by Mitscherlich (1949), where an excess amount of water is percolated through a known amount of air-dried soil; the volume of percolate is determined and the volume of water retained in the soil is calculated. Twenty-gram soil (air-dried and sieved $<2 \mathrm{~mm}$ ) was placed into a $50 \mathrm{ml}$ funnel lined with filter paper Whatman No. 1. The bottom of the funnel was closed with cotton. The funnel was connected to a plastic tube and closed with a clamp to prevent the loss of water. Thirty to $45 \mathrm{ml}$ of distilled water were added to the soil, covered to avoid evaporation, and left standing overnight. The next day the funnel tube was opened to allow the water to percolate in a pre-weighed beaker. The drained water was weighed and the $\mathrm{FC} 1(\%)$ calculated as:

FC $(\%)=\frac{[\text { initial amount of water }- \text { weight of percolated water }]}{\text { air }- \text { dried soil weight }} \times 100$

This methodology did not work for the Lithosols (black soils from the forest sites) as the water could not percolate the soil and remained on top of the soil samples. Therefore, an alternative approach (FC 2) was applied based on the "capillary model" by Hillel (1971): the rise of water in the soil from a free-water surface. About 8-15 $\mathrm{g}$ soil (sieved and air-dried) was placed in a bottomless iron-tube of $7 \mathrm{~cm} \mathrm{x} 4 \mathrm{~cm}$. The tube was covered at the bottom with filter paper and put upright in a desiccator. The desiccator was filled with water until $3 / 4$ of the tube was submerged and left overnight. Thereafter, the tubes were removed and the water allowed to percolate for about 1 hour. The soils were weighed and then placed in an oven at $105{ }^{\circ} \mathrm{C}$ for 12 hours and weighed again. The FC 2 was calculated as the difference between moist soil and dried soils. Problems encountered for the black forest soils were the pushing of soil out of the tubes by the capillary force of the water, and inconsistent values for PWP and FC (PWP > $\mathrm{FC})$.

Therefore, the procedure was adopted again based on the percolation principle (FC 3). Bottomless glass-tubes of $15 \mathrm{~cm}$ high x $1.5 \mathrm{~cm}$ diameter were filled with $10 \mathrm{~g}$ of soil (sieved and air-dried) and watered to two different moisture levels (FC and $1 / 2$ FC). The bottom of the 
tube was covered with parafilm, and $15 \mathrm{ml}$ and $25 \mathrm{ml}$ of distilled water was added to the red and black soils, respectively. The top was closed with parafilm to prevent evaporation, and left for 24 hours until soils were completely saturated with water. Some black forest soils required 48 hours for complete saturation. Thereafter, the parafilm was removed to allow drainage of the water for 2 hours or until constant weight was obtained. The field capacity (FC) was calculated as the difference between the amount of water used for complete saturation and the amount of the drained water. Half of the amount of water needed to reach saturation was used to establish "half field capacity" (1/2 FC) condition.

\subsection{Classification and identification of soil fauna}

Soil fauna was determined in both wet and dry season. The living organisms were sorted out within 2 days after soil sampling and preserved in $70 \%$ ethanol until quantification and classification. The body width classification was carried out in two different ways. (1) According to the size of litterbag pores $<250 \mu \mathrm{m}$ body width like the pores of the medium mesh bags and $<1000 \mu \mathrm{m}$ that comprise the decomposer of the big mesh bags, so we can have idea which organisms are involved in the decomposition process. (2) According the functional groups classification, described by Swift et al. (1979) as: macrofauna ( $>2 \mathrm{~mm}$ body width) and mesofauna ( $<2 \mathrm{~mm}$ body width). Also soil fauna was taxonomically identified to phylum and the most abundant groups were recognized. In the literature, there are some groups that are classified as macrofauna (ants, termites, beetle, millipedes, centipedes). It is important to clarify that in the present study, these groups are considered as mesofauna (with the exception of beetle), because the body width of these organisms was $<2 \mathrm{~mm}$.

\subsection{Soil microbiological and biochemical analysis}

\subsubsection{4.a Soil Respiration}

Soil respiration was determined through $\mathrm{CO}_{2}$ evolution in closed jars over 39 days. Two different water regimes were established, FC and 1/2 FC (see above) to assess the effect of moisture on microbial activity. In addition, the selective inhibition method of Anderson and Domsch $(1973,1975)$ was applied to study the contribution of both bacteria and fungi to soil respiration and their influence by moisture. Str was used as bacterial inhibitor. To ensure a complete inhibition the amount of Str applied was $16 \mathrm{mg} \mathrm{g}^{-1}$ soil according to Alphei et al. (1995). Modification of the original methodology was the sole application of Str dissolved in 
water (normally a mixture of glucose, Str and talcum are added dry powder on a weight-toweight basis). Here, Str was applied in aqueous solution because the distribution in the soil is improved and access to soil microorganisms enhanced (West and Sparling 1986). The amount of water for dissolution of Str corresponded to the amount needed to reach $1 / 2$ FC condition.

Treatments comprised two moisture regimes, FC and 1/2 FC and inhibition of bacteria by Str under $1 / 2$ FC. Soils without water addition served as control. Blanks were empty jars without soil and with beaker of $20 \mathrm{ml} 1 \mathrm{M} \mathrm{NaOH}$. Five replicates for each treatment were used. Fifty gram soils were placed in $400 \mathrm{ml}$ jars, each containing a beaker with $20 \mathrm{ml} 1 \mathrm{M} \mathrm{NaOH}$. The soils were acclimatized for six days and then the soil respiration was measured every three days during eighteen days for soils under FC, $1 / 2$ FC, Str, and control soils. The Str treatment was measured eighteen days because after then an increase in the soil respiration was observed. Thereafter, $\mathrm{CO}_{2}$ evolved was measured every week until thirty-nine days for soils under $1 / 2$ FC, FC, and control. The samples were stored in controlled conditions at $22{ }^{\circ} \mathrm{C}$ until the end of the experiment. The moisture was checked at every measurement; when it was needed, more distilled water was added until reaching the moisture required. $\mathrm{CO}_{2}$ evolved was trapped in $\mathrm{NaOH}$ and the amount determined by titration of unused $\mathrm{NaOH}$ with $0.5 \mathrm{M} \mathrm{HCl}$ and carbonic anhydrase according to Underwood method (1961) and modified according to Tiessen et al. (1981). Before titration, the $\mathrm{NaOH}$ contained in the beakers was brought to a $\mathrm{pH}$ of about 10 with $1 \mathrm{M} \mathrm{HCl}$, then 5 drops of carbonic anhydrase solution were added and the $\mathrm{pH}$ adjusted to exactly 8.30 with $\mathrm{HCl}$. Next the $\mathrm{pH}$ was lowered to 3.70 and the volume of $\mathrm{HCl}$ required for this step was recorded. The amount of $\mathrm{C}$ in the samples were calculated as:

$\operatorname{mgC}=(\mathrm{ml} \mathrm{HCl}$ used for sample $\mathrm{ml} \mathrm{HCl} \mathrm{used} \mathrm{for} \mathrm{blank}) \times 1.2$

Based on the mg $\mathrm{CO}_{2}-\mathrm{C} \mathrm{kg}^{-1}$ soil of each measurement, it was possible to obtain the evolution curves of $\mathrm{CO}_{2}-\mathrm{C}$ throughout 39 days of incubation by each land uses and soil types under different FC and bacteria inhibition (Str). Also, it was calculated the total $\mathrm{CO}_{2}-\mathrm{C}$ evolved during the incubation for each treatment over the time, which can be expressed as $m g \mathrm{CO}_{2}-\mathrm{C}$ $\mathrm{kg}^{-1}$ soil, based on the sum of $\mathrm{CO}_{2}-\mathrm{C}$ evolved. 


\subsubsection{4.b Microbial Biomass Nitrogen}

Microbial biomass $\mathrm{N}$ was determined by the chloroform-fumigation-extraction method (Brookes et al., 1985) for biomass ninhydrin-N (Joergensen and Brookes 1990). Ten g of soils (non-fumigated control samples) were extracted with $40 \mathrm{ml}$ of $0.5 \mathrm{M} \mathrm{K}_{2} \mathrm{SO}_{4}$ for 30 minutes filtered and stored frozen until further analysis. The samples to be fumigated $(10 \mathrm{~g})$ were placed in a desiccator and fumigated under vacuum for 24 hours at $25{ }^{\circ} \mathrm{C}$ in the dark. After allowing the chloroform to dissipate, the released microbial compounds were then extracted with $0.5 \mathrm{~m} \mathrm{~K}_{2} \mathrm{SO}_{4}$ by shaking for 30 minutes with $40 \mathrm{ml}$ of $0.5 \mathrm{M} \mathrm{K}_{2} \mathrm{SO}_{4}$. The $\alpha$-amino nitrogen containing molecules (amino acids, peptides, proteins; $30 \%$ ) as well as ammonium (70\%) were determined colorimetrically at $570 \mathrm{~nm}$ in the presence of ninhydrin according to Joergensen and Brookes (1990). Biomass $\mathrm{N}$ was calculated by multiplying the ninhydrinreactive $\mathrm{N}$ with 3.1 (Amato and Ladd 1988). Ninhydrin-reactive $\mathrm{N}\left(\mathrm{N}_{\text {nin }}\right)$ was calculated by using 1-leucine standards as the difference between $\mathrm{N}_{\text {nin }}$ extracted from fumigated soils and $\mathrm{N}_{\text {nin }}$ extracted from non-fumigated soils.

\subsubsection{4.c. Acid and Alkaline Phosphatase}

Acid and alkaline phosphatase activity in the soil was measured according to Tabatabai and Bremner (1969) with slight modifications. The release of p-nitrophenol from a pnitrophenylphosphate solution (disodium-p-nitrophenylphosphate hexahydrate) added to the soil was determined colorimetrically at $400 \mathrm{~nm} 1$ hour after incubation at $37{ }^{\circ} \mathrm{C}$. Results of activity are expressed as micrograms p-nitrophenol released over 1 hour by $1 \mathrm{~g}$ soil and are averages of triplicate assays. They are presented as the mean of fifteen replicates for each soil types and land use system. Toluene was not included in the procedure. Modified from the original method to assaying alkaline phosphatase activity was the application of the modified universal buffer (MUB) of $\mathrm{pH} 9$ rather than $\mathrm{pH} 11$. However, the optimal activity was not affected since the pH-optimum lies between pH 9 and 11 (Eivazi and Tabatabai, 1977).

\subsubsection{4.d $\beta$-Glucosidase}

$\beta$-Glucosidase was analysed according to Eivazi and Tabatabai (1988). The method is based on the colorimetric determination of $\mathrm{p}$-nitrophenol released by $\beta$-glucosidase after the soil is incubated with buffered ( $\mathrm{pH}$ 6.0) p-nitrophenyl- $\beta$-D-glucoside solution for $1 \mathrm{~h}$ at $37^{\circ} \mathrm{C}$. Toluene was not included in the procedure, and was modified from the original method. The 
extracted p-nitrophenol is measured at $400 \mathrm{~nm}$ on a spectrophotometer. Results reported are averages of triplicate assays, expressed on an oven dry basis (drying at $105{ }^{\circ} \mathrm{C}$ for $24 \mathrm{~h}$ ). The results of activity are expressed as micrograms p-nitrophenol released over 1 hour by $1 \mathrm{~g}$ soil. They are presented as the mean of fifteen replicates for each soil types and land use system.

\subsubsection{4.e Protease}

Protease activity (N-benzoyl-L-argininamide hydrolysis) of the soil was determined according to Bonmati et al. (1998). The released $\mathrm{NH}_{4}{ }^{+}$was measured according to the procedure of Kandeler and Gerber (1988), and results of activity are expressed as micrograms $\mathrm{NH}_{4}^{+}$ released per g of dry soil per hour. They are presented as the mean of fifteen replicates for each soil types and land use system.

\subsubsection{Statistical analyses}

Statistical analysis was done with SPSS software version 9.0 (SPSS Inc. 1999, Chicago, USA). The data were analysed by three-way ANOVA with the factors land uses (forest, milpa and homegardens), soil types (red and black) and seasons (dry and rainy season) or moisture levels ( $1 / 2$ FC and FC), also their possible interactions were evaluated. Differences between soil types, seasons as well as FC were confirmed by paired T-Test. Mean separation was accomplished using Fisher protected Least Significant Difference (FPLSD) at $\alpha: 0.05$ of significance level. In addition, Pearson correlation coefficient $\mathbf{r}$ was used to describe the degree of linear association between variables and moisture content, amongst others. 
III. LITTER DECOMPOSITION, SOIL FAUNA, MICROBIAL BIOMASS, AND ENZYME ACTIVITY INVOLVED IN THE C -CYCLE IN KARSTIC SOILS OF YUCATAN, MEXICO.

\subsection{Introduction}

Organic matter represents a relevant source for the plants and soil organisms in the environment that is crucial to soil quality and to the regulation of many soil functions. Changes on it, as food source, structure and function brought on by disturbance may be important for the understanding of nutrient cycling in ecosystems (Beare et al. 1992). These alterations can occur in various ways, either due to climate changes (rainfall and temperature), which affect the soil microclimate and their processes, or perturbation in the soil by the implementation of agricultural activities that also produces variations in the ecosystem functioning and nutrient cycling. For example, agricultural soils and non-cultivated soil have revealed a number of biologically and functionally distinct properties (Doran 1980, Hendrix et al. 1986). Also, seasonal variations produce changes in the soil microenvironment, which affect nutrient availability through several biogeochemical processes (Sardans et al. 2007). Both, season and management disturbances can produce alteration in the organic matter dynamics and nutrient cycling processes (Doran 1980, Sardans et al. 2007). However, the causal mechanisms for these differences have not been well described.

Few studies have focused on the relations between functioning of ecosystems and soil fauna communities (González et al. 2001, Cortet et al. 2003). This is an interesting issue since, organic matter decomposition and nutrient recycling are regulated by the physical-chemical environment in which decay takes place, and the resource quality, acting through the decomposer organisms (Joffre and Ågren 2001, Lavelle et al. 1993). The decomposers are represented by microflora (bacteria and fungi), microfauna (nematode and Protozoa), mesofauna (mainly microarthropods such as Collembola, and enchytraeids), and macrofauna (especially earthworms and diplopods) (Cortet et al. 2003). The determinants that operate at the largest scales on the ecosystems functioning (climate followed by soil properties) constrain determinants that operate at smaller scales: plant communities, macroorganisms, and microorganisms. Feedbacks exist, however, whereby determinants at lower levels of the hierarchy may influence upper level (Lavelle 2002). Due to the functional complexity of the 
soil organisms, and the complexity generated by the interactions, little consensus has been reached as to what extent soil fauna can regulate microbial activities (Moore and Walter 1998). In this context, the importance of the interactions between soil fauna and microbial community on decomposition processes remains one of the key issues in ecology (Wardle and Giller 1996, Wardle and Lavelle 1997).

Land uses affect the ecosystem function mainly due to its effect on the biological and biochemical processes and chemical properties of the soils (Dick 1992, Gunapala et al. 1998, Stark et al. 2007). Agriculture management is critical in maintaining soil fertility in the long term because some of them reduce the SOM (Holland and Coleman 1987) by disturbing their physical environment, which produce a decrease in the diversity and abundance of organic inputs that soil fauna normally use for feeding (Curry 1987, Eggleton et al. 1997, Lavelle et al. 2001). Therefore, the soil microbial biomass and activity is affected (Carpenter-Boggs et al. 2003, Dumontet et al. 2001).

Traditional agricultural techniques, where crop residues are removed, buried or ploughing, promote bacterial population on litter (Beare et al. 1992). Since bacteria have lower C assimilation efficiencies and faster turnover rates than fungi, this should therefore be important in determining the greater rates decomposition and organic matter loss in agricultural soils as compared to non-cultivated soils (Adu and Oades 1978). Holland and Coleman (1987) showed that fungal biomass and retention of straw C and N are lower where vegetal material is incorporated than where they are placed on the soil surface. In noncultivated soils or in no-tillage practice, fungi with their extensive hyphal networks may be able to form hyphal bridge between the straw $\mathrm{C}$ and soil $\mathrm{N}$, allowing use of both resources. Additionally, fungal decomposition may aid in the retention of SOM by producing more recalcitrant organic matter than bacteria (Holland and Coleman 1987). Also, fungi are more tolerant of the dry surface residue than bacteria (Griffin 1972, quoted in Holland and Coleman 1987).

Under tropical conditions rainfall is a determinant climatological factor influencing the soil processes, so wetting and rewetting cycles may have considerable importance in regulating fauna activity, their interaction with the soil microorganisms and consequently the nutrients 
transformation rates. The most serious effects of climate may be those related to drought (IPCC 2001), as water stress is already the principal constraint in arid and semi-arid zones. Nevertheless, there are several papers that suggest that above some amount of water (200-250 mm.yr ${ }^{-1}$ ), other factors limit productivity in arid and semi-arid ecosystems (Floret et al. 1982); the nutrient limitation is one of these.

In the Yucatan Peninsula, Mexico, several studies have shown a decline in soil fertility under agricultural managements: milpa (shifting cultivation) (Weisbach et al. 2002) and solares (homegardens) (Bejamin 2000). However, the mechanisms leading to the soil fertility constraints are not well understood because the SOM and nutrient contents are higher in comparison to other soils in tropical regions (Weissbach et al. 2002). For instance, a study carried out by Ceccon et al. (2002) reported that SOM content in forest soils in Yucatan was about $20 \%$. Therefore, it has been suggested that nutrient availability may be influenced by moisture conditions or by water. Additionally, high accumulation of organic matter of hydrophobic characteristics (Shang and Tiessen 2003) further may lead to low soil fertility due to low nutrient diffusion. Limited information is available regarding decomposition process and nutrient transformations related to changes in the moisture regimes. Since water is a limiting factor in these soils, it is necessary to assess how the moisture influences the decomposition and the biological processes associated under different land uses (forest, milpa and homegardens).

Studies about the decomposition process mediated by the soil fauna, microbial biomass, and enzyme activity involved in the C-cycle are useful tools to characterize the biological processes and how is the ecosystem functioning through the interaction between the soil fauna and microbial and biochemical processes. Decomposition of maize leaves in litterbags of different mesh sizes have been used to study the relative importance of the soil fauna in litter decomposition, and soil fauna abundance characterizes soil organisms that contribute to this process. Microbial biomass comprises one part of the active fraction of organic matter. It is useful to evaluate plant nutrients availability in short term (weeks to several months). The measurement of $\beta$-glucosidase activity helps to know the potential of degradation of cellulose in the reactions involved to $\mathrm{C}$-cycle. Therefore, the main objective of this research is to evaluate the soil decomposition process mediated by the soil fauna, microbial and biochemical 
characteristics associated to C-cycle under different moisture regimes and land uses from the Yucatan Peninsula. Our hypotheses were: (1) High moisture levels promote an increase in the microbial biomass quantity and activity, which would enhance the potential $\mathrm{C}$ transformation rates. (2) Land uses affect the soil physical and chemical environment in which soil organisms live, thereby affecting soil fauna groups in different ways and the global C-cycle mediated by the soil fauna and microorganisms. In this study, parameters mentioned previously were assessed in soils of milpa, homegardens and forest systems located in two representative communities of the Peninsula, where these land uses have an important contribution to the living and income of families in the region. Also, the indicators were measured under two conditions: field and laboratory to know the characteristics and the potential of these soils. 


\section{III.A. Soil Biological, Microbial and Biochemical Characteristics under Field Conditions.}

\subsection{Decomposition and mass loss of maize leaves}

Mass loss of maize leaves was higher from litterbags of $1000 \mu \mathrm{m}$ mesh sizes than of $250 \mu \mathrm{m}$ mesh size (Figure 3.1). After 30 DAI the differences were not significant. At 225 DAI, at the end of the incubation study, mass loss from litterbags of $1000 \mu \mathrm{m}$ mesh size was $80 \%$ for both black and red soils in milpa plots and 82 and $65 \%$ for red and black soils, respectively in forest sites. In the $250 \mu \mathrm{m}$ mesh size bags; the mass loss was around $40 \%$ in both black and red soils of the milpa. The forest system showed greater mass loss in the medium mesh bags than the milpa with mass loss between 69 and $59 \%$ in the red and black soils respectively. Significant differences were found between mesh sizes, the big mesh reported higher mass loss than the medium mesh. The exclusion of the macrofauna was stronger in the forest, where high fauna abundance $(>250 \mu \mathrm{m})$ was recorded (Table 3.1.a, b) (with the exception of the red soils in the dry season). Differences between land uses were only found in the big mesh bag (T-Test, p: 0.000), milpa showed higher mass loss than forest. Also, Paired-Samples T-Test reported differences between the soil types, black soil showed higher mass loss than the red soils.

The mass loss is determined by several factors, among them the qualitative and quantitative composition of the decomposer community, their physical environment (temperature and moisture principally), and the quality of the resources the animals and microorganisms are using (Swift et al. 1979, Anderson et al. 1983). The use of bags with different mesh sizes allows to evaluate the role of the soil fauna sizes groups in the decomposition of the organic material enclosed into the bags. Mesh sizes enable to know the activity of the microorganisms and small mesofauna $(<250 \mu \mathrm{m})$, and of the whole soil fauna $(1000 \mu \mathrm{m})$. Studies with the different mesh size bags allow separating the activity of principal groups that are normally attributed to the following: bacteria, protozoa, and fungi (microflora), enchytraeids, springtails and mites (mesofauna), and other arthropods and earthworms (macrofauna) (Anderson et al. 1983, Beck et al. 1998, Höfer et al. 2000, Kurzatkowski et al. 2004). The highest mass loss from leaves in the big mesh-size suggests that the soil fauna with size $>250 \mu \mathrm{m}$ determine the decomposition of the leaf litter in both milpa and forest sites. This is correlated with the 
analysis of soil fauna abundance, which reported higher abundance of organisms with body width $>250 \mu \mathrm{m}$ (Table 3.1.a and 3.1.b).
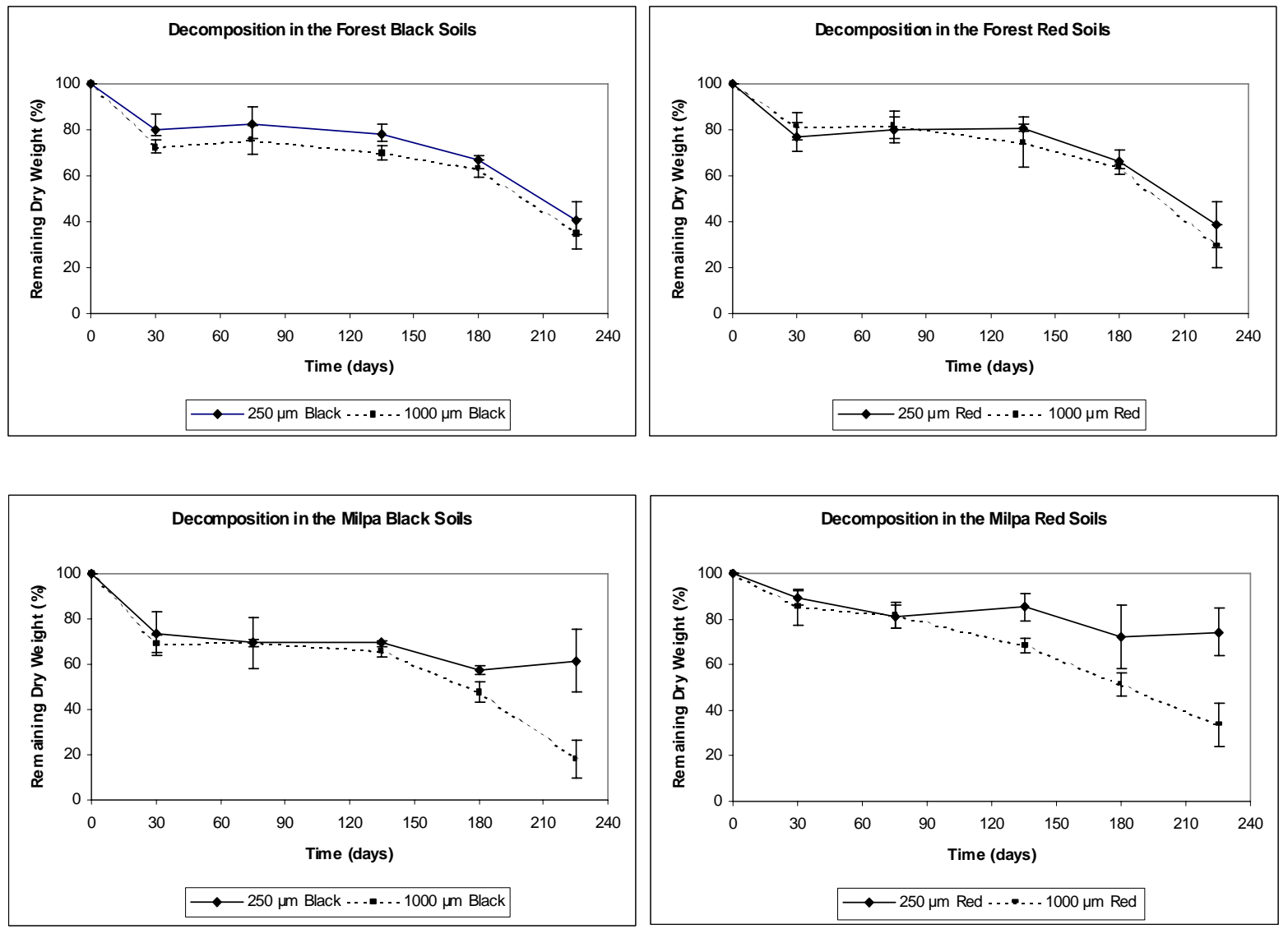

Figure 3. 1. Decomposition of Maize leaves in the litterbags (big-size mesh: $1000 \mu \mathrm{m}$, medium-size mesh: $250 \mu \mathrm{m})$. Each data point is based on 5 replicates. Error bars indicate standard deviation.

Note: Around the day 180 began the rainy season. 
Mass loss increased with the time, through the season change (from dry to rainy). Two phases in the decomposition process were identified: one phase of slow mass loss and the other of faster decomposition. The first phase until 120 days and the second phase between 120 days and 225 days. According to Swift and Anderson (1989) there are three principal factors that influence the decomposition process of leaves: climate, chemical composition, and soil fauna, also, microorganisms are considered important. In this study, the seasonal variation was an important factor that influenced the decomposition, since the weight loss began to increase from the 180 day, after the rainy season began. This observation is in accordance with Couteaux et al. (1995) who reported that regions with extreme climatic conditions of drought and rain, the climate is one of the principal factors that influence the decomposition. Rainfall influences the decomposition process both through leaching and through maintenance of optimal residue moisture content for microbial catabolism (Swift et al. 1981). Moreover, other studies have shown a positive effect of rainfall on decomposition and nutrient release (Gupta and Sing 1981, Montaña et al. 1988, Dyer et al. 1990, Anderson 1991, Austin and Vitousek 2000). Additionally, litter decomposition in tropical ecosystems is often very fast at high temperatures and precipitation (Gupta and Singh 1981, Cuevas and Medina 1986, Vitousek et al. 1994). Interestingly, the mass loss of maize was similar to those reported by Kurzatkowski et al. (2004) in three different plantations (peach palm, rubber, and polyculture), where the mass loss ranged near to $70 \%$. Also, studies carried in Sarawak (Anderson et al. 1983), native forest on Hawaii (Austin and Vitousek 2000), showed similar results.

The quality of litter plays an important role in the decomposition process. In the present study, concentrations of $\mathrm{N}$ and $\mathrm{P}$ in the maize leaves were determined. $0.31 \mathrm{~g} . \mathrm{kg}^{-1} \mathrm{~N}_{\mathrm{t}}$ and $0.05 \mathrm{~g} . \mathrm{kg}^{-1}$ $\mathrm{P}_{\mathrm{t}}$ were found. The C:N ratio and C:P ratio were 14 and 89, respectively (Table A.11, Appendix). It is well known that the relations $\mathrm{C}: \mathrm{N}$ and $\mathrm{C}: \mathrm{P}$ are used as indicators of litter quality. Generally, the $\mathrm{C}$ to $\mathrm{N}$ ratios of added substrates have been used to explain different turnover rates for initial residue decomposition. The rate of residue decomposition decreased as the $\mathrm{C}$ to $\mathrm{N}$ ratio increased because $\mathrm{N}$ becomes the limiting factor (Hendrickson 1985). When the relation $\mathrm{C}: \mathrm{N}$ is greater than 20 , means that the decomposer organisms are limited by $\mathrm{N}$, then $\mathrm{N}$ is immobilized in their biomass (Lüttge 1977). According to the results, the C:N relation is low, indicating that the $\mathrm{N}$ can be easily released to the soil and the soil organisms are not inhibited to the decomposition process. Another indicator is the relation C:P in the 
leave, this relation shows the limitation of P. During the decomposition process, the P demand by the microorganisms is high (Alexander 1980). When the relation C:P is high, a high amount of $\mathrm{P}$ is immobilized by the microorganisms. The $\mathrm{P}$ concentration in the leaves is within a standard range (standard concentration: 0.2-0.5\%, according to Adeoye and Agboola 1983), and the ratio $\mathrm{C}: \mathrm{P}$ is low indicating that this nutrient is not immobilized by the microbial biomass. It is well established that species with high $\mathrm{N}$ content decompose more quickly than those with lower N (Xuluc-Tolosa et al. 2003). Then, the higher mass loss of maize in the litterbags was probably influenced by the quality of the leave material due to the high $\mathrm{N}$ concentration and the presence of readily degraded substances that characterize the maize leave composition. As decomposition proceeds, soluble components and relatively easily degraded compounds such as sugars, starches, and proteins will be rapidly utilized by the decomposers, whereas recalcitrant materials such as cellulose, fats, tannins, and lignin will be slowly degraded (Wieder and Lang 1982).

Forest and milpa systems showed differences in the mass loss in the big mesh sizes, the major loss was observed in the milpa. This result is in line with those reported by the soil fauna abundance according to body width of the mesh pores, which reported major abundance of soil macrofauna $(1000 \mu \mathrm{m})$ in milpa red soils compared to forest red soils (Table 3.1.b). Analyses more detailed about soil fauna abundance and their possible influence on the decomposition process will be discussed in the next section (3.3). Differences in the decomposition process between milpa and forest might also be explained by the extreme microclimatic conditions. In milpa system, the plant community is composed principally by maize, and pumpkin and beans as associated plants, the incidence of radiation is higher than in forest where the trees prevent higher temperature and water evaporation, these factors influence on the soil processes and possibly allow an acceleration on the decomposition in the milpa. Similarly, Hoefer et al. (2001) reported that although the soil and litter inhabiting fauna depends on litter quality and quantity, abiotic factors have important influences in the decomposition rates. Several studies have compared the leaf decomposition rates in different ecosystems across ecosystem types in Sarawak (Anderson et al. 1983), North America and Puerto Rico (Gholz et al. 2000), Amazonia (Kurzatkowski et al. 2004) and Germany (Ke et al. 2005); and these have shown that the decomposition rate varies between different ecosystems. Hoefer et al. (2001) reported differences between primary forest and polyculture tree 
plantations, where the decomposition rates were about $60 \%$ lower in comparison to the primary forest. However, Gunapala et al. (1998) found no differences between conventional and organic farming systems when both were amended with organic matter and maintained under similar conditions.

\subsection{Soil Fauna abundance and their relation to observations of litter mass loss}

Results show that the soil fauna which had influence on the decomposition of maize leaves were those organisms with $>250 \mu \mathrm{m}$ body size. A wide group of soil fauna could influence this, amongst them: Araneida, Coleoptera, Formicidae, Termite, Diplopoda and a small number of Lumbricidae (especially in the rainy season) (Table A.1 and A.2, Appendix). Several studies have reported that in the tropics and semi-arid regions, the most important decomposer groups are earthworms and termites respectively (Höfer et al. 2000, Whitford 1996). In the present study, termites were found as one of the most abundant groups, which could have a strong influence on the decomposition process (more details section 3.4.1). According to Lal (1988), termites are considered in semi-arid regions as the group that have major control on the soil properties. In this study, Araneida, Coleoptera, and Formicidae, are considered also as the principal groups that drive the decomposition process in these ecosystems because these groups were found as the most abundant. Regarding the soil fauna with $<250 \mu \mathrm{m}$ body width, the groups within this range of size were: Acaris, Diplura, and Myriapoda. The abundance of these organisms was significantly lower in comparison with the soil fauna of major size (Paired-Samples T-Test). Therefore, the relation between soil fauna abundance and mass loss suggest that the macrofauna $(>250 \mu \mathrm{m})$ has higher influence than the mesofauna $(<250 \mu \mathrm{m})$. According to our results, litterbags experiments (using mesh sizes with Vismia leaves), in a peach palm monoculture, rubber tree plantation, and agroforestry system, reported a decrease of decomposition rates by exclusion of the macrofauna (Kurzatkowski et al. 2004). Also, other studies have shown the influence of the macrofauna to the decomposition of the leaf litter in litterbags in tropical regions (Tian et al. 1992, Yamashita and Takeda 1998). In contrast, other studies have found small impact of the macrofauna on the decomposition process in forests of temperate climates (Wise and Schaefer 1994, Eisenbeis et al. 1996, Geissen and Brümmern 1999). These results suggest that the 
impact of the soil fauna on decomposition process is highly variable and depends on the type of litter and soil, as well as the climate.

Table 3.1. a. Abundance of the soil fauna (ind. $\mathrm{m}^{-2}$ ) in the black soils under different landuse during the dry and rainy season. Classification according to body width of the mesh sizes pores (medium: $\leq 250 \mu \mathrm{m}$ and big: $1000 \mu \mathrm{m})$.

\begin{tabular}{|l|l|l|l|l|}
\hline \multicolumn{3}{|l|}{ Dry season } & \multicolumn{2}{l|}{ Rainy season } \\
\hline Land Use & $\mathbf{2 5 0} \boldsymbol{\mu m}$ & $\mathbf{1 0 0 0} \boldsymbol{\mu m}$ & $\mathbf{2 5 0} \boldsymbol{\mu m}$ & $\mathbf{1 0 0 0} \boldsymbol{\mu m}$ \\
\hline Forest & $12 \pm 1$ & $80 \pm 3$ & $25 \pm 1$ & $84 \pm 6$ \\
\hline Milpa & $12 \pm 1$ & $64 \pm 6$ & $25 \pm 2$ & $30 \pm 2$ \\
\hline FPLSD & 2 & 10 & 4 & 9 \\
\hline
\end{tabular}

Mean \pm 1 SD.

Within the same column, differences are significant when greater than FPLSD.

Table 3.1. b. Abundance of the soil fauna (ind. $\mathrm{m}^{-2}$ ) in the red soils under different landuse during the dry and rainy season. Classification according to body width of the mesh sizes pores (medium: $\leq 250 \mu \mathrm{m}$ and big: $1000 \mu \mathrm{m})$.

\begin{tabular}{|l|l|l|l|l|}
\hline & \multicolumn{2}{|l|}{ Dry season } & \multicolumn{2}{l|}{ Rainy season } \\
\hline Land Use & $\mathbf{2 5 0} \boldsymbol{\mu m}$ & $\mathbf{1 0 0 0} \boldsymbol{\mu m}$ & $\mathbf{2 5 0} \boldsymbol{\mu m}$ & $\mathbf{1 0 0 0} \boldsymbol{\mu m}$ \\
\hline Forest & $7 \pm 1$ & $94 \pm 6$ & $95 \pm 6$ & $232 \pm 25$ \\
\hline Milpa & $9 \pm 1$ & $158 \pm 12$ & $23 \pm 2$ & $28 \pm 1$ \\
\hline FPLSD & 2 & 19 & 10 & 37 \\
\hline
\end{tabular}

Mean \pm 1 SD.

Within the same column, differences are significant when greater than FPLSD.

\begin{tabular}{|l|l|l|}
\hline Factor and Interactions & $\mathbf{P}-\mathbf{1 0 0 0} \boldsymbol{\mu m}$ & $\mathbf{P} \mathbf{- 2 5 0} \mathbf{\mu m}$ \\
\hline Land Use & 0.083 & 0.024 \\
\hline Soil Type & 0.036 & 0.053 \\
\hline Season & 0.857 & 0.000 \\
\hline Land x Soil Type & 0.554 & 0.024 \\
\hline Land Use x Season & 0.012 & 0.017 \\
\hline Soil Type x Season & 0.751 & 0.014 \\
\hline Land Use x Soil Type x Season & 0.058 & 0.017 \\
\hline
\end{tabular}




\subsection{Soil fauna abundance and their functional role in different land use at Yucatan, Mexico}

\subsubsection{Soil mesofauna $(<2 \mathrm{~mm})$}

In the dry season, soil mesofauna abundance $(<2 \mathrm{~mm})$ was around 57 ind. $\mathrm{m}^{-2}$ and 70 ind. $\mathrm{m}^{-2}$ in black forest soils and black milpa soils, respectively, and 208 ind. $\mathrm{m}^{-2}$ in the homegardens (Table 3.2.a). In the red forest soils mesofauna abundance was around 75 ind. $\mathrm{m}^{-2}$ while in the red milpa- and homegardens-soils 148 ind. $\mathrm{m}^{-2}$ and 230 ind. $\mathrm{m}^{-2}$ were found, respectively. (Table 3.2.b). In the black soils, homegardens had the highest mesofauna abundance (174 ind. $\mathrm{m}^{-2}$ ), whereas milpa and forest black soils had 38 and 78 ind. $\mathrm{m}^{-2}$ respectively. In the red soils, mesofauna abundance in forest increases to 222 ind. $\mathrm{m}^{-2}$, in contrast milpa and homegardens reported mesofauna abundance of 35 and 59 ind. $\mathrm{m}^{-2}$. No differences in the soil mesofauna abundance between the dry and rainy season were found (Paired - Samples T-Test); however, soil mesofauna was influenced by the land uses (Univariate analysis, Tukey post hoc test). Mesofauna abundance was significantly lower in milpa than in both homegardens and forest, with the latter not being different from one another. Also mesofauna abundance was determined by the interaction land use $\mathrm{x}$ season (LU, p-significance: 0.018 ).

The abundance of the whole soil mesofauna is affected by changes in soil moisture and land use (LU x Season) and according to their specific groups, only Araneae showed a significant seasonal variation. In arid ecosystems the functional importance of species of soil organisms is directly related to their physiological characteristic; the guilds or species of soil organisms that are active at a particular time in arid and semi-arid ecosystems are determined by abiotic factors like soil moisture and temperature, and some individual species vary considerably in their ability to remain active in very dry soils (Whitford 1996). In contrast, other studies have shown seasonal variations in the soil fauna where high abundance of soil fauna in period of high precipitation was reported, for example Withford (1978) reported that variation in the precipitation between years resulted in differences in seasonal abundance activity of ants, these were high in period of precipitation. Noble et al. (1996) reported a markedly decline in the relative abundance of microarthropods when summer sampling was carried out. 
Table 3.2. a. Abundance of the meso-and macrofauna (ind. $\mathrm{m}^{-2}$ ) in the black soils under different land uses during dry and rainy season.

\begin{tabular}{|l|l|l|l|l|}
\hline & \multicolumn{2}{|l|}{ Dry season } & \multicolumn{2}{l|}{ Rainy season } \\
\hline Land Use & Meso & Macro & Meso & Macro \\
\hline Forest & $57 \pm 3$ & $35 \pm 1$ & $78 \pm 4$ & $30 \pm 3$ \\
\hline Milpa & $70 \pm \_$ & $6 \pm 1$ & $38 \pm 3$ & $17 \pm 2$ \\
\hline Homegardens & $208 \pm 22$ & $24 \pm 2$ & $174 \pm 14$ & $53 \pm 4$ \\
\hline FPLSD & 22 & 2 & 15 & 5 \\
\hline
\end{tabular}

Mean \pm 1 SD.

Within the same column, differences are significant when greater than FPLSD

Table 3.2. b. Abundance of the meso-and macrofauna (ind. $\mathrm{m}^{-2}$ ) in the red soils under different land uses during dry and rainy season.

\begin{tabular}{|l|l|l|l|l|}
\hline \multicolumn{3}{|l|}{ Dry season } & \multicolumn{2}{l|}{ Rainy season } \\
\hline Land Use & Meso & Macro & Meso & Macro \\
\hline Forest & $75 \pm 5$ & $26 \pm 1$ & $222 \pm 19$ & $10 \pm 18$ \\
\hline Milpa & $148 \pm 12$ & $20 \pm 1$ & $35 \pm 3$ & $15 \pm 1$ \\
\hline Homegardens & $230 \pm 19$ & $29 \pm 2$ & $59 \pm 4$ & $29 \pm 2$ \\
\hline FPLSD & 22 & 2 & 19 & 18 \\
\hline
\end{tabular}

Mean \pm 1 SD.

Within the same column, differences are significant when greater than FPLSD

\begin{tabular}{|l|l|l|}
\hline Factors and Interactions & P - Macrofauna & P - Mesofauna \\
\hline Land Use & 0.100 & 0.018 \\
\hline Soil Type & 0.447 & 0.379 \\
\hline Season & 0.165 & 0.269 \\
\hline Land Use x Soil Type & 0.411 & 0.159 \\
\hline Land Use x Season & 0.558 & 0.013 \\
\hline Soil Type x Season & 0.600 & 0.572 \\
\hline Land Use x Soil Type x Season & 0.159 & 0.123 \\
\hline
\end{tabular}

Land uses had impact on the soil mesofauna abundance, especially milpa that showed the lowest abundance. Studies have reported that land uses generally deplete the soil fauna communities, whereas tree plantations allow a better conservation of communities in term of richness and abundance (Lavelle et al. 2001). Soil temperature is a factor, which could influence the low abundance in milpa. In this system a high input of maize leaves is found, however, there are no canopy that prevent high incidence of radiation and avoid high temperature in the soil surface. High temperature makes that many soil organisms go down into the subsoil. Moreover, soil fauna abundance depend also on litter quantity and quality (Höfer et al. 1996, Höfer et al. 2001), although in the present study it was not measure the 
quantity and quality of the soil litter, it might be possible that the quality and quantity of soil litter influenced on the high mesofauna abundance in forest and homegardens. In the forest systems there is high input of leaves that fall and stay on the soil surface. In homegardens, although the leaves are sometime swept and burned, the high plant diversity promotes probably the high abundance comparable to forest and higher than milpa, where the diversity is restricted basically to maize, pumpkins, and beans. This observation is in accordance with Robertson et al. (1994) and Lavelle et al. (2001), who showed the importance of organic matter as an energy source to maintain soil fauna communities and as a physical component to allow the stabilization of the biogenic structures that they produce; and who stated that all practices, which allow a significant return of plant residues to soil, maintain high levels of invertebrate activities.

In the present research, mesofauna $(>250 \mu \mathrm{m})$ was the most abundant soil fauna group. The soil mesofauna comprise a diverse group of invertebrate with high relationship in the trophic chain. In the literature Collembola and mites are usually the dominant group of microarthropods reported for temperate climates, however, in tropical regions the microarthropods are the most commonly studied (Araneae, Copepoda, Diplopoda, Insecta, Isopoda, Pseudoscorpionida, Scorpionida, and others) (Anderson 1988). Within this group, some soil organisms have been classified as macrofauna, however, in the present study they are considered as mesofauna because their body width is within range $<2 \mathrm{~mm}$ (Swift 1979). For instance, spiders (Araneae), ants (Formicidae), and termites (Isoptera) were found within the most abundant soil fauna groups to be analysed (Tables 3.3.a and 3.3.b). Here, social insects (mainly termites and ants) occurred in high abundance, especially in milpa and homegardens, whereas in forest other decomposer groups like Coleoptera (classified as macrofauna) were found. These organisms are able to use almost all the organic resource available in the soil system; especially termites that have developed sophisticated digestive mutualisms with the soil microflora (Lavelle 1997). High influence of the termites, ants, spider and beetle to the decomposition process in tropical regions have already been reported (Geissen and Brümmer 1999, Catarino 2007, Sileshi and Mafongoya 2007), and according to the results in the litterbags experiment the higher mass loss in the big mesh size $(1000 \mu \mathrm{m})$ indicate that these organisms are involved in these processes. 
Termites showed similar abundances in forest, milpa and homegardens. The abundance of termites was affected by the interaction land use $\mathrm{x}$ season (LU x S, p: 0.018, Table A.8, Appendix). The variation of termites in the land uses through the seasons could be partially explained by organic matter quantity and quality since termites show high abundance in those systems with high litter inputs (milpa and forest). During the dry season this group had higher abundance in both soil types at milpa sites. During the rainy season, the abundance was higher in the black homegarden soils and at the forest red soils. In tropical ecosystems termites are considered as an important group (Luizão et al. 1998) because they consume a high amount of the decomposing leaves in tropical and semi-arid regions. According to Martius (1994), termite alone consume approximately one third of the annual litter production in Amazonian rain forests. They can be able to use a wide variety of organic resources commonly found in the soil systems (Sileshi and Mafongoya 2007) which lies in its physical breakdown as well as in its chemical degradation, often achieved with the help of symbiotic microorganisms (Mishra and Sen-Sarma 1985, Bignell 1994 quoted in Martius 1994). Accordingly, the greater mass loss of maize leaves in litterbags of $1000 \mu \mathrm{m}$ mesh size could be by the high termite abundance. Termites incorporate $\mathrm{C}$ into the soil and thus may contribute to the high organic $\mathrm{C}$ content present at these sites. This observation is in accordance with Ndiaye et al (2004), who showed that termite's habitats (termites sheeting) constituted a soil functional compartment with high organic C concentration. Also, Holt (1987) showed that Amitermes contributed 4$10 \%$ of C mineralised in semi-arid woodland soils. We cannot prove directly the link between the nutrient concentrations in the soil and the abundance of termites, but it might infer that this group has influence on the nutrient concentrations in the land uses due to the high organic $\mathrm{C}$ and total $\mathrm{N}$ concentration reported by Aguila (2007) in the milpa and forest soils, where termites had also high abundance. Termites were significant higher in the red soils than the black; the low abundance of termite in the black soils is probably due to the high stone content in these soils. The termites found in the soils of Yucatan were principally subterranean. It is assumed that the high content of stone and "laja" (gravel layer) that characterizes the black soils, contributed to the low abundance of termites. These results corroborate studies by Romanyà et al. (2000), who showed that the presence of stones affects the microclimatic conditions of the soil surface and the distribution and activity of the soil fauna by limiting the circulation through the soil profile. 
Season, land uses, and soil types had not influence on Formicidae (ants) abundance (Table A.7, Appendix). It is important to stress that ants showed similar abundance than termites, therefore their importance as an important group of the soil fauna and to their possible influence on the decomposition process and nutrient cycling are considered. Although it was not found significant differences in the land uses and season, it can be observed slight high ant abundance in the homegarden black soils in the dry season and forest red soil in the rainy season. This result may be an indication of the habitat heterogeneity and biological phenomenon such as their foraging habits. Plant diversity in homegardens and high leaves input in forest could promote the high abundance of ants in these land uses. Ants have various functional roles such as leaf-cutter, scavenging, granivory, and omnivory (Boulton and Amberman 2006). We cannot completely confirm the influence of ants on the decomposition process, because one of the systems where they had higher abundance was in homegardens (no data of mass loss in this system). However, it can suggest their influence on the mass loss in the forest, where high abundance was reported (principally in the rainy season). Moreover, influence of ants on the soil chemical properties have been reported; studies in the Chihuahuan Desert have shown that colonies of some species of ants affect the nutrient concentrations in soil around the nest disc (Whitford 1996), similar patterns have been observed in African Karoo Desert (Dean and Yeaton 1993) and in the desert in Israel (Danin and Yom-Tov 1990). They have shown that ant-modified soil invariably increased nutrients such as $\mathrm{C}, \mathrm{PO}_{4}$ and $\mathrm{N}$, however sometimes the increases are small or negligible (Lobry de Bruyn and Conacher 1990, Boulton and Amberman 2006). Based on the previous mentioned, it might infer the influence of ants on the soil nutrient contents in the land uses, because $\mathrm{C}$ and $\mathrm{N}$ content were higher in forest and homegardens where ants showed high abundance.

Araneae showed similar abundance in the land uses systems. However, significant and high abundance in the dry compared to the rainy season was reported. In the present study, Araneae were classified among the principal decomposers, rather than predators. McIver et al. (1992) summarised the spider features to three attributes of the environment that may influence on their abundance and composition: canopy closure, litter development, and prey availability. Others have characterized the spiders based on two environmental factors: light (open, semiopen, shady, and light-indifferent) and moisture (dry, mesic, moisture-indifferent) (Huhta 1971). Each of these environmental attributes suggest that differences in Araneae abundance 
can be expected due to each of them provide different structural and microclimatic conditions for spiders. The seasonal variation of spiders could be also referred to the higher litter amount in the dry season, which allows maintaining of some groups of spiders in the land uses during this season and increasing their abundance. This observation is in agreement with a study carried out by York (1999) in southeastern Australia, who showed that the litter environment can support a high number of spiders and suggested that the reduction of leaf litter can result in lower population of these organisms. Although spiders were not as abundant as termites and ants, their abundance is within a range of studies carried out in diverse agricultural practices through several climates (York 1999, Sunderland and Samu 2000, Greenstone 2001). Therefore, their influence on the decomposition process could be minimal.

\subsubsection{Macrofauna (> 2mm)}

Macrofauna was characterized by a small group of organisms that was represented by: Coleoptera, Pseudoscorpinida, Scorpionida, and Siphonaptera; and their abundance were significantly lower compared to the mesofauna. During the dry season macrofauna numbers were was low in the black soils of the milpa $\left(6\right.$ ind. $\mathrm{m}^{-2}$ ) whereas forest and homegardens had around 35 and 24 ind. $\mathrm{m}^{-2}$ respectively (Table 3.2a). The abundance in the red soils was similar at all sites (Table 3.2.b). In the rainy season, soil macrofauna showed an abundance of 53 ind. $\mathrm{m}^{-2}$ in the homegardens black soils and 17 ind. $\mathrm{m}^{-2}$ in the milpa black soil, whereas forest kept values similar than dry season $\left(30\right.$ ind. $\mathrm{m}^{-2}$ ). During the rainy season, the macrofauna abundance in the red soils was similar than in the dry season at all sites (Table 3.3.b). Soil macrofauna abundance was not affected by any factor (land uses, soil types and season). In contrast to our results, several authors have reported the effect of land uses and season on the macrofauna communities (Sileshi and Mafongoya 2006a, 2006b, Sileshi and Mafongoya 2007). However, it is important to keep in mind that the majority of the organisms that they classify as macrofauna are considered in this study as mesofauna (ants, termites, earthworm and spiders). As mentioned above, macrofauna is influenced by the organic input (quality and quantity), radiation, soil temperature, and moisture. High quantity of leaves serves as source of food for these organisms (Sileshi and Mafongoya 2006a). According to our results, it infers that the land uses have kept an "adequate" litter input that in general, not affected the macrofauna abundance, however could influence specific groups due to their 
specific features and adaptations to environment. Therefore, their importance as a group by their contribution to the soil processes is considered, especially Coleoptera that was one of the most abundant.

Coleoptera abundance under different land use systems, soil types and seasons is shown in the table 3.3.a and 3.3.b. Land use and season had effect on the abundance and the interaction between land uses and soil types was statistically significant (LU x ST, p: 0.029, Table A.6 Appendix). The abundance in both forest and homegardens was similar and was significantly higher than in the milpa plots; besides, the coleopteran abundance in the dry season was significantly higher than in the rainy season. The effect of the agricultural practices on the specific soil fauna groups has been shown in several studies (Robertson et al. 1994, Höfer et al. 2001, Lavelle et al. 2001, Barros et al. 2002, Sisleshi and Mafongoya 2007). Of the most abundant groups, land uses only impacted on Coleoptera. The spatial heterogeneity in organic residues quality and quantity explain the observed variation in the abundance of Coleoptera. Beetles occupy a near complete spectrum of consumer roles, including herbivores, predator, and litter transformers (Lawrence and Britton 1994, quoted in Caterino 2007). This group was probably influenced because they feed directly on the biomass incorporated in the soil and possibly reflect the resource availability. Vegetation structure and complexity has shown direct effect on beetle species (Catarino 2007). Also, the heterogeneity of structure in high diversity habitats have been reported to support more potential niches for a functional diversity of fauna and is likely to support a greater range of food webs than less complex habitats (Catarino 2007). Therefore, the high abundance of beetle in forest and homegardens can be explained by the high plant diversity in these systems. Regarding the influence of the season on the Coleoptera, the high abundance of this group in the rainy season could also be attributed to optimal soil moisture conditions, as well as the source availability (food) and to their temporal variation. This idea is in keeping with results reported by Lassau et al. (2005), who observed that high abundance of beetle occur following differential "seasonality" of food resources. They attributed that habitat with high diversity and complexity can promote better conditions of soil moisture, which provides shelter from beetles. With the results it might infer that the responses of beetles are likely driven by their feeding habits, indicated by differing habitat components (land uses). According to the high abundance of Coleoptera in the soil 
fauna, and because these organisms are characterized as litter transformers, it deduces also their influence on the decomposition process.

Table 3.3. a. Abundance of the most important decomposer groups (ind. $\mathrm{m}^{-2}$ ) in the black soils under different land uses during the dry and rainy season.

\begin{tabular}{|l|l|l|l|l|l|l|}
\hline & \multicolumn{3}{|l|}{ Dry season } & \multicolumn{2}{l|}{ Rainy season } \\
\hline Group & Forest & Milpa & Homegardens & Forest & Milpa & Homegardens \\
\hline Araneae & $20 \pm 1$ & $13 \pm \_1$ & $21 \pm \_$ & $10 \pm 2$ & $5 \pm 1$ & $17 \pm 4$ \\
\hline Coleoptera & $23 \pm 1$ & $6 \pm 0$ & $12 \pm 1$ & $5 \pm 1$ & $0 \pm 0$ & $8 \pm 1$ \\
\hline Formicidae & $6 \pm 3$ & $4 \pm 0$ & $113 \pm 31$ & $20 \pm 3$ & $8 \pm 3$ & $31 \pm 4$ \\
\hline Isoptera:Termites & $7 \pm 0$ & $35 \pm 10$ & $2 \pm 0$ & $0 \pm 0$ & $0 \pm 0$ & $57 \pm 36$ \\
\hline
\end{tabular}

FPLSD values by Groups

\begin{tabular}{|l|l|l|}
\hline Group & Dry season & Rainy season \\
\hline Araneae & 3 & 3 \\
\hline Coleoptera & 2 & 1 \\
\hline Formicidae & 21 & 4 \\
\hline Isoptera: Termites & 6 & 13 \\
\hline
\end{tabular}

Mean \pm 1 SD

Within the same column, differences are significant when greater than FPLSD

Table 3.3. b. Abundance of the most important decomposer groups (ind. $\mathrm{m}^{-2}$ ) in the red soils under different land uses during the dry and rainy season.

\begin{tabular}{|l|l|l|l|l|l|l|}
\hline & \multicolumn{3}{|l|}{ Dry season } & \multicolumn{2}{l|}{ Rainy season } \\
\hline Group & Forest & Milpa & Homegardens & Forest & Milpa & Homegardens \\
\hline Araneae & $9 \pm 1$ & $21 \pm 1$ & $13 \pm 1$ & $8 \pm 1$ & $2 \pm 0$ & $2 \pm 0$ \\
\hline Coleoptera & $10 \pm 1$ & $10 \pm 0$ & $22 \pm 1$ & $2 \pm 0$ & $1 \pm 0$ & $7 \pm 1$ \\
\hline Formicidae & $36 \pm 6$ & $4 \pm 1$ & $73 \pm 9$ & $84 \pm 29$ & $5 \pm 2$ & $13 \pm 2$ \\
\hline Isoptera:Termites & $4 \pm 0$ & $83 \pm 13$ & $0 \pm 0$ & $103 \pm 26$ & $0 \pm 0$ & $4 \pm 0$ \\
\hline
\end{tabular}


FPLSD values by Groups

\begin{tabular}{|l|l|l|}
\hline Group & Dry season & Rainy season \\
\hline Araneae & 2 & 1 \\
\hline Coleoptera & 2 & 1 \\
\hline Formicidae & 9 & 18 \\
\hline Isoptera: Termintes & 10 & 16 \\
\hline
\end{tabular}

Mean \pm 1 SD.

Within the same soil type at the same season, differences are significant when greater than FPLSD.

FPLSD values correspond to factor land use within the same soil type at the same season.

In the present research, the soil fauna abundance is lower than those reported for tropical and temperate climates (House and Brust 1989, Stinner and House 1990, Robertson et al. 1994). This varies of several hundred to thousands. However, our results are in line with those carried out by Elkins and Whitford (1982), who reported that in semi-arid ecosystems the soil fauna is generally impoverished and strongly localized in its distribution. The data reported here suggest that a relatively small number of soil fauna groups are adapted to the climatic conditions in Yucatan. The comparatively low abundance of the soil fauna found at the sites might partly be explained by the analytical protocol. The extraction of the soil fauna was done mechanically by hand; this procedure only extracts those organisms that can be seen directly. The time of sampling likely contributed to the low abundance. Sampling was done around noon when air temperatures were high. Some soil organisms move to greater depth $(>10 \mathrm{~cm})$ to escape heat. Whitford et al. (1981) reported that diurnal patterns of microarthropod abundance in surface leaf litter were related to its moisture content, where it was higher early in the morning and fell by around noon. Some soil organisms present high or low activity depending upon the degree of aridity in the system, the activity food web that is processing leaf litter at the soil surface may be limited to a few organisms that are active for a few hours each day (Whitford 1989).

\subsection{Microbial biomass nitrogen during the dry and rainy season}

The quantity of the microbial biomass $\mathrm{N}$ as affected by land use, season, and soil type is summarized in Tables 3.4.a and 3.4.b. During the dry season the microbial biomass $N$ ranged between $2.47-13.57 \mathrm{mg} \mathrm{N} \mathrm{kg}^{-1}$ dry soil in the black soils and $2.01-3.87 \mathrm{mg} \mathrm{N} \mathrm{kg}^{-1}$ dry soil in the red soils. In the rainy season, the values varied between $4.81-24.46 \mu \mathrm{g} \mathrm{N} \mathrm{kg}^{-1} \mathrm{dry}$ soil and $2.79-7.50 \mathrm{mg} \mathrm{N} \mathrm{kg}^{-1}$ dry soil in the black and red soils respectively. The black soils 
showed higher microbial biomass (13.11 $\mathrm{mg} \mathrm{N} \mathrm{kg}^{-1}$ dry soil) $\mathrm{N}$ than the red soils $(5.21 \mathrm{mg} \mathrm{N}$ $\mathrm{kg}^{-1}$ dry soil). Also, microbial biomass $\mathrm{N}$ was significantly higher during the rainy season (8.91 $\mathrm{mg} \mathrm{N} \mathrm{kg}^{-1}$ dry soil) than the dry season (4.93 $\mathrm{mg} \mathrm{N} \mathrm{kg}^{-1}$ dry soil) and was affected by the interactions land use x soil type; land use x season; and soil type $\mathrm{x}$ season. In the present study, microbial biomass $\mathrm{N}$ was in the same range in Chichihuan desert soils reported by Gallardo and Schlesinger (1995), who found values around 15 and 10-17 (mg N. kg-1 soil). However, these values are lower than those reported by Srivastava (1992), Hossain et al. (1995) and Li and Chen (2004) who found values around 39-100 mg N. kg-1 soil in different agricultural management, soil type and texture.

The microbial biomass $\mathrm{N}$ increased about $45 \%$ in the rain compared with the dry season. Correlation analysis showed that microbial biomass $\mathrm{N}$ was significantly related with the moisture content during the dry season $(\mathrm{p}<0.0001 ; \mathrm{r}=0.47)$ and during the rainy season $(\mathrm{p}<$ 0.0001, $\mathrm{r}=0.74$ ). High values in the microbial $\mathrm{N}$ during the rainy season are related with an increase in the moisture and nutrient availability. Under optimal moisture conditions there is high nutrient availability that the microorganisms can immobilize in their biomass. Also, the low values in the dry season could be that under low soil moisture many microorganisms are intolerant to the drought conditions (Reid 1980, Harris 1981, Piao et al. 2000). Previous studies (Ross 1987, Wardle and Parkinson 1990, Van Gestel et al. 1993) suggested that soil drying-rewetting cycles enhance the turnover of the microbial biomass. During the dry season part of the biomass is killed and on the rewetting in the rainy season, the surviving biomass can utilize the cell debris (Kieft et al. 1987); thus microbial activity may have been higher during the rainy season than during the dry period when the moisture level are low. Normally seasonal fluctuation in biomass $\mathrm{N}$ follows different trends; many authors have found that abrupt changes in soil moisture stimulate the turnover of microbial biomass in soils (Wardle and Parkinson 1990, Mazzarino et al. 1991, Gallardo Schlesinger 1995, Piao et al. 2000). However, others have shown little soil microbial biomass variation throughout the seasons (Bardgett et al. 1999, Spedding et al. 2004, Tonon et al. 2005). This variation can be explained by variation in the climatic conditions of temperate and tropical regions, differences in texture, and type of management, amongst others. 
Table 3.4. a. Microbial biomass $\mathrm{N}$ ( $\mathrm{mg} \mathrm{N} \mathrm{kg}^{-1}$ dry soil) in the black soils under different land uses during the dry and rainy season.

\begin{tabular}{|l|l|l|}
\hline Land Use & Dry & Rainy \\
\hline Forest & $13.57 \pm 4.02$ & $24.46 \pm 11.41$ \\
\hline Milpa & $4.45 \pm 1.78$ & $9.32 \pm 4.52$ \\
\hline Homegardens & $2.47 \pm 1.50$ & $4.81 \pm 4.38$ \\
\hline FPLSD & 4.42 & 12.41 \\
\hline
\end{tabular}

Mean \pm 1 SD.

Within the same column, differences are significant when greater than FPLSD

Table 3.4. b. Microbial biomass $\mathrm{N}$ ( $\mathrm{mg} \mathrm{N} \mathrm{kg}^{-1}$ dry soil) in the red soils under different land uses during the dry and rainy season.

\begin{tabular}{|l|l|l|}
\hline Land Use & Dry & Rainy \\
\hline Forest & $2.01 \pm 1.54$ & $7.50 \pm 4.07$ \\
\hline Milpa & $3.84 \pm 1.15$ & $2.79 \pm 1.56$ \\
\hline Homegardens & $3.26 \pm 1.39$ & $4.58 \pm 2.93$ \\
\hline FPLSD & 2.26 & 5.01 \\
\hline
\end{tabular}

Mean \pm 1 SD.

Within the same column, differences are significant when greater than FPLSD

\begin{tabular}{|l|l|}
\hline Factors and Interactions & P \\
\hline Land Use & 0.000 \\
\hline Soil Type & 0.000 \\
\hline Season & 0.000 \\
\hline Land Use x Soil Type & 0.000 \\
\hline Land Use x Season & 0.000 \\
\hline Soil Type x Season & 0.002 \\
\hline Land Use x Soil Type x Season & 0.236 \\
\hline
\end{tabular}

Results from this study show that the land uses have had significant effects on the microbial biomass $\mathrm{N}$. Means by land uses indicate that microbial biomass $\mathrm{N}$ varied among land uses and were approximately $57 \%$ higher in forest than in milpas and $68 \%$ higher in forest than in homegardens soils. Several studies conducted in the tropics have indicated that the conversion of forests into several agricultural practices is often accompanied by a significant reduction in the SOM, nutrients (especially N and P), and microbial biomass (Prasad et al. 1994, Templer et al. 2005). Also, it is well known that changes in the microbial biomass pools coincide with changes in the availability of mineralizable substrate or soil conditions (Spedding et al. 2004). It is important to stress that $\mathrm{N}$ is poorly immobilized by the microbial biomass, this part of the total $\mathrm{N}$ represent about $0.06 \%$ in black forest soils, whereas in milpa and homegardens 
microbial biomass immobilized around $0.03 \%$ of the total $\mathrm{N}$. Low microbial biomass $\mathrm{N}$ in the milpa and homegarden soils could be due to a low availability of mineralizable substrate and to soil conditions that create a different microclimate and promote changes in the microbial biomass. Under shifting cultivation (milpa) lower input of organic matter is provided; similarly regular removal and burning of organic material in homegardens let to reduced organic matter input. This observation is in agreement with Benjamin et al. (2001), who reported low contribution of nutrient from the litter in homegardens of Yucatan due to this is removed. They stated that if litter were not removed, potential $\mathrm{N}$ contribution in homegardens of Yucatan would be very high. However, in the forest the high input of organic matter that stays on the soil is an important source for microbial growth and, allows an increase in the microbial biomass. In addition, the composition of plants is dominated by legumes, which often have lager amounts of litterfall $\mathrm{N}$, thus the large input of this material could also be a further explanation of high microbial $\mathrm{N}$ in the forest. Our observation is based on a study carried out by Ruiz-Garvia (unpublished data 2007) who reported high amount of $\mathrm{N}$ in the litter and leaf of forests in Yucatan. Ruiz-Garvia reported values around $17 \mathrm{mg} \mathrm{N} . \mathrm{g}^{-1}$ litter and $26 \mathrm{mg} \mathrm{N} . \mathrm{g}^{-1}$ leaf of forests at different ages in Yucatan. About the differences reported between soil types, the higher biomass $\mathrm{N}$ in the black soils can be attributed to the high organic matter content in the black soils, which creates major substrate availability to mineralise and immobilize in the microbial biomass. This observation can be stated by the significant correlation between the organic $\mathrm{C}$ and the microbial biomass in the dry season (r: $0.639, \mathrm{p}<0.0001)$.

\subsection{The activity of $\beta$-glucosidase during the dry and rainy season}

The activity of $\beta$-glucosidase in the black and red soils is summarized in Tables 3.5.a and 3.5.b respectively. During the dry season, black soils presented means of $98 \mathrm{mg} \mathrm{PNP} \mathrm{kg}^{-1} \mathrm{~h}^{-1}$ in homegardens, $78 \mathrm{mg}$ PNP kg $\mathrm{k}^{-1}$ in milpas and $110 \mathrm{mg}$ PNP kg- $\mathrm{h}^{-1}$ in forest soils. Red soils during the same season showed activities of $90 \mathrm{mg} \mathrm{PNP} \mathrm{kg}^{-1} \mathrm{~h}^{-1}$ in homegardens, $69 \mathrm{mg}$ PNP $\mathrm{kg}^{-1} \mathrm{~h}^{-1}$ in milpa, and $95 \mathrm{mg}$ PNP $\mathrm{kg}^{-1} \mathrm{~h}^{-1}$ in forest. In the rainy season, black soils had values around $70 \mathrm{mg}$ PNP $\mathrm{kg}^{-1} \mathrm{~h}^{-1}$ in homegardens, $87 \mathrm{mg} \mathrm{PNP} \mathrm{kg}^{-1} \mathrm{~h}^{-1}$ in milpas; in contrast, forest presented a mean in the activity of $144 \mathrm{mg} \mathrm{PNP} \mathrm{kg}^{-1} \mathrm{~h}^{-1}$. Red soils showed activities of $87 \mathrm{mg}$ PNP kg ${ }^{-1} \mathrm{~h}^{-1}$ in homegardens and milpas and $97 \mathrm{mg} \mathrm{PNP} \mathrm{kg}^{-1} \mathrm{~h}^{-1}$ in forest soils. Land use had influence on the $\beta$-glucosidase activity and also was determined by the interaction 
land use $\mathrm{x}$ season and land use $\mathrm{x}$ soil types. The data are similar to those reported by Badiane et al. (2001) for improved fallows systems in Senegal (37 to $79 \mathrm{mg} \mathrm{PNP} \mathrm{kg}^{-1} \mathrm{~h}^{-1}$ ). Also Dick et al. (1994) reported values around of $130 \mathrm{mg} \mathrm{PNP} \mathrm{kg}^{-1}$ soil h${ }^{-1}$ in uncultivated and abandoned soils at the Colca Valley, Peru. However, other studies have shown higher activity in sites with high input of organic material (Garcia et al. 1994, Caldwell et al. 1999, Caravaca et al. 2002, Turner et al. 2002, Gianfreda et al. 2005). In general, these studies have stated that this enzyme is affected by the soil composition under field conditions, non-uniform soil, incorporation, and quality of crop residues that changes the microbial environment and influences the enzyme synthesis and persistence.

In the present research, $\beta$-glucosidase showed the lowest sensitivity to seasonal effect compared to the results found of the others enzyme activities. Differences between the dry (89.84 mg PNP kg ${ }^{-1} \mathrm{~h}^{-1}$ ) and rainy season (95.26 $\mathrm{mg} \mathrm{PNP} \mathrm{kg}^{-1} \mathrm{~h}^{-1}$ ) were not found. However, $\beta$ -glucosidase activity was significantly correlated with the moisture content during the dry season $(\mathrm{p}<0.01, \mathrm{r}=0.323)$ and during the rainy season $(\mathrm{p}<0.0001, \mathrm{r}=0.582)$. Several studies have shown different trends of the $\beta$-glucosidase activity with change in the soil moisture, for example Rastin et al. (1988) reported no correlation between the soil moisture and $\beta$ glucosidase activity in a beech forest in Germany. However, Eivazi and Tabatabai (1990) reported a marked increase in the activity of this enzyme in soils of USA when it was airdrying of field moist. In the present research low seasonal variation of $\beta$-glucosidase is attributed to complexation to organic substances with the soil colloids. Chemical complexation/sorption processes control stabilization of $\beta$-glucosidase in the soil matrix, the chemical nature of organic matter input and physical protection mechanisms (Turner et al. 2002, Knight and Dick 2004). Therefore, these processes would not show wide temporal/seasonal variability and thus would cause abiontic $\beta$-glucosidase accumulation or degradation to proceed at a steady pace over time under given management systems (Knight and Dick 2004). Also, it is important to highlight that $\beta$-glucosidase is produced principally by mucoraceous fungi such as Actinomucor sp and Mortirella sp (Hayano and Tubaki 1995), which could give major tolerance to extreme conditions of drought and so maintain the activity of $\beta$-glucosidase during the dry season. 
The activity of $\beta$-glucosidase was influenced by land use. This enzyme showed the highest activity in the forest soil (111.56 mg PNP kg${ }^{-1}$ dry soil $\left.\mathrm{h}^{-1}\right)$ whereas milpa and homegardens presented similar values (80.16 mg PNP kg${ }^{-1}$ dry soil h${ }^{-1}$ and $85.94 \mathrm{mg} \mathrm{PNP} \mathrm{kg}^{-1}$ dry soil h respectively). $\beta$-glucosidase plays an important role in degradation of carbohydrate in soils; and the hydrolysis products of this enzyme are believed to be important energy sources for the growth of the soil microbial heterotrophos, in particular fungi (mucorales) which predominantly produce $\beta$-glucosidase (Deng and Tabatabai 1996, Ajwa et al. 1999, Turner et al. 2002). Therefore, the high $\beta$-glucosidase activity in the forest system is due to an accumulation of litter on the soil surface of this ecosystem that increases the supply of the readily available substrates, such as carbohydrates. The low activity in milpa and homegardens might be due to the burning and removal of the litter. This observation is in accordance with Eivazi and Bayan (1996), who studied the long-term burning effect on enzyme activities in a forest ecosystem and found that $\beta$-glucosidase activity was greatly reduced by burning due to the destruction of the forest floor vegetation.

$\beta$-glucosidase activity was significant and positively controlled by the microbial biomass and organic $\mathrm{C}$ in the dry season. The significant and positive correlation was possibly due to the role of the enzyme in the degradation of cellulose and cycling of carbohydrates in soils and enzyme synthesis by soil organisms. This idea is in keeping with previous studies which have reported that $\beta$-glucosidase activity is related to organic $\mathrm{C}$ and microbial biomass and is influenced by the availability of the vegetal material on the soil (Burns 1978, Doran 1980, Nannipieri et al. 1983). Additionally, $\beta$-glucosidase activity was significant and negatively correlate with the $\mathrm{CO}_{2}-\mathrm{C}$ evolved under dry field conditions; however, positive correlations were found between the activity of $\beta$-glucosidase and the $\mathrm{CO}_{2}-\mathrm{C}$ evolved under optimal and controlled conditions of moisture throughout the incubation experiment (Table 3.5.c), the activation of the microorganisms and production of enzyme under optimal moisture condition indicate that $\beta$-glucosidase is a measurement of the potential activity. 
Table 3.5. a. $\beta$-glucosidase activity ( $\mathrm{mg}$ PNP $\mathrm{kg}^{-1}$ dry soil $\mathrm{h}^{-1}$ ) in black soils under different land uses during the dry and rainy season.

\begin{tabular}{|l|l|l|}
\hline Land Use & Dry season & Rainy season \\
\hline Forest & $110 \pm 20$ & $144 \pm 45$ \\
\hline Milpa & $78 \pm 13$ & $87 \pm 13$ \\
\hline Homegardens & $98 \pm 44$ & $70 \pm 30$ \\
\hline FPLSD & 57 & 61 \\
\hline
\end{tabular}

Mean \pm 1 SD.

Within the same column, differences are significant when greater than FPLSD

Table 3.5. b. $\beta$-glucosidase activity (mg PNP kg ${ }^{-1}$ dry soil $\mathrm{h}^{-1}$ ) in red soils under different land uses during the dry and rainy season.

\begin{tabular}{|l|l|l|}
\hline Land Use & Dry season & Rainy season \\
\hline Forest & $95 \pm 29$ & $97 \pm 38$ \\
\hline Milpa & $69 \pm 21$ & $87 \pm 26$ \\
\hline Homegardens & $90 \pm 57$ & $87 \pm 28$ \\
\hline FPLSD & 64 & 51 \\
\hline
\end{tabular}

Mean \pm 1 SD.

Within the same column, differences are significant when greater than FPLSD

\begin{tabular}{|l|l|}
\hline Factors and Interactions & P \\
\hline Land Use & 0.000 \\
\hline Soil Type & 0.054 \\
\hline Season & 0.308 \\
\hline Land Use x Soil Type & 0.020 \\
\hline Land Use x Season & 0.021 \\
\hline Soil Type x Season & 0.948 \\
\hline Land Use x Soil Type x Season & 0.083 \\
\hline
\end{tabular}


Table 3.5. c. Correlation matrix: $\beta$-glucosidase activity during the dry and rainy season vs. moisture content, organic $\mathrm{C}$ (Corg) and $\mathrm{CO}_{2}-\mathrm{C}$ evolved.

\begin{tabular}{|l|l|l|}
\hline & Dry season & Rainy season \\
\hline Moisture & $0.323^{* *}$ & $0.582^{* *}$ \\
\hline $\begin{array}{l}\text { Corg } \\
(\text { Dry }\end{array}$ & $0.274^{* *}$ & - \\
\hline $\begin{array}{l}\text { Nmic } \\
\left(\text { Dry }^{1}\right)\end{array}$ & $0.209^{* *}$ & - \\
\hline $\begin{array}{l}\text { Nmic } \\
\left(\text { Rain }^{4}\right)\end{array}$ & - & $0.644^{* *}$ \\
\hline $\begin{array}{l}\mathbf{C O}_{2}-\mathbf{C} \\
\left.\text { (Dry }^{1}\right)\end{array}$ & $-0.221^{*}$ & -0.003 \\
\hline $\begin{array}{l}\mathbf{C O}_{2}-\mathbf{C} \\
\left(\mathbf{M o i s t}^{2}\right)\end{array}$ & $0.273^{* *}$ & $0.491^{* *}$ \\
\hline $\begin{array}{l}\mathbf{C O}_{2}-\mathbf{C} \\
\left.\text { (FC }^{3}\right)\end{array}$ & $0.273^{* *}$ & $0.472^{* *}$ \\
\hline
\end{tabular}

Pearson's correlation coefficients calculated from means of the determined parameters from all land uses. Nmic: microbial biomass N, Corg: organic Carbon (Source: Aguila 2007), $\mathrm{CO}_{2}-\mathrm{C}$ : $\mathrm{CO}_{2}$ evolved in the incubation experiment, $\mathrm{NO}_{3}-\mathrm{N}$ : available Nitrate in the incubation experiment (Source: Aguila 2007). N=90.

* Correlation is significant at the 0.05 level (2-tailed)

** Correlation is significant at the 0.01 level (2-tailed)

${ }^{1}$ Dry season field conditions

${ }^{2}$ under moist condition incubation experiment

${ }^{3}$ under FC condition incubation experiment

${ }^{4}$ Rainy season field condition 


\section{III.B. Soil Microbial and Biochemical Characteristics upon wetting and Laboratory incubation.}

\subsection{Response of the soil microbial activity (soil respiration) after artificial wetting}

\section{7.a) $\mathrm{CO}_{2}$ evolution}

In this experiment the rate of $\mathrm{CO}_{2}$ evolution from soils is used as index of microbial activity. Soils were moistened with the aim to activate the dormant microorganisms and to know their activity potential. Furthermore, streptomycin (Str) was used to inhibit the activity of bacteria and distinguish the contribution of fungi in the soil respiration. Soil respiration evolution curves at contrasting moisture level, with Str and control soils are shown in Fig. 3.2. In general, $1 / 2$ FC, FC, and Str curves showed irregular evolution through the incubation experiment, whereas the control soil curves were smooth. Soil respiration began with a slight drop until day 12; from thereon to day 18, the curves reached a stable phase. At day 18 soil respiration showed a strong increase under $1 / 2 \mathrm{FC}$ and $\mathrm{FC}$ due to an accumulation of the $\mathrm{CO}_{2}$ (when the measurements were done weekly), at the day 25 equilibrium seemed to be reached (with the exception of black soil in the forest sites under FC conditions). In general, the moisture produced a positive effect on the $\mathrm{CO}_{2}-\mathrm{C}$ respiration rate; the soil respiration rates were higher under FC. Under Str treatment the respiration evolution dropped until day 15, afterwards there were increases. The Str curves were higher than the control soils curves but lower than those under FC and $1 / 2$ FC conditions, however from day 9 the Str curves were similar to those under $1 / 2 \mathrm{FC}$ conditions.

Regarding land uses, forest soils showed the highest soil respiration rates, and homegardens the lowest. Black soils had higher respiration than the red soils. Under $1 / 2$ FC conditions, at the beginning of the incubation experiment, soil respiration increased after wetting and was 4-fold greater in black forest soils than in black homegardens soils, whereas under FC soil respiration was 2-fold greater in the black soils at the forest sites than in black homegardens soils. Through the incubation experiment $1 / 2$ FC and $\mathrm{FC}$ maintained an elevated soil respiration rate after wetting. At the end of the incubation, respiration was 4- and 3-fold greater in black forest soils than in black homegardens soils respectively. In red soils, soil respiration increased after wetting at the homegardens soils, the effect was marked at the end of the incubation and was 
2-fold greater in red forest soils than in red homegarden soils under both $1 / 2$ FC and FC. At the beginning of the experiment with Str, soil respiration was 3-fold greater in the black forest soils than in homegardens. Through the incubation time, the Str effect declined, because the respiration rates increased. However, in the red soils, the Str effect was marked at the end of the experiment in the homegardens where the soil respiration was 3-fold lower than in the red forest soils.

Soil respiration was affected by both moisture and antibiotic effect in soils under different land uses in Yucatan. These findings show the sensitivity of the soil respiration to the changes in the moisture soil and land uses. It clearly shows that the increase in the moisture content had a positive effect on the soil respiration as well as the inhibition of bacteria on the soil respiration through its inhibition with Str was shown. Respiration reflects moisture content with wetter samples being more active than the drier samples. As above mentioned, microorganisms are susceptible to drought (Howard and Howard 1993, Vincent et al. 2006), when the soil moisture increases, those microorganisms that have survived response to change in the environment, as example, an increase in the moisture levels, and therefore increase their activity. Studies have shown that the $\mathrm{CO}_{2}$ evolution have been low under moisture stress, but rise rapidly with the increase in the water content until a saturation point where the $\mathrm{O}_{2}$ uptake decreases due to their poor availability. In the present study, the saturation point was not reached. The conservation of high soil respiration rates during the incubation time shows the availability of substrate, which was not exhausted throughout the incubation experiment.

Regarding Str treatment, soil respiration rates were higher with bacteria inhibition than the control soils but lower than under $1 / 2$ FC conditions, which had the same moisture level. In the present study, the first measurement was carried out at the $6^{\text {th }}$ day after the antibiotic was added, possibly a strong inhibition occurred before and it was not detected. The inhibitor effect was recorded for a short time (9 days), and also the moisture content had possibly strong influence on the soil respiration, which promoted the fungi activity and increased the soil respiration under these conditions compared to the control treatments. However, Str curves showed lower respiration rates than under $1 / 2$ FC conditions, this suggests that Str had their target effect on the bacteria activity.. Studies have shown the Str effect for short time, as hours or until 10 days of incubation (Anderson and Domsch 1973, Badaluco et al. 1994). In the 
present test it was observed that until day 9, the soils respiration slightly decreased and after then had a rise. The evolution curves show a possibly reactivation of the bacteria that survived which could mineralise the biocide-killed bacteria and consequently enhance the soil respiration in the next days. Badaluco et al. (1994) showed that Str molecule can be mineralised by fungi as a $\mathrm{C}$ and $\mathrm{N}$ source due to its contain of $\mathrm{N}$ atoms in aliphatic chains that may well be easily mineralised by microorganisms. Comparing the soil respiration between land uses under this treatment, the forest soils showed the highest soil respiration rates, indicating that fungi might dominate the population of microorganisms in this ecosystem.

Soil respiration is a function of the decomposition of organic matter, root respiration, and rootassociated respiration (Conant et al. 2000). In the present research, the measurements of the soil respiration were principally derived from organic matter decomposition by microorganisms because all roots were excluded. Forest soils had greater soil respiration rates than milpa and homegardens. They maintained elevated rates, possibly due to high SOM input that is decomposed. It is also observed that the black soils showed higher soil respiration rates than the red soils. This can be related to the quantity of the organic matter due to the red soils containing half as much organic matter as black soils (Shang and Tiessen 2003). In agreement with this observation, Vincent et al. (2006) reported that soils with less quantity of organic matter have a lower soil respiration. Therefore, the high organic matter content in the black soil plays an important role in the soil respiration and microbial activity, since this serves as substrate for the microorganisms. 

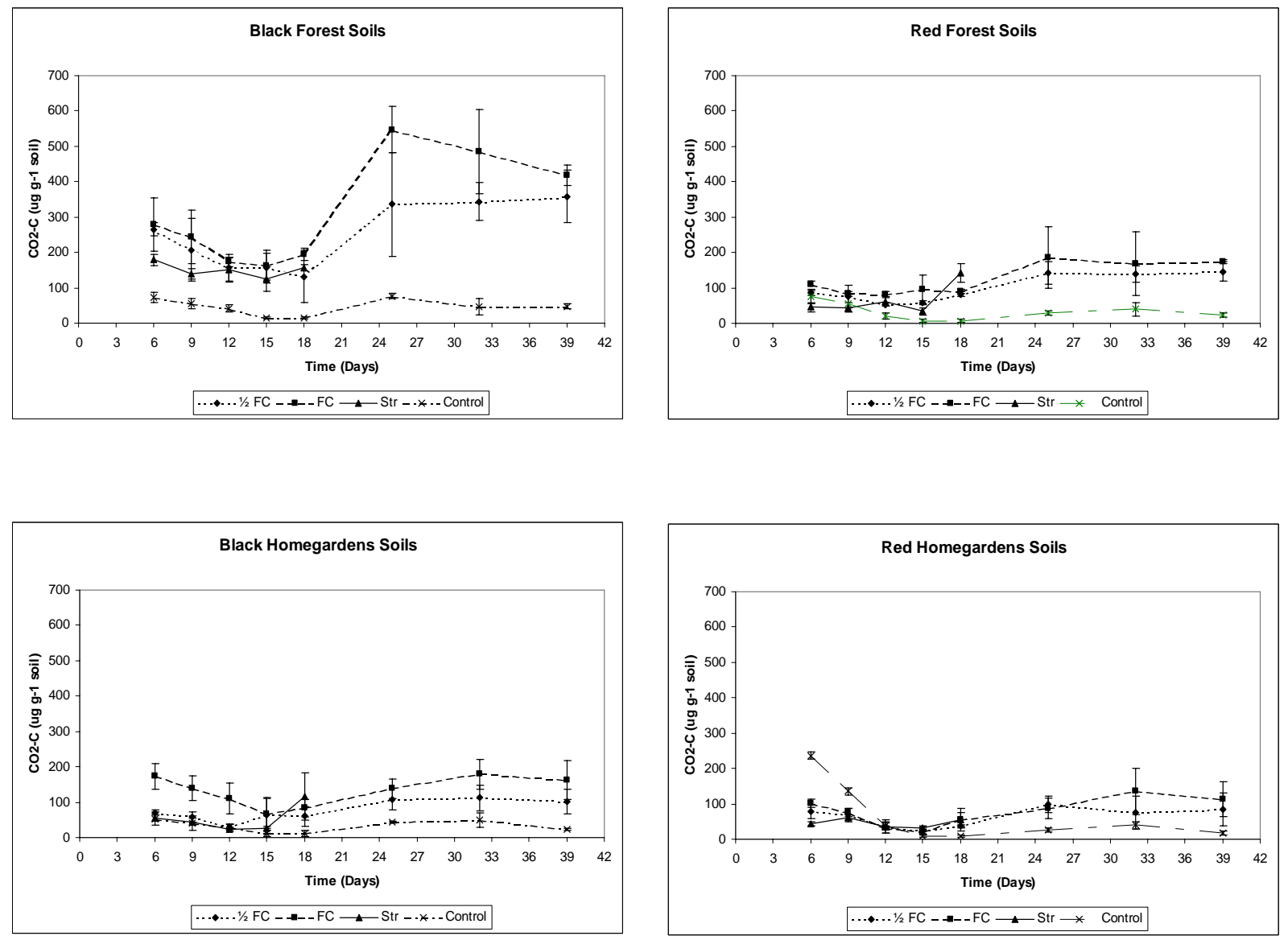

Figure 3. 2. $\mathrm{CO}_{2}-\mathrm{C}$ evolution rate recorded for the incubation treatments: control soils (x), Str ( $\triangle$ ), FC (口), $1 / 2$ FC $(\diamond)$ in different land uses; $n=15$, bar show \pm standard deviation. 


\section{7.b) $\mathrm{CO}_{2}$ evolved during eighteen days incubation: Differential activity of bacteria and} fungi

The means of the total $\mathrm{CO}_{2}-\mathrm{C}$ evolved during the incubation experiment under different moisture levels and with bacteria inhibition is shown in table 3.6.a and 3.6.b. Moisture levels, land use systems and soil types affected cumulative $\mathrm{CO}_{2}-\mathrm{C}$. Under $\mathrm{FC}$ conditions, cumulative $\mathrm{CO}_{2}-\mathrm{C}$ was even higher (598.15 $\mathrm{mg} \mathrm{CO}_{2} \mathrm{~kg}^{-1}$ soil) than under $1 / 2 \mathrm{FC}$ conditions $(456.77 \mathrm{mg}$ $\mathrm{CO}_{2} \mathrm{~kg}^{-1}$ soil), this was higher than Str treatment and $\mathrm{CO}_{2}-\mathrm{C}$ evolved under bacteria inhibition (404 mg CO $\mathrm{kg}^{-1}$ soil) was higher than control soils (246 mg CO $\mathrm{kg}^{-1}$ soil) $(\mathrm{FC}>$ $1 / 2 \mathrm{FC}>\mathrm{Str}>$ control). Land uses also influenced on the $\mathrm{CO}_{2}-\mathrm{C}$ evolved, forest soils (527.07 $\mathrm{mg} \mathrm{CO} \mathrm{kg}^{-1}$ soil) presented the highest cumulative $\mathrm{CO}_{2}-\mathrm{C}$ followed by the milpa (445.03 $\mathrm{mg}$ $\mathrm{CO}_{2} \mathrm{~kg}^{-1}$ soil) and the lowest cumulative $\mathrm{CO}_{2}-\mathrm{C}$ was observed in the homegardens sites (306.67 mg $\mathrm{CO}_{2} \mathrm{~kg}^{-1}$ soil). Also, significant differences between soil types (p: 0.000) were observed, black soils (459.72 $\mathrm{mg} \mathrm{CO}_{2} \mathrm{~kg}^{-1}$ soil) showed higher $\mathrm{CO}_{2}-\mathrm{C}$ evolved than the red soils (352.79 $\mathrm{mg} \mathrm{CO}_{2} \mathrm{~kg}^{-1}$ soil).

Table 3.6. a. Cumulative $\mathrm{CO}_{2}-\mathrm{C}\left(\mathrm{mg} \mathrm{CO} \mathrm{kg}^{-1}\right.$ soil) emission during 18 days of the black soils in 4 treatments: $1 / 2$ FC, FC, with Str, and control under different land uses.

\begin{tabular}{|l|l|l|l|l|}
\hline Land Use & $1 / 2$ FC & FC & Str & Control \\
\hline Forest & $901.5 \pm 200$ & $1054.3 \pm 139$ & $751.2 \pm 94$ & $200.0 \pm 26$ \\
\hline Milpa & $485.1 \pm 32$ & $717.4 \pm 79$ & $426.4 \pm 30$ & $191.4 \pm 19$ \\
\hline Homegardens & $282.0 \pm 85$ & $573.6 \pm 162$ & $265.4 \pm 75$ & $148.3 \pm 51$ \\
\hline FPLSD & 209.04 & 217.14 & 117.89 & 57.56 \\
\hline
\end{tabular}

Mean \pm 1 SD.

Within the same column, differences are significant when greater than FPLSD 
Table 3.6. b. Cumulative $\mathrm{CO}_{2}-\mathrm{C}\left(\mathrm{mg} \mathrm{CO} \mathrm{Cg}^{-1}\right.$ soil) emission during 18 days of the red soils in 4 treatments: $1 / 2$ FC, FC, with Str, and control under different land uses.

\begin{tabular}{|l|l|l|l|l|}
\hline Land Use & $1 / 2 \mathrm{FC}$ & $\mathrm{FC}$ & Str & Control \\
\hline Forest & $355.2 \pm 41$ & $464.4 \pm 40$ & $327.3 \pm 30$ & $162.6 \pm 45$ \\
\hline Milpa & $473.5 \pm 48$ & $493.0 \pm 43$ & $426.4 \pm 37$ & $346.8 \pm 77$ \\
\hline Homegardens & $243.3 \pm 55$ & $286.1 \pm 70$ & $228.1 \pm 14$ & $426.6 \pm 29$ \\
\hline FPLSD & 80.37 & 87.06 & 47.10 & 89.30 \\
\hline
\end{tabular}

Mean \pm 1 SD.

Within the same column, differences are significant when greater than FPLSD

\begin{tabular}{|ll|}
\hline Factors and Interactions & $\mathbf{P}$ \\
\hline Land Use & 0.000 \\
\hline Soil Type & 0.000 \\
\hline Moisture & 0.000 \\
\hline Land Use x Soil Type & 0.000 \\
\hline Land Use x Moisture & 0.000 \\
\hline Soil Type x Moisture & 0.000 \\
\hline Land Use x Soil Type x Moisture & 0.000 \\
\hline
\end{tabular}

The use of Str produced a declined of around $6 \%-17 \%$ in the cumulated $\mathrm{CO}_{2}-\mathrm{C}$ compared with the $1 / 2$ FC treatment. The results are in agreement with a previous study, which reported an inhibition about of $11-22 \%$ with the use of this antibiotic (Alphei et al. 1995). Slight decrease in the bacterial contribution to the $\mathrm{CO}_{2}-\mathrm{C}$ might indicate major fungal activity. Although in the present study fungi biomass was not directly determined, it might suppose a fungal dominance in the $\mathrm{CO}_{2}-\mathrm{C}$ evolved, but an increased bacterial dominance in Homegardens soils. Higher fungal dominance can be expected in yucatecan soils, because fungi are more tolerant to dry soil conditions than bacteria due to their filamentous nature, allowing better translocation of nutrients between soil and surface residues for their growth and activity (Holland and Coleman 1987). There are also significant interactions between moisture content, temperature, and nutrient availability, which influence the microbial activity. Bacterial movement is largely limited by water film in soil and bacteria can only remain active while the nutrients are able to diffuse toward (Orchad and Cook 1983). Consequently the low $\mathrm{CO}_{2}-\mathrm{C}$ evolved in the control soil is produced only by a small part of the microorganisms that can remain active (fungi) under this drought conditions. Therefore it is likely that bacterial activity has been constrained in the yucatecan soils, which are generally limited by the water 
content, allowing to suppose that the $\mathrm{CO}_{2}-\mathrm{C}$ evolved from the Str- and control- treatment is of fungal origin.

On the other hand, land uses bring changes in the soil and consequently alteration in the microbial communities and associated processes of decomposition. For instance, the surface of forest, as compared to the homegardens, is characterized by greater incorporation and accumulation of litter, which promote the fungi dominance (Stamatiadis et al. 1990) and produce the differentiation in the $\mathrm{CO}_{2}-\mathrm{C}$ evolved and associated process as compared to the others land uses. Most of the experiments aimed at distinguishing the fungal and bacterial components of selective inhibition respiration in forest soil (Blagodatskaya and Anderson 1998) and grassland soil (West 1986, Wardle and Parkinson 1990) and have shown that fungi dominate the microbial soil community, which agrees with our data. Fungi are dominant in natural ecosystems due to their capacity of degrade substrate with high lignin and cellulose content, as well as secondary compound that are normally present in high amount in the litter of forest ecosystems (Singh and Gupta 1977). While bacteria might dominate in homegardens and milpa where the presence of substance easily degradable confers benefits on fungi.

\section{7.c) $\mathrm{CO}_{2}$ evolved during thirty-nine days: Influence of the soil moisture on the microbial activity}

At the end of the incubation (39 days), moisture levels, land use systems, and soil types affected cumulative $\mathrm{CO}_{2}-\mathrm{C}$ during the whole period of incubation. The influence of the moisture on the cumulative $\mathrm{CO}_{2}-\mathrm{C}$ was remained through all time of incubation experiment. Cumulative $\mathrm{CO}_{2}-\mathrm{C}$ under FC (1281.47 mg CO $2 \mathrm{~kg}^{-1}$ soil) was higher than $1 / 2 \mathrm{FC}$ (962.33 mg $\mathrm{CO}_{2} \mathrm{~kg}^{-1}$ soil), and this also was higher than control soils (376.75 $\mathrm{mg} \mathrm{CO}_{2} \mathrm{~kg}^{-1}$ soil). During the 39 days incubation cumulative $\mathrm{CO}_{2}-\mathrm{C}$ was significantly related with the moisture content under $1 / 2$ FC and FC conditions, however, control soils have not showed a significant correlation with the moisture level. Under $1 / 2$ FC and FC positive correlation coefficients (r) 0.807 and 0.753 respectively were found between cumulative $\mathrm{CO}_{2}-\mathrm{C}$ and moisture content. On the other hand forest soils $\left(1140.77 \mathrm{mg} \mathrm{CO}_{2} \mathrm{~kg}^{-1}\right.$ soil) presented the highest cumulative $\mathrm{CO}_{2}-\mathrm{C}$, milpa soils showed a middle level in the cumulative $\mathrm{CO}_{2}-\mathrm{C}\left(886.46 \mathrm{mg} \mathrm{CO}_{2} \mathrm{~kg}^{-1}\right.$ soil) and the lowest cumulative $\mathrm{CO}_{2}-\mathrm{C}$ was observed in the homegardens sites (593.32 $\mathrm{mg}$ $\mathrm{CO}_{2} \mathrm{~kg}^{-1}$ soil). Differences between soil types were reported, cumulative $\mathrm{CO}_{2}-\mathrm{C}$ was 
significantly higher in black soils $\left(1066.17 \mathrm{mg} \mathrm{CO}_{2} \mathrm{~kg}^{-1}\right.$ soil) than in red soils $\left(680.86 \mathrm{mg} \mathrm{CO}_{2}\right.$ $\mathrm{kg}^{-1}$ soil).

Table 3.7. a. Cumulative $\mathrm{CO}_{2}-\mathrm{C}\left(\mathrm{mg} \mathrm{CO}_{2} \mathrm{~kg}^{-1}\right.$ soil) emission during 39 days of the black soils in 3 treatments: $1 / 2$ FC, FC and control under different land uses.

\begin{tabular}{|l|l|l|l|}
\hline Land Use & $1 / 2 \mathrm{FC}$ & FC & Control \\
\hline Forest & $1972.2 \pm 385$ & $2504.0 \pm 217$ & $370.2 \pm 36$ \\
\hline Milpa & $1063.4 \pm 80$ & $1434.6 \pm 100$ & $368.5 \pm 76$ \\
\hline Homegardens & $605.2 \pm 180$ & $1054.7 \pm 220$ & $263.8 \pm 50$ \\
\hline FPLSD & 390.54 & 309.70 & 93.03 \\
\hline
\end{tabular}

Mean \pm 1 SD.

Within the same column, differences are significant when greater than FPLSD

Table 3.7. b. Cumulative $\mathrm{CO}_{2}-\mathrm{C}\left(\mathrm{mg} \mathrm{CO} \mathrm{Cg}^{-1}\right.$ soil) emission during 39 days of the red soils in 3 treatments: $1 / 2$ FC, FC and control under different land uses.

\begin{tabular}{|l|l|l|l|}
\hline Land Use & $1 / 2 \mathrm{FC}$ & FC & Control \\
\hline Forest & $778.0 \pm 78$ & $992.6 \pm 148$ & $254.4 \pm 48$ \\
\hline Milpa & $889.3 \pm 104$ & $1080.8 \pm 82$ & $491.8 \pm 73$ \\
\hline Homegardens & $502.4 \pm 130$ & $622.0 \pm 194$ & $511.8 \pm 36$ \\
\hline FPLSD & 170.98 & 229.79 & 90.06 \\
\hline
\end{tabular}

Mean \pm 1 SD.

Within the same column, differences are significant when greater than FPLSD

\begin{tabular}{|ll|}
\hline Factors and Interactions & P \\
\hline Land Use & 0.000 \\
\hline Soil Type & 0.000 \\
\hline Moisture & 0.000 \\
\hline Land Use x Soil Type & 0.000 \\
\hline Land Use x Moisture & 0.000 \\
\hline Soil Type x Moisture & 0.000 \\
\hline Land Use x Soil Type x Moisture & 0.000 \\
\hline
\end{tabular}

The correlation between the soil respiration as a measure of microbial activity and the soil water content has been widely defined. For both, black and red soils, the soil respiration was positively related with the moisture content, causing increases of $27 \%$ to $78 \%$ in the red and black soils respectively under $1 / 2$ FC compared to control soils and $30 \%$ to $81 \%$ in the red and black soils respectively under FC in comparison with the control soils. These results agree well with some in the literature (Orchard and Cook 1983, Smolander et al. 2005, Vincent et al. 
2006) that reported a positive relationship between water content and soil respiration. Besides, an earlier soil respiration study of soils conduced in semiarid region concluded that both precipitation and temperature influence soil respiration, but this is constrained principally by the soil moisture (Conant et al. 2000). However, a comparison of these results with some others is difficult due to the authors express the values on the bases of soil water content in others terms as for example water potential, water holding capacity, and others.

Forest showed the highest soil respiration rate and $\mathrm{CO}_{2}-\mathrm{C}$ evolved in comparison with milpa and homegardens. As well as black soil showed higher $\mathrm{CO}_{2}-\mathrm{C}$ evolved than red soils. Under optimal moisture conditions the microbial activity is governed by the energy substrate availability. The burn and sweep of the organic material in homegardens reduced the organic matter availability which is used as source by microorganisms, whereas in forest soils the organic material is accumulated and it can be used for the microorganisms for their growth and activity. This result reflects that the organic matter content and soil moisture largely control the $\mathrm{CO}_{2}-\mathrm{C}$ evolved, but the soil moisture limits these.

\subsection{Microbial biomass nitrogen upon wetting at the end of the incubation experiment}

The impact of the soil water regimes on microbial biomass $\mathrm{N}$ under different land use and soil types is summarized in table 3.8.a and 3.8.b. Under $1 / 2$ FC conditions microbial biomass $\mathrm{N}$ showed values around $12.28-24.13 \mathrm{mg} \mathrm{N} \mathrm{kg}^{-1}$ dry soil in the black soils and $7.25-10.61 \mathrm{mg}$ $\mathrm{N} \mathrm{kg}^{-1}$ dry soil in the red soils. Under FC, microbial biomass $\mathrm{N}$ ranged between $8.90-21.12$ $\mathrm{mg} \mathrm{N} \mathrm{kg}^{-1}$ dry soil in the black soils and $3.14-4.63 \mathrm{mg} \mathrm{N} \mathrm{kg}^{-1}$ dry soil in the red soils. A statistically significant interaction (p: 0.021) between land use and wetting was detected in the factorial ANOVA test, also paired-samples T-Test reported significant differences between $1 / 2$ FC (14.06 $\mathrm{mg} \mathrm{N} \mathrm{kg}^{-1}$ dry soil) and FC (9.10 $\mathrm{mg} \mathrm{N} \mathrm{kg}^{-1}$ dry soil) conditions. Microbial biomass $\mathrm{N}$ dropped around $34 \%$ under FC in comparison with $1 / 2$ FC and it was positively correlated with the moisture content under $1 / 2$ FC conditions (r: 0.660, p: 0.000) and FC conditions (r: 0.475, p: 0.000). Since soils under FC conditions showed higher microbial activity (soil respiration) than soils under $1 / 2 \mathrm{FC}$, therefore this might suppose that $\mathrm{FC}$ promote an increase in the microbial activity but no in their biomass. Also, it could be possible that higher soil water content influenced the extractability of soil microbial biomass $\mathrm{N}$ in the fumigation process and 
the chloroform did not produce a total biocide effect. In contrast with our results, higher microbial biomass $\mathrm{N}$ at 100\% FC was observed by Zaman et al. (1999) and Zaman and Chang (2004), which indicated that with the increase of the moisture content there is a rise in the microbial biomass N. However, this study did not find similar results possibly to methodological differences, Zaman and co-workers determined microbial $\mathrm{N}$ according to Brooke et al. (1985), whereas in the present study it was determined by ninhydrin-reactive. It is important to stress that the values found in the present experiment are higher than those reported in the dry season but similar than in the rainy season.

Table 3.8. a. Microbial Biomass $\mathrm{N}$ by artificial wetting of black soils under different land uses $\left(\mathrm{mg} \mathrm{N}^{\mathrm{N}} \mathrm{g}^{-1}\right.$ dry soil).

\begin{tabular}{|l|l|l|}
\hline Land Use & $1 / 2 \mathrm{FC}$ & $\mathrm{FC}$ \\
\hline Forest & $24.13 \pm 6.19$ & $21.12 \pm 9.19$ \\
\hline Milpa & $20.35 \pm 5.54$ & $11.02 \pm 3.27$ \\
\hline Homegardens & $12.28 \pm 5.73$ & $8.90 \pm 5.62$ \\
\hline FPLSD & 9.61 & 10.73 \\
\hline
\end{tabular}

Mean \pm 1 SD.

Within the same column, differences are significant when greater than FPLSD

Table 3.8. b. Microbial Biomass $\mathrm{N}$ by artificial wetting of red soils under different land uses (mg N kg $\mathbf{~ d r y ~}^{-1}$ soil).

\begin{tabular}{|l|l|l|}
\hline Land Use & $1 / 2 \mathrm{FC}$ & $\mathrm{FC}$ \\
\hline Forest & $7.83 \pm 3.04$ & $3.14 \pm 2.31$ \\
\hline Milpa & $10.61 \pm 4.23$ & $3.93 \pm 2.32$ \\
\hline Homegardens & $7.25 \pm 5.27$ & $4.63 \pm 4.93$ \\
\hline FPLSD & 7.06 & 5.51 \\
\hline
\end{tabular}

Mean \pm 1 SD.

Within the same column, differences are significant when greater than FPLSD

\begin{tabular}{|l|l|}
\hline Factors and Interactions & $\mathbf{P}$ \\
\hline Land Use & 0.000 \\
\hline Soil Type & 0.000 \\
\hline Moisture & 0.000 \\
\hline Land Use x Soil Type & 0.000 \\
\hline Land Use x Moisture & 0.021 \\
\hline Soil Type x Moisture & 0.576 \\
\hline Land Use x Soil Type x Moisture & 0.515 \\
\hline
\end{tabular}


Table 3.8. c. Pearson's correlation coefficients of microbial biomass nitrogen upon artificial wetting with moisture content, organic $\mathrm{C}$, microbial activity $\left(\mathrm{CO}_{2}-\mathrm{C}\right)$ and nitrate.

\begin{tabular}{|l|l|l|}
\hline & Nmic $1 / 2 \mathrm{FC}$ & Nmic FC \\
\hline Moisture & $0.660^{* *}$ & $0.475^{* *}$ \\
\hline $\begin{array}{l}\text { Corg } \\
\left(\mathbf{D r y}^{1}\right)\end{array}$ & $0.665^{* *}$ & $0.530^{* *}$ \\
\hline $\begin{array}{l}\mathbf{C O}_{2}-\mathbf{C} \\
\left(1 / 2 \mathrm{FC}^{2}\right)\end{array}$ & $0.720^{* *}$ & $0.657^{* *}$ \\
\hline $\begin{array}{l}\mathbf{C O}_{2}-\mathbf{C} \\
\left(\mathrm{FC}^{3}\right)\end{array}$ & $0.771^{* *}$ & $0.749^{* *}$ \\
\hline $\begin{array}{l}\mathbf{N O}_{3}-\mathbf{N} \\
\left(1 / 2 \mathrm{FC}^{2}\right)\end{array}$ & $0.534^{* *}$ & $0.535^{* *}$ \\
\hline $\begin{array}{l}\mathbf{N O}_{3}-\mathbf{N} \\
\left(\mathrm{FC}^{3}\right)\end{array}$ & $0.587^{* *}$ & $0.559^{* *}$ \\
\hline
\end{tabular}

Pearson's correlation coefficients calculated from means of the determined parameters from all land uses. Nmic: microbial biomass N, Corg: organic Carbon (Source: Aguila 2007), $\mathrm{CO}_{2}-\mathrm{C}: \mathrm{CO}_{2}$ evolved in the incubation experiment, $\mathrm{NO}_{3}-\mathrm{N}$ : available Nitrate in the incubation experiment (Source: Aguila 2007). N=90.

** Correlation is significant at the 0.01 level (2-tailed)

${ }^{1}$ Dry field conditions

2 under $1 / 2$ FC condition incubation experiment

${ }^{3}$ under FC condition incubation experiment

Land uses influenced the microbial biomass $\mathrm{N}$, forest soils showed the highest microbial $\mathrm{N}$ with a mean of $14.30 \mathrm{mg} \mathrm{N} \mathrm{kg}^{-1}$ dry soil. Milpa and homegardens had means of 11.68 and 8.41 $\mathrm{mg} \mathrm{N} \mathrm{kg}{ }^{-1}$ dry soil, respectively. Moreover, black soils showed higher microbial biomass $\mathrm{N}$ (16.50 $\mathrm{mg} \mathrm{N} \mathrm{kg}^{-1}$ dry soil) than red soils (6.46 $\mathrm{mg} \mathrm{N} \mathrm{kg}^{-1}$ dry soils). As was also reported in the section III.A (3.5), higher amount of microbial biomass in forest and black soils is attributed to greater availability of substrate for the microorganisms and also to the improve of soil microclimate condition with high litter on surface. Litter serves as substrate that is converted into microbial biomass and SOM (Billore et al. 1995). Litter quantity varies at the land uses; this is higher in forest soils than in milpa and homegardens. High amount of litter on the soil surface improve water infiltration by reducing runoff, maintaining optimal temperature and reducing the evaporation (Spedding et al. 2004). Therefore, better moisture condition and increased SOM can be involved in the positive effect on the microbial biomass in forest soils. The loss of the vegetal material in homegardens soils is reflected in the decline of the microbial biomass; and microorganisms with faster turnover can possibly faster mineralise the maize leaves in milpa. Also, the high fungal biomass in forest system could increase the nutrient immobilization in their biomass, since fungi can maintain more $\mathrm{C}$ and $\mathrm{N}$ than bacteria. Bacteria have lower $\mathrm{C}$ assimilation efficiencies and faster turnover rates than 
fungi (Adu and Oades 1978), therefore this should be an important characteristic in determining the higher microbial biomass in forest system than in homegardens and milpa.

The quantity and quality of litter indirectly affects the microbial biomass N. High organic C concentrations stimulate microbial activities (Gaillard et al. 1999), because organic substrates are sources of energy for the microorganisms (Staafs and Berg 1981, Zaman et al. 1998). In the present test, organic $\mathrm{C}$ under dry field conditions significantly correlated with the microbial biomass $\mathrm{N}$ under $1 / 2 \mathrm{FC}$ and $\mathrm{FC}$ (Table 3.8.c). The high organic $\mathrm{C}$ concentration found by Aguila (2007) in forest sites and the significant correlation between these parameters suggest that organic $\mathrm{C}$ could be used as source by the microorganisms and has influence on the microbial biomass N. However, it is important to highlight that this relation is strongly constrained by the soil moisture, which could indicate that the accumulation of the organic matter in the soil is due to the limited conditions of moisture in Yucatan.

Soil microorganisms are responsible for both production and consumption of inorganic $\mathrm{N}$ (Dannenmann et al. 2006). The microbial biomass $\mathrm{N}$ under $1 / 2 \mathrm{FC}$ and $\mathrm{FC}$ conditions was significantly correlated with the $\mathrm{CO}_{2}-\mathrm{C}$ evolved and available nitrate under $\mathrm{FC}$ and $1 / 2 \mathrm{FC}$ (Table 3.8.c). In the present study, microbial biomass $\mathrm{N}$ represents both a measure of $\mathrm{N}$ retention into active microbial biomass and mineralization of $\mathrm{N}$, because microbial biomass $\mathrm{N}$ correlated with both the microbial activity $\left(\mathrm{CO}_{2}-\mathrm{C}\right.$ evolved) and the available nitrate under $1 / 2$ FC and FC conditions. As it was reported in the previous section (III.B: 3.7.a), the maintenance of microbial activity under optimal moisture conditions indicates that there is enough substrate to decompose and mineralise. Also, increasing microbial biomass is coupled with the soil respiration $\left(\mathrm{CO}_{2}-\mathrm{C}\right.$ evolved) and $\mathrm{N}$ mineralization (nitrates). This supports the suggestion that wetting dried soil stimulates the activity of growing decomposer. Indeed it is well established that wetting of dried soils causes an increase in microbial mineralization of organic N (Birch 1958) and organic C (Powlson and Jenkinson 1976). 


\section{9. $\beta$-Glucosidase activity upon artificial wetting at the end of the incubation experiment}

$\beta$-glucosidase activities under $1 / 2 \mathrm{FC}$ and $\mathrm{FC}$ in the black and red soils are summarized in Tables 3.9.a and 3.9.b respectively. Under $1 / 2$ FC, black soils had means of $85 \mathrm{mg} \mathrm{PNP} \mathrm{kg}^{-1} \mathrm{~h}^{-1}$ in homegardens, $81 \mathrm{mg}$ PNP kg ${ }^{-1} \mathrm{~h}^{-1}$ in milpas and $153 \mathrm{mg} \mathrm{PNP} \mathrm{kg}^{-1} \mathrm{~h}^{-1}$ in forest soils. Red soils showed activities of $73 \mathrm{mg}$ PNP kg-1 $\mathrm{h}^{-1}$ in homegardens, $76 \mathrm{mg} \mathrm{PNP} \mathrm{kg}^{-1} \mathrm{~h}^{-1}$ in milpa, and $94 \mathrm{mg}$ PNP kg${ }^{-1} \mathrm{~h}^{-1}$ in forests. Under FC conditions, black soils had values around $60 \mathrm{mg}$ PNP kg ${ }^{-1} \mathrm{~h}^{-1}$ in homegardens, $51 \mathrm{mg}$ PNP kg- $\mathrm{h}^{-1}$ in milpas and $99 \mathrm{mg} \mathrm{PNP} \mathrm{kg}^{-1} \mathrm{~h}^{-1}$ in forests. Red soils showed activities of $54 \mathrm{mg}$ PNP kg-1 $\mathrm{h}^{-1}$ in homegardens, $45 \mathrm{mg} \mathrm{PNP} \mathrm{kg}^{-1} \mathrm{~h}^{-1}$ in milpas, and $71 \mathrm{mg}$ PNP kg- $\mathrm{h}^{-1}$ in forest soils. The wetting influenced $\beta$-glucosidase activity; significant differences between $1 / 2$ FC (93 mg PNP kg$\left.{ }^{-1} \mathrm{~h}^{-1}\right)$ and FC (52 mg PNP kg ${ }^{-1} \mathrm{~h}^{-1}$ ) conditions were reported. Also, correlation analysis showed that $\beta$-glucosidase activity was significantly related with the moisture content under $1 / 2 \mathrm{FC}(\mathrm{p}<0.0001, \mathrm{r}=0.532)$ and $\mathrm{FC}(\mathrm{p}<$ $0.0001, \mathrm{r}=0.424)$.

The moisture effect on the $\beta$-glucosidase activity under laboratory conditions was reported, in contrast to field conditions that did not present a strong influence. Soil moisture controlled the $\beta$-glucosidase activity and it was higher under $1 / 2$ FC than FC. Unlike to this research other studies have reported no differences in the $\beta$-glucosidase activity by changes in the soil moisture (Turner et al. 2002, Knight and Dick 2004). These authors attributed the stabilization of the enzyme in the soil matrix with organic matter, forming chemical complexation and sorption of the soil particles. However, enzyme activity can vary depending on the conditions of measurement amongst other factors. It is important to stress that the soils were kept for a period of 39 days of incubation under controlled condition of moisture and temperature. After wetting, part of organic matter provides more readily substrate available by physical and chemical changes imposed as a result of dry conditions followed by wetting (Marumoto et al. 1982), consequently the producer microorganisms could increase the activity and production of this enzyme. 
Table 3.9. a. $\beta$-glucosidase activity by artificial wetting of black soils under different land uses (mg PNP $\mathrm{kg}^{-1}$ dry soil $\left.\mathbf{h}^{-1}\right)$.

\begin{tabular}{|l|l|l|}
\hline Land Use & $1 / 2 \mathrm{FC}$ & FC \\
\hline Forest & $153 \pm 77$ & $99 \pm 59$ \\
\hline Milpa & $81 \pm 22$ & $51 \pm 9$ \\
\hline Homegarden & $85 \pm 30$ & $60 \pm 24$ \\
\hline FPLSD & 82 & 61 \\
\hline
\end{tabular}

Mean \pm 1 SD.

Within the same column, differences are significant when greater than FPLSD

Table 3.9. b. $\beta$-glucosidase activity by artificial wetting of red soils under different land uses (mg PNP $\mathbf{~ k g}^{-1}$ dry soil $h^{-1}$ ).

\begin{tabular}{|l|l|l|}
\hline Land Use & $1 / 2$ FC & FC \\
\hline Forest & $94 \pm 32$ & $71 \pm 30$ \\
\hline Milpa & $76 \pm 18$ & $45 \pm 10$ \\
\hline Homegarden & $73 \pm 44$ & $54 \pm 39$ \\
\hline FPLSD & 54 & 48 \\
\hline
\end{tabular}

Mean \pm 1 SD.

Within the same column, differences are significant when greater than FPLSD

\begin{tabular}{|l|l|}
\hline Factors and Interactions & $\mathbf{P}$ \\
\hline Land Use & 0.000 \\
\hline Soil Type & 0.001 \\
\hline Moisture & 0.000 \\
\hline Land Use x Soil Type & 0.012 \\
\hline Land Use x Moisture & 0.464 \\
\hline Soil Type x Moisture & 0.297 \\
\hline Land Use x Soil Type x Moisture & 0.529 \\
\hline
\end{tabular}


Table 3.9. c. Pearson's correlation coefficients of $\beta$-glucosidase upon artificial wetting with moisture content, microbial activity $(\mathrm{CO} 2-\mathrm{C})$ and organic $\mathrm{C}$.

\begin{tabular}{|l|l|l|}
\hline & $\boldsymbol{\beta}$-gluc. $1 / 2 \mathrm{FC}$ & $\boldsymbol{\beta}$-gluc. $\mathrm{FC}$ \\
\hline Moisture & $0.532^{* *}$ & $0.424 * *$ \\
\hline $\begin{array}{l}\mathbf{C O}_{2}-\mathrm{C} \\
\left(1 / 2 \mathrm{FC}^{2}\right)\end{array}$ & $0.623 * *$ & $0.501^{* *}$ \\
\hline $\begin{array}{l}\mathbf{C O}_{2}-\mathrm{C} \\
\left(\mathrm{FC}^{3}\right)\end{array}$ & $0.596^{* *}$ & $0.482^{* *}$ \\
\hline $\begin{array}{l}\text { Corg } \\
(\text { Dry }\end{array}$ & $0.427 * *$ & $0.326^{* *}$ \\
\hline
\end{tabular}

Pearson's correlation coefficients calculated from means of the $\beta$-glucosidase under $1 / 2 \mathrm{FC}$ and FC condition with determined parameters from all land uses. $\mathrm{CO}_{2}-\mathrm{C}$ : $\mathrm{CO}_{2}$ evolved in the incubation experiment, Corg: organic Carbon (Source: Aguila 2007). $\mathrm{N}=90$.

** Correlation is significant at the 0.01 level (2-tailed)

$\beta$-gluc: $\beta$-glucucosidase

${ }^{1}$ Dry field conditions

2 under $1 / 2$ FC condition incubation experiment

${ }^{3}$ under FC condition incubation experiment

Higher activity in the forest soils is due to major availability of substrate provided by the litter and used by microorganisms that synthesize $\beta$-glucosidase. Generally, this enzyme is abundant and rarely limited due to microorganisms responding to the presence of suitable substrate for their production (Turner et al. 2002). As it was explained in the section III.A (3.6), the lack of enough substrate in milpa and homegardens produced a decline in these ecosystems. Decrease in the $\beta$-glucosidase activity may have negative effects on the activity of the others enzymes and consequently in the nutrient availabilities. A study carried out by Sardans and Pañuelas (2005) reported that the action of $\beta$-glucosidase is important to release nutrients, due to this enzyme reduces the molecular size or organic structures of compound like as cellulose and other carbohydrate polymers, and consequently facilitates microbial activity.

The variation of $\beta$-glucosidase was correlated with the $\mathrm{CO}_{2}-\mathrm{C}$ evolved under $1 / 2 \mathrm{FC}$ and $\mathrm{FC}$ conditions, as well as with the organic $\mathrm{C}$ under dry field conditions, indicating that microbial activity and the organic $\mathrm{C}$ control the activity of this enzyme. According to Wick et al. (2002), the significant correlation of $\beta$-glucosidase with the organic $\mathrm{C}$ and microbial activity is due to participation of the enzyme in the mineralization and cycling of carbohydrates in soils and to the synthesis of the enzyme by the microorganisms respectively. However, the present study suggests that the soil moisture highly controls these parameters due to the fact they correlate 
more strongly under controlled conditions in the laboratory than under natural conditions (dry and rainy season). As mentioned in the section III.A (3.5), $\beta$-glucosidase is a measurement of the potential activity because, although there is enough substrate (organic $\mathrm{C}$ ) for their activity under dry field conditions, this enzyme presented low activity, whereas under $1 / 2$ FC and FC the enzyme showed high activity and higher correlation with the microbial activity $\left(\mathrm{CO}_{2}-\mathrm{C}\right.$ evolved) and organic $\mathrm{C}$. 


\subsection{Synthesis: Effect of seasonal field and simulated laboratory moisture conditions on microbial biomass and activity and soil enzymes}

This study shows that the rates of litter decomposition and $\mathrm{C}$ dynamics in land uses of Yucatan Peninsula can be tied to differences in the abundance and activity of their decomposer communities. Moreover, these relationships are strongly influenced by moisture conditions and source availability. Under the semiarid conditions of Yucatan it was also seen that the rainfall strongly promoted an increase in the decomposition and associated processes. The effect of the land uses was detected, influencing the abundance of the soil fauna groups. This change also produced an effect on the microbial and biochemical processes, which affected Ccycling.

Increase in the soil moisture under different land uses is generally profitable for the soil microbial and biochemical processes. In semiarid soils of Yucatan rainfall accelerated about $20 \%$ the decomposition process; consequently soil biological and biochemical processes were also influenced. Despite the mass loss was highly influenced by the rainfall, the soil fauna also plays an important role on the process. However, the seasonal effect did not influence on their abundance. Macro- and meso-fauna were not affected by the season, but changes in the season influenced on specific groups (spiders and beetles). Araneae abundance was $50 \%$ higher in the dry season than in the rainy season. In contrast, Coleoptera abundance was $73 \%$ higher in the rainy season than in the dry season. Different responses to environmental changes are due to the specific characteristics of each group as well as to their resource availability. Ants and termites are most abundant among the groups. They represent about $30 \%$ of the total soil mesofauna abundance. Due to their functional characteristics, these groups of organisms possibly control the mass loss, because they consume a high amount of decomposing leaves.

High moisture content produced an effect on the microbial biomass and microbial activity. An increase of $45 \%$ was reflected in the microbial biomass in the rainy season compared to the dry season. Higher resource availability and optimal condition of moisture promotes the growth of microorganisms. However, under incubation experiment, FC conditions produced a decrease of approximately $35 \%$ in the biomass. But FC promoted a significant increase in the microbial activity. Positive correlation between the moisture content and the microbial activity was reported. Microorganisms are susceptible to drought; some of them can survive under 
extreme conditions. After wetting, those organisms in dormant state can activate their metabolism in response to change in the moisture. Str treatment inhibited $6-17 \%$ of the bacteria respiration; the low inhibition suggests that fungi have major activity, which could show a low decomposition rate and high immobilization of nutrients in their biomass. Moreover, high litter accumulation on the soil forest promoted higher microbial and fungi activity. Homegarden and milpa produced a significant decline in the microbial activity of 51 and $76 \%$ respectively. The reduction in the microbial activity is a reflection of the lack of suitable substrate to decompose and mineralise.

Despite seasonal influence was not significant, under artificial wetting $\beta$-glucosidase showed significant changes in their activity. This enzyme showed about $32 \%$ lower under FC conditions than under $1 / 2$ FC conditions. Under field conditions, adsorption of the enzyme with the soil colloids could promote a stabilization of their activity. In contrast, under laboratory tests with stable and optimal moisture conditions, this enzyme can reveal the potential activity of the soils. It is important to stress that $\beta$-glucosidase activity was highly influenced by the organic $\mathrm{C}$ and by the microbial activity $\left(\mathrm{C}-\mathrm{CO}_{2}\right.$ evolved). Since microorganisms produce this enzyme, the close relationship between the glucosidase and microorganisms is confirmed. Also it stated the importance of the organic soil matter in these soils as source of nutrients and important factor for the biological and biochemical processes. Nonetheless these interactions were always constrained by the moisture levels.

Additionally, land uses and soil types are also important factors affecting the soil biological properties and their relation in the C-Cycle. In the present research, land uses had impact on the soil fauna abundance. Milpa produced a decrease in the soil fauna, whereas homegarden showed similar abundance than forests. High accumulation of organic matter in forest soils and high organic $\mathrm{C}$ content in black soils influenced on the decomposition process drive, in part, by the high abundance of the soil fauna in these systems (forests and homegardens). The high comminution activity of ants and termites possibly promotes a high accumulation of litter on the soil surface, which could provide better microclimate conditions for higher fungi biomass and activity, especially in forest soils. In forest fungi exerted higher control on the microbial activity due to the accumulation of the litter on the soil surface that promote the conditions for their activity, because these organisms can tolerate dry condition and have 
better capacities of degrade complex substance than bacteria did not have. Consequently, these conditions also enhance the enzyme activities, especially of those enzymes involved in the CCycle ( $\beta$-glucosidase). An increase in the enzyme activity means an enhancement in the mineralization rates, which will have a positive effect on nutrient availability. 


\section{SOIL ENZYMES INVOLVED IN N AND P MINERALIZATION IN KARTIC SOILS OF YUCATAN, MEXICO.}

\subsection{Introduction}

Soil fertility in semiarid soils is primarily constrained by moisture (Evans and Ehleringer 1994, Nadeau et al. 2007). However, once water limitation in the soil has been overcome, essential nutrients such as $\mathrm{N}$ and $\mathrm{P}$ often become the factors that limit the production in soils (Nadeau et al. 2007). Sometimes it is due to intrinsic characteristics of the soils that consequently affect the nutrient transformation. For example, the high carbonate concentrations in many soils in semiarid areas limit P-availability due to sorption and/or precipitation as calcium phosphate minerals (Lajtha and Schlesinger 1988).

In semi-arid regions, often less than half of the total $\mathrm{P}$ pool is present as organic $\mathrm{P}$ (Turner et al. 2003) because organic $P$ is covalently bound to carbonaceous material (Nadeau et al. 2007). This fraction can potentially become available to the plants and microorganisms through mineralization. Also, much of the inorganic $\mathrm{P}$ in the soils is either bound in the soil matrix or very insoluble and inaccessible for uptake by organisms (Brady 1990). The $\mathrm{N}$ that is present in soils of arid and semiarid ecosystems is often located in stable organic complexes that have slow turnover rates. Polyphenolic compounds can protect organic $\mathrm{N}$ from mineralization, slow decomposition and may produce $\mathrm{N}$ limitation (Fox et al. 1990).

There have been a number of studies on $\mathrm{N}$ and $\mathrm{P}$ mineralization processes in arid and semiarid ecosystems that include the effect of water pulses (Austin et al. 2004, James and Richard 2006), disturbance of soils (Bolton et al. 1993) and season (Smolander et al. 2005), on biochemical processes. Some studies have not only evaluated the nutrient availability of $\mathrm{N}$ and $\mathrm{P}$, but also measured soil enzyme activity as measurement of potential of mineralization and microbial activity (Dick 1994, Deng and Tabatabai 1997, Holt and Mayer 1998, Sardans et al. 2007).

The mineralization of organic compounds in soils is largely a result of enzymatic reactions. Enzymes play crucial roles in the soil's biochemical processes (Dick 1984). The major 
processes in soil such as decomposition, mineralization, and immobilization are catalyzed by soil enzymes and are important for the release of nutrients used for plant and microbial growth (Frankerberger and Dick 1983, Bergstrom et al. 1998). Previous studies have shown that soil enzyme activities are sensors of soil degradation, as they integrate information regarding soil microbial status and its physical-chemical conditions (Wick et al. 1998, Aon and Colaneri 2001, Baum et al. 2003). Important enzymes involved in the mineralization of $\mathrm{N}$ and $\mathrm{P}$ include protease, alkaline phosphatase and acid phosphatase. Protease catalyses the first step in the mineralization of protein to polypeptides and oligopeptides to amino acids; therefore is considered important in the $\mathrm{N}$ mineralization processes of soil (Ladd and Paul 1973). Orthophosphoric monoester phosphohydrolases (acid and alkaline phosphatases) particularly catalyze the hydrolysis of P-ester bonds binding P to C (C-O-P ester bonds) in organic matter. Inorganic $\mathrm{P}$ is released from organically bound $\mathrm{P}$ (leaf litter, dead root systems and other organic debris) without concomitant release of C (Harrison 1983; Clarholm 1993). Acid phosphatase is mainly produced by plants, but also soil microorganisms release acid phosphatases. Acid phosphatase was detected in rhizodermal and root cap cells, in soil fungi and bacteria, in mucilage covering roots, and in microbial membranes in soil (Fraser et al. 1991). The production of acid phosphatase by fungal hyphae, however, is discussed controversially in the literature. Häussling and Marschner (1989) and Tarafdar and Marschner (1994) found a positive correlation of phosphatase and mycelial hyphae length, whereas others reported no difference in activity between soils with or without fungal mycelium (Joner et al. 1995). Alkaline phosphatase is produced by soil microorganisms and soil fauna (Chhonkar and Tarafdar 1984; Nakas et al. 1987), whereas higher plants are devoid of alkaline phosphatase (Tarafdar and Claassen, 1988; Juma and Tabatabai 1988). The optimal pH for acid and alkaline phosphatase activity was reported as pH 6-6.6 (Nakas et al. 1987) and pH 911 (Tabatabai and Bremner, 1969), respectively.

Previous studies have shown that slightly decrease in water availability produce a considerable reduction in the soil enzyme activities like protease and phosphatases (Sardans and Pañuelas 2005). Also, agricultural practices (crop rotation, mulching, tillage and shifting cultivation) may have diverse effects on enzyme activity in soils (Ladd 1985, Dick et al. 1987, Deng and Tabatabai 1996, 1997, Ajwa et al. 1999). Some of these practices can minimize the organic matter content in the soil and consequently reduce the enzyme activities (Dick et al. 1988, 
Bergstrom et al. 1998). The decrease in the activity of the enzymes that are involved in nutrient cycling can, in the long term, affect the availability of nutrient for the plants (Mayor et al. 1994, Sardans and Pañuelas 2005). Therefore, knowledge about enzyme activity is of considerable significance.

This study was focused on the potential bioavailability of nutrients in soils under different moisture regimes and different land uses of the Yucatan Peninsula, Mexico. Several studies have shown that the practices associated with the land uses (milpa and homegardens) can affect soil properties (Weisbach et al. 2002, Aguila 2007), however, limited information is available regarding their impact on soil biochemical processes and how these processes are regulated by the availability of water. Therefore the objectives of this study are: (1) characterize the potentially available nutrients ( $\mathrm{N}$ and $\mathrm{P}$ ) as mediated by biochemical processes (enzymes involved in $\mathrm{N}$ and $\mathrm{P}$ cycling) during the dry and rainy season in karstic soils under different land uses of the Yucatan Peninsula. (2) Evaluate the potential of nutrients under contrasting moisture levels and determine the limiting factors of the biochemical processes. 


\section{IV.A. Soil enzyme activities under field conditions.}

\subsection{Acid phosphatase activity during the dry and rainy season}

The activity of acid phosphatase under different land uses and season is presented in Table 4.1.a and 4.1.b for the black and red soils, respectively. Acid phosphatase activity was affected by season, land use, and soil type. In the black soils during the dry season, acid phosphatase was $69 \mathrm{mg}$ PNP kg${ }^{-1}$ dry soil $\mathrm{h}^{-1}$ in homegardens, $94 \mathrm{mg}$ PNP kg${ }^{-1}$ dry soil $\mathrm{h}^{-1}$ in milpas, and $360 \mathrm{mg}$ PNP $\mathrm{kg}^{-1}$ dry soil $\mathrm{h}^{-1}$ in forest. The activities increased during the rainy season, homegardens black soils showed a mean of $96 \mathrm{mg} \mathrm{PNP} \mathrm{kg}^{-1}$ dry soil $\mathrm{h}^{-1}$ and milpas black soils presented $196 \mathrm{mg}$ PNP kg-1 dry soil h${ }^{-1}$. Forest black soils reached a mean of $1200 \mathrm{mg} \mathrm{PNP} \mathrm{kg-}$ ${ }^{1}$ dry soil $\mathrm{h}^{-1}$ during the rainy season. Red soils showed values lower than the black soils, in the dry season homegardens showed a mean of $56 \mathrm{mg}$ PNP kg-1 dry soil h${ }^{-1}$ and $72 \mathrm{mg} \mathrm{PNP} \mathrm{kg}{ }^{-1}$ dry soil $\mathrm{h}^{-1}$ in milpas. Forest red soils had a mean of $174 \mathrm{mg} \mathrm{PNP} \mathrm{kg}^{-1}$ dry soil $\mathrm{h}^{-1}$. During the rainy season, the acid phosphatase activity also increased in the red soils. Homegardens had a mean of $67 \mathrm{mg}$ PNP kg-1 dry soil $\mathrm{h}^{-1}$ whereas milpas red soils had $44 \mathrm{mg}$ PNP kg $^{-1}$ dry soil h${ }^{-1}$. In contrast forest red soil reached a mean of $579 \mathrm{mg} \mathrm{PNP} \mathrm{kg}^{-1}$ dry soil $\mathrm{h}^{-1}$.

The acid phosphatase activity was significantly higher during the rainy season than during the dry season $(\mathrm{p}<0.0001$; Samples-Paired T-Test). The variation in the acid phosphatase activity was significantly related to the moisture content (Table 4.1.c). With the exception of red soil at the milpa system, the activity increased between 16-70 \% during the rainy season. This fact could be attributed to the growth period of the plants. In the rainy season the plants require major concentration of nutrients, there is more demand of $\mathrm{P}$ and it shoots up the acid phosphatase activity. Since acid phosphatase is considered as adaptive enzyme, the secretion of this enzyme by the plant roots is determined by the P-demand of the plants (Tarafdar and Jungk 1987). In addition, environmental factors have been identified as determinants in the acid phosphatase activity amongst them: moisture was found as a major control of acid phosphatase activity (Rastin et al. 1988, Moscatelli et al. 2001, Boerner et al. 2005). For instance, Sardans et al. (2007) concluded that soil moisture and temperature affect root-surface phosphatase activity. They attributed that if scarce soil water and/or low temperature are limiting plant production, the phosphatase activity also decreases. 
Several studies about the seasonal variation on the acid phosphatase have been carried out, mainly in agricultural soils (Deng and Tabatabai 1997, Kraemer and Green 2000, Wick et al. 2002, Gianfreda et al. 2005) but the results have been contrasting. For example, Rastin et al. (1988), conducted a study of the seasonal variation of various enzymes including acid phosphatase, and reported a lack of a significant relationship between seasonal variation in soil moisture content and acid phosphatase activity. However, acid phosphatase and alkaline phosphatase activities have shown significant variations through the different seasons in semiarid woodland soils. A study reported maximal activities in summer and winter when the temperature reached the maximal and minimal values and the soil moisture varied (Kraemer and Green 2000). Enzyme activity is dependent on many factors, amongst them: aeration, vegetation, microflora, soil moisture, soil temperature, and soil type (Burns 1978), which can produce variation in the activity and originate contrasting results.

Forest soils had the highest activity (577.92 mg PNP kg ${ }^{-1}$ dry soil $\mathrm{h}^{-1}$ ) whereas enzyme activities in both milpa and homegardens soils were similar (101.54 and $71.91 \mathrm{mg} \mathrm{PNP} \mathrm{kg}^{-1}$ dry soil $\mathrm{h}^{-1}$ in milpa and homegarden respectively). Despite higher organic $\mathrm{P}$ concentration in forest and milpa sites, the latter site exhibited lower activity. This might be attributed to more accessible organic $\mathrm{P}$ in forest as compared to milpa, where lower moisture conditions could affect the activity. Also, the high activity in forest soils could indicate lower inorganic $\mathrm{P}$ conditions, since plant roots secrete acid phosphatase under low availability of $\mathrm{P}$ to compensate their deficiency (Tarafdar and Claassen 1988, Tadano et al. 1993). These results are in line with those obtained by Aguila (2007) who reported lower available P in forest (113 $\mathrm{mg} \cdot \mathrm{kg}^{-1}$ and $79 \mathrm{mg} \cdot \mathrm{kg}^{-1}$ in the black and red soils respectively) and in milpa soils (142 mg. $\mathrm{kg}^{-1}$ and $88 \mathrm{mg} . \mathrm{kg}^{-1}$ in the black and red soils respectively) than in homegardens soils (739 mg. $\mathrm{kg}^{-1}$ and $593 \mathrm{mg} \cdot \mathrm{kg}^{-1}$ in the black and red soils respectively); while organic P concentration was higher in the forest (21 mg. $\mathrm{kg}^{-1}$ and $23 \mathrm{mg} \cdot \mathrm{kg}^{-1}$ in the black and red soils respectively) and milpa sites (20 mg. $\mathrm{kg}^{-1}$ and $25 \mathrm{mg} \cdot \mathrm{kg}^{-1}$ in the black and red soils respectively) than in homegardens sites (9 mg. $\mathrm{kg}^{-1}$ and $12 \mathrm{mg} \cdot \mathrm{kg}^{-1}$ in the black and red soils respectively). Pearson's correlation reported negative and significant correlations of -0.363 between inorganic total $\mathrm{P}$ and the acid phosphatase activity during the dry season (Table 4.1.c). Thus, the plants release higher amounts of acid phosphatase to supply the P-demand, especially in 
forest sites, where the deficiency of $\mathrm{P}$ was reported. However, the activity was not influenced by the organic $\mathrm{P}$ concentration. Consequently, it might suggest that the acid phosphatase is influenced by the inorganic $\mathrm{P}$ availability, but is constrained by the soil moisture content because this factor is stronger correlated than the available $\mathrm{P}$.

On the other hand, black soils showed higher activity (335.62 mg PNP kg-1 dry soil $\mathrm{h}^{-1}$ ) than red soils (165.30 mg PNP kg ${ }^{-1}$ dry soil $\mathrm{h}^{-1}$ ). High activity in the black soils might be due to sorption of the enzyme onto organic matter. Phosphatase production and activity have been reported to be very sensitive to SOM concentration (Goldstein et al. 1988). Although in the present study it was not determined the SOM content, previous studies have reported that the black soils have higher organic content than the red soils (Weisbach et al. 2002, Shang and Tiessen 2003).

Table 4.1. a. Acid phosphatase activity (mg PNP $\mathrm{kg}^{-1}$ dry soil $\mathrm{h}^{-1}$ ) in black soils under different land uses during the dry and rainy season.

\begin{tabular}{|l|l|l|}
\hline Land Use & Dry season & Rainy season \\
\hline Forest & $360 \pm 75$ & $1200 \pm 216$ \\
\hline Milpa & $94 \pm 14$ & $196 \pm 51$ \\
\hline Homegardens & $69 \pm 31$ & $96 \pm 32$ \\
\hline FPLSD & 111 & 355 \\
\hline
\end{tabular}

Mean \pm 1 SD.

Within the same column, differences are significant when greater than FPLSD

Table 4.1. b. Acid phosphatase activity (mg PNP kg ${ }^{-1}$ dry soil $h^{-1}$ ) in red soils under different land uses during the dry and rainy season.

\begin{tabular}{|l|l|l|}
\hline Land Use & Dry season & Rainy season \\
\hline Forest & $174 \pm 77$ & $579 \pm 137$ \\
\hline Milpa & $72 \pm 14$ & $44 \pm 9$ \\
\hline Homegardens & $56 \pm 50$ & $67 \pm 29$ \\
\hline FPLSD & 66 & 134 \\
\hline
\end{tabular}

Mean +1 SD.

Within the same column, differences are significant when greater than FPLSD 


\begin{tabular}{|l|l|}
\hline Factors and Interactions & $\mathrm{p}$ \\
\hline Land Use & 0.000 \\
\hline Soil Type & 0.000 \\
\hline Season & 0.000 \\
\hline Land Use x Soil Type & 0.000 \\
\hline Land Use x Season & 0.000 \\
\hline Soil Type x Season & 0.000 \\
\hline Land Use x Soil Type x Season & 0.000 \\
\hline
\end{tabular}

Table 4.1. c. Pearson's correlation coefficients of the acid phosphatase activity (acP) during the dry and rainy season with moisture content, inorganic $P$ and organic $P$.

\begin{tabular}{|l|l|l|}
\hline & acP Dry season & acP Rainy season \\
\hline Moisture & $0.680^{* *}$ & $0.880^{* *}$ \\
\hline $\begin{array}{l}\text { Inorganic P } \\
\left(\text { dry }^{1}\right)\end{array}$ & $-0.363^{* *}$ & - \\
\hline $\begin{array}{l}\text { Organic P } \\
\left(\text { dry }^{1}\right)\end{array}$ & 0.108 & - \\
\hline
\end{tabular}

Pearson's correlation coefficients calculated from means of the determined parameters from all land uses. Inorganic $\mathrm{P}$ (Source: Aguila 2007), Organic P (Source: Aguila 2007). N=90.

** Correlation is significant at the 0.01 level (2-tailed)

${ }^{1}$ Dry season field conditions

\subsection{Alkaline phosphatase activity during the dry and rainy season}

The activities of alkaline phosphatase are presented in Table 4.2.a and 4.2.b for black and red soils, respectively under different land uses and seasons. In the black soils during the dry season, alkaline phosphatase was $160 \mathrm{mg} \mathrm{PNP} \mathrm{kg}^{-1}$ dry soil $\mathrm{h}^{-1}$ in the homegardens, $189 \mathrm{mg}$ PNP $\mathrm{kg}^{-1}$ dry soil $\mathrm{h}^{-1}$ in milpas and $331 \mathrm{mg} \mathrm{PNP} \mathrm{kg}^{-1}$ dry soil $\mathrm{h}^{-1}$ in forest soils. Red soils showed values of $99 \mathrm{mg}$ PNP kg${ }^{-1}$ dry soil h${ }^{-1}$ in homegardens, $134 \mathrm{mg} \mathrm{PNP} \mathrm{kg}^{-1}$ dry soil h${ }^{-1}$ milpas and $176 \mathrm{mg}$ PNP $\mathrm{kg}^{-1}$ dry soil $\mathrm{h}^{-1}$ in forest soils. During the rainy season the activity increased, the black soils presented activities of $263 \mathrm{mg} \mathrm{PNP} \mathrm{kg}^{-1}$ dry soil h $\mathrm{h}^{-1}$ in homegardens, $128 \mathrm{mg}$ PNP kg${ }^{-1}$ dry soil $\mathrm{h}^{-1}$ in milpas and $293 \mathrm{mg} \mathrm{PNP} \mathrm{kg}^{-1}$ dry soil $\mathrm{h}^{-1}$ in forests. Red soils showed activities of $159 \mathrm{mg}$ PNP kg${ }^{-1}$ dry soil h${ }^{-1}$ in homegardens, $124 \mathrm{mg}$ PNP kg-1 dry soil $\mathrm{h}^{-1}$ in milpas and $130 \mathrm{mg}$ PNP kg${ }^{-1}$ dry soil $\mathrm{h}^{-1}$ in forest. Alkaline phosphatase was determined by the interactions land use $\mathrm{x}$ season and land use $\mathrm{x}$ soil types. 
No significant differences were found between rainy season and dry season. Stabilization of the enzyme by the organic matter could be the cause of the no variation in the activity between the seasons. Wick et al. (2002) reported similar results and they proposed that despite the influence of environmental changes, the enzyme activity might remain stable. In agreement with the finding, Haynes (1987), and Ross et al. (1995), did not find variations in the alkaline phosphatase activity with changes in the seasons. However, Kraemer and Green (2000) found significant differences during the changes of season. They reported peaks of activity during the winter and summer in semiarid woodland.

Alkaline phosphatase had the highest activity in the forest sites $\left(232.43 \mathrm{mg} \mathrm{PNP} \mathrm{kg}^{-1}\right.$ dry soil h ${ }^{1}$ ) compared to the milpa (143.84 $\left.\mathrm{mg} \mathrm{PNP} \mathrm{kg}^{-1} \mathrm{dry} \mathrm{soil} \mathrm{h}^{-1}\right)$ and homegardens sites $(170.23 \mathrm{mg}$ PNP kg ${ }^{-1}$ dry soil $\mathrm{h}^{-1}$ ), also differences between red and black soils were found. The activity of alP in milpa and homegarden was $39 \%$ and $26 \%$ lower, respectively compared to forest. The black soils had higher activity (227.30 mg PNP kg ${ }^{-1}$ dry soil ${ }^{-1}$ ) than the red soils (137.03 mg PNP $\mathrm{kg}^{-1}$ dry soil $\mathrm{h}^{-1}$ ). Because alkaline phosphatase is produced by microorganisms, the higher activity in both, forest and black soils, indicate greater biological activity in these soils. Also, the higher activity in forest and black soils is due to differences in the organic matter decomposition in the different soil types (black and red) and ecosystems. These results can be related to those reported in the microbial activity, where forest soils showed the highest respiration (Chapter III, Section II.B. (3.7)). It is important to highlight that negative and significant correlation was reported by the alkaline phosphatase activity and the $\mathrm{CO}_{2}-\mathrm{C}$ evolved under dry field condition. However, under controlled and optimal conditions of moisture $(1 / 2 \mathrm{FC}$ and $\mathrm{FC})$ significant and positive correlation between the $\mathrm{CO}_{2}-\mathrm{C}$ evolved and alkaline phosphatase was reported (Table 4.2.c). These results indicate that under optimal moisture conditions, microbial activity increases and therefore alkaline phosphatase is produced. High microbial activity is desirable in decomposing the plant residue deposited on the soil surface so the nutrients contained in the residue can be recycled (Lindenmann et al. 1984). In the forest system, there is a major accumulation of the organic material that can be used as substrate for the microorganisms, which produce alkaline phosphatase. Alkaline phosphatase is produced by soil microorganisms and soil fauna (Chhonkar and Tarafdar 1984, Nakas et al. 1987), but principally by soil fungi (Dick and Tabatabai 1984, Tarafdar and Claassen 1988). A significant and positive correlation of the alkaline phosphatase with the 
fungi activity $\left(\mathrm{CO}_{2}-\mathrm{C}\right.$ under Str treatment) (Table 4.2.c) was found; this result is coupled with those reported in chapter III (section 3.7.a, b), which show higher activity of fungi under Str inhibition in forest soils. In addition, high density of hyphae in the forest soils during the samplings was observed. Tarafdar et al. (1989) reported high alkaline phosphatase activity and significant fungal communities under trees and grass for arid soils in India.

Table 4.2. a. Alkaline phosphatase activity (mg PNP $\mathrm{kg}^{-1}$ dry soil $\mathrm{h}^{-1}$ ) in black soils under different land uses during the dry and rainy season.

\begin{tabular}{|l|l|l|}
\hline Land Use & Dry season & Rainy season \\
\hline Forest & $331 \pm 100$ & $293 \pm 71$ \\
\hline Milpa & $189 \pm 19$ & $128 \pm 42$ \\
\hline Homegardens & $160 \pm 39$ & $263 \pm 41$ \\
\hline FPLSD & 127 & 160 \\
\hline
\end{tabular}

Mean \pm 1 SD.

Within the same column, differences are significant when greater than FPLSD

Table 4.2. b. Alkaline phosphatase activity ( $\mathrm{mg} \mathrm{PNP} \mathrm{kg}^{-1}$ dry soil $\left.\mathrm{h}^{-1}\right)$ in red soils under different land uses during the dry and rainy season.

\begin{tabular}{|l|l|l|}
\hline Land Use & Dry season & Rainy season \\
\hline Forest & $176 \pm 55$ & $130 \pm 25$ \\
\hline Milpa & $134 \pm 35$ & $124 \pm 29$ \\
\hline Homegardens & $99 \pm 64$ & $159 \pm 57$ \\
\hline FPLSD & 87 & 65 \\
\hline
\end{tabular}

Mean \pm 1 SD.

Within the same column, differences are significant when greater than FPLSD

\begin{tabular}{|l|l|}
\hline Factors and Interactions & P \\
\hline Land Use & 0.000 \\
\hline Soil Type & 0.000 \\
\hline Season & 0.914 \\
\hline Land Use x Soil Type & 0.000 \\
\hline Land Use x Season & 0.000 \\
\hline Soil Type x Season & 1.000 \\
\hline Land Use x Soil Type x Season & 0.178 \\
\hline
\end{tabular}


Table 4.2. c. Pearson's correlation coefficients of alkaline phosphatase activity (alP) during the dry and rainy season with moisture content and microbial activity $\left(\mathrm{CO}_{2}-\mathrm{C}\right)$.

\begin{tabular}{|l|l|l|}
\hline & alP Dry season & alP Rainy season \\
\hline Moisture & $0.732 * *$ & $0.432^{* *}$ \\
\hline $\begin{array}{l}\mathbf{C O}_{2}-\mathbf{C} \\
\left(\mathbf{D r y}^{1}\right)\end{array}$ & $-0.210^{*}$ & $-0.212^{*}$ \\
\hline $\begin{array}{l}\mathbf{C O}_{2}-\mathbf{C} \\
\left(1 / 2 \mathrm{FC}^{2}\right)\end{array}$ & $0.753^{* *}$ & $0.253^{*}$ \\
\hline $\begin{array}{l}\mathbf{C O}_{2}-\mathbf{C} \\
\left(\mathrm{FC}^{3}\right)\end{array}$ & $0.774 * *$ & $0.327 * *$ \\
\hline $\begin{array}{l}\mathbf{C O}_{2}-\mathbf{C} \\
\left(\mathbf{S t r}^{4}\right)\end{array}$ & $0.695 * *$ & $0.248^{* *}$ \\
\hline
\end{tabular}

Pearson's correlation coefficients calculated from means of the determined parameters from all land uses. $\mathrm{CO}_{2}-\mathrm{C}$ : $\mathrm{CO}_{2}$ evolved in the incubation experiment. $\mathrm{N}=90$.

* Correlation is significant at the 0.05 level (2-tailed)

** Correlation is significant at the 0.01 level (2-tailed)

${ }^{1}$ Dry season field conditions

2 under $1 / 2$ FC condition incubation experiment

${ }^{3}$ under $\mathrm{FC}$ condition incubation experiment

${ }^{4}$ under $1 / 2$ FC condition under bacteria inhibition with Str

Str: Streptomycin

\subsection{Protease activity during the dry and rainy season}

In the dry season, protease activity ranged about $77-211 \mathrm{mg} \mathrm{NH}_{4}^{+} \mathrm{kg}^{-1}$ dry soil $\mathrm{h}^{-1}$ in the black soils and $37-78 \mathrm{mg} \mathrm{NH}_{4}{ }^{+} \mathrm{kg}^{-1}$ dry soil $\mathrm{h}^{-1}$ in the red soils. In the rainy season protease activity varied around $90-271 \mathrm{mg} \mathrm{NH}_{4}{ }^{+} \mathrm{kg}^{-1}$ dry soil h${ }^{-1}$ and $59-133 \mathrm{mg} \mathrm{NH}_{4}^{+} \mathrm{kg}^{-1}$ dry soil $\mathrm{h}^{-1}$ in the black and red soils respectively (Table 4.3.a and 4.3.b). Protease activity was affected by the interaction land use $\mathrm{x}$ soil types and land use $\mathrm{x}$ season. The activity of this enzyme was significantly higher in the rainy season (128 $\mathrm{mg} \mathrm{NH}_{4}{ }^{+} \mathrm{kg}^{-1}$ dry soil h${ }^{-1}$ ) than in the dry season (92 $\mathrm{mg} \mathrm{NH}_{4}{ }^{+} \mathrm{kg}^{-1}$ dry soil $\mathrm{h}^{-1}$ ). It was about 2-22\% and 8-66 \% higher in the rainy period than in the dry period in the black soils and red soils respectively. Correlation analysis showed that protease activity was significantly related to the moisture content during the dry season $(\mathrm{p}<0.0001, \mathrm{r}=0.379)$ and during the rainy season $(\mathrm{p}<0.0001, \mathrm{r}=0.753)$. Normally high moisture conditions promote an increase in the protease activity, due to under optimal moisture conditions the proteolysis increases. Several authors have found similar results (Rao and Tarafdar 1992, Watanabe and Hayano 1996, Kraemer and Green 2000, Wick et al. 2002); they found that under water stress the protease activity decreases and the proteolysis is inhibited. However, others have not reported seasonal variations (Skujins 1976, Ross et al. 1995). Protease is considered an enzyme with variable activity; their activity depends on a 
variety of factors, which can produce high divergence in the results showed in the literature; amongst them: nutritional conditions, temperature, water availability, proton concentration, oxygen supply, and type of vegetation (Bastida et al. 2006a).

Table 4.3. a. Protease activity $\left(\mathrm{mg} \mathrm{NH}_{4}{ }^{+} \mathrm{kg}^{-1}\right.$ dry soil $\left.\mathrm{h}^{-1}\right)$ in black soils under different land uses during the dry and rainy season.

\begin{tabular}{|l|l|l|}
\hline Land Use & Dry season & Rainy season \\
\hline Forest & $211 \pm 31$ & $271 \pm 75$ \\
\hline Milpa & $77 \pm 32$ & $90 \pm 18$ \\
\hline Homegardens & $127 \pm 27$ & $129 \pm 41$ \\
\hline FPLSD & 106 & 97 \\
\hline
\end{tabular}

Mean \pm 1 SD.

Within the same column, differences are significant when greater than FPLSD

Table 4.3. b. Protease activity (mg $\mathrm{NH}_{4}{ }^{+} \mathrm{kg}^{-1}$ dry soil $\mathrm{h}^{-1}$ ) in red soils under different land uses during the dry and rainy season.

\begin{tabular}{|l|l|l|}
\hline Land Use & Dry season & Rainy season \\
\hline Forest & $45 \pm 25$ & $133 \pm 42$ \\
\hline Milpa & $37 \pm 13$ & $59 \pm 49$ \\
\hline Homegardens & $78 \pm 59$ & $85 \pm 57$ \\
\hline FPLSD & 61 & 82 \\
\hline
\end{tabular}

Mean \pm 1 SD.

Within the same column, differences are significant when greater than FPLSD

\begin{tabular}{|l|l|}
\hline Factors and Interactions & P \\
\hline Land Use & 0.000 \\
\hline Soil Type & 0.000 \\
\hline Season & 0.000 \\
\hline Land Use x Soil Type & 0.000 \\
\hline Soil Type x Season & 0.664 \\
\hline Land Use x Soil Type x Season & 0.984 \\
\hline
\end{tabular}


Table 4.3. c. Pearson's correlation coefficients of protease activity during the rainy and dry season with moisture content, microbial biomass $\mathrm{N}$, total $\mathrm{N}$, organic $\mathrm{C}$ and microbial activity $\left(\mathrm{C}-\mathrm{CO}_{2}\right)$.

\begin{tabular}{|l|l|l|}
\hline & Protease Dry season & Protease Rainy season \\
\hline Moisture & $0.379^{* *}$ & $0.753^{* *}$ \\
\hline $\begin{array}{l}\text { Nmic } \\
(\mathbf{d r y})^{1}\end{array}$ & $0.572^{* *}$ & $0.591^{* *}$ \\
\hline $\begin{array}{l}\mathbf{N t} \\
\left.\text { dry }^{1}\right)\end{array}$ & $0.520^{* *}$ & $0.533^{* *}$ \\
\hline $\begin{array}{l}\text { Corg } \\
\left.\text { (ry }^{1}\right)\end{array}$ & $0.488^{* *}$ & $0.435^{* *}$ \\
\hline $\begin{array}{l}\mathbf{C O}_{2}-\mathbf{C} \\
\left(\mathbf{S t r}^{4}\right)\end{array}$ & $0.517^{* *}$ & $0.524 * *$ \\
\hline
\end{tabular}

Pearson's correlation coefficients calculated from means of the determined parameters from all land uses. Nmic: microbial biomass N, Nt: total Nitrogen, Corg: organic Carbon (Source: Aguila 2007), $\mathrm{CO}_{2}-\mathrm{C}: \mathrm{CO}_{2}$ evolved in the incubation experiment under bacteria inhibition with Str, Str: Streptomycin. N=90.

** Correlation is significant at the 0.01 level (2-tailed)

${ }^{1}$ Dry season field conditions

${ }^{4}$ under $1 / 2$ FC condition and inhibition with Streptomycin

Significant differences in the land uses were reported, protease activity was higher in the forest $>$ homegarden $>$ milpa (159-, 105-, 66- $\mathrm{mg} \mathrm{NH}_{4}{ }^{+} \mathrm{kg}^{-1}$ dry soil $\mathrm{h}^{-1}$ respectively). The high activity in the forest could also be due to the high organic substrate content in this ecosystem. Some studies have shown that the protease activity increases with high organic matter in the soil (Bonmati et al. 1991); the quality of the organic matter also plays an important role in the activity (Tateno 1988, Palm and Sanchez 1991). However, high amounts of litter together with high fungi biomass in the forest floor can be the factors that determined the higher protease activity in the forest. We could not directly prove the link between protease activity and fungi biomass, as fungi biomass was not measured in this study, but as mentioned before, at the moment of the sampling a high amount of fungi hyphen in the forest soils was observed. Also, as was discussed in the previous chapter, (Section 3.7), fungi plays an important role in the microbial activity of the forest soils, which also suggests that fungi contributed to a higher production and activity of protease in forests. The idea is based on the study carried out by Kandeler et al. (1999), who indicated that saprophytic fungi are the major decomposers and excrete several enzymes as for example protease. On the other hand, sweeping and burning are factors that could influence the low activity found in the homegardens soils, where this is regularly practiced. In agreement with this idea, Hernandez et al. (1997) reported a significant decline in the protease activity due to the constant burning in Mediterranean pine forest soils. They suggested that fire decreases the most labile $\mathrm{N}$ forms and increases the most recalcitrant 
$\mathrm{N}$ forms (the non-hydrolysable $\mathrm{N}$ ). Furthermore, differences between black and red soils were also found (paired-samples T-Test). The black soils had higher activity (148 $\mathrm{mg} \mathrm{NH}_{4}^{+} \mathrm{kg}^{-1}$ dry soil $\mathrm{h}^{-1}$ ) than the red soils $\left(74 \mathrm{mg} \mathrm{NH}_{4}{ }^{+} \mathrm{kg}^{-1}\right.$ dry soil $\mathrm{h}^{-1}$ ) due possibly to differences in the organic matter content which is higher in the black soils than the red soils. Microbial biomass $\mathrm{N}$, total $\mathrm{N}$, organic $\mathrm{C}$ and $\mathrm{CO}_{2}-\mathrm{C}$ evolved under bacteria inhibition correlated with protease activity. The correlation between microbial biomass $\mathrm{N}$, total $\mathrm{N}$, organic $\mathrm{C}$ and $\mathrm{CO}_{2}-\mathrm{C}$ with protease activity was $0.572,0.520,0.488,0.517$, in the dry season and $0.591,0.533,0.435$, 0.524 in the rainy season, respectively (Table 4.3.c). The correlations state that the protease activity is influenced by the organic matter content and the fungal activity; microbial biomass and total $\mathrm{N}$ content also influence their activity.

\section{IV.B. Soil biochemical characteristics upon wetting and laboratory incubation.}

\subsection{Acid Phosphatase activity upon artificial wetting}

The means of the acid phosphatase activity are shown in table 4.4.a and 4.4.b in the black and red soils respectively, land uses, and under $1 / 2$ FC and FC. Significant interactions between land use $x$ moisture (p: 0.017) and land use $x$ soil types (p: 0.030) were detected in the factorial ANOVA test. In the black soils under $1 / 2$ FC conditions, acid phosphatase showed the highest activity in the forest soils (227 mg PNP kg-1 dry soil $\mathrm{h}^{-1}$ ). In contrast, milpa and homegardens black soils showed means of $94 \mathrm{mg}$ PNP kg-1 dry soil h${ }^{-1}$ and $84 \mathrm{mg} \mathrm{PNP} \mathrm{kg}{ }^{-1}$ dry soil $\mathrm{h}^{-1}$, respectively. The activities decreased under FC, homegardens black soils showed a mean of $62 \mathrm{mg}$ PNP kg-1 dry soil $\mathrm{h}^{-1}$ and milpas black soils presented $90 \mathrm{mg}$ PNP kg-1 dry soil $\mathrm{h}^{-1}$. The activity in the forest black soils reached a mean of $155 \mathrm{mg} \mathrm{PNP} \mathrm{kg}{ }^{-1}$ dry soil h${ }^{-1}$. Red soils showed values lower than the black soils under 1/2 FC conditions; homegardens, showed a mean of $59 \mathrm{mg}$ PNP kg-1 dry soil h $\mathrm{h}^{-1}$ and milpa had an activity of $67 \mathrm{mg} \mathrm{PNP} \mathrm{kg}{ }^{-1}$ dry soil $\mathrm{h}^{-1}$. Forest red soils had the highest activity with a mean of $149 \mathrm{mg}$ PNP $\mathrm{kg}^{-1} \mathrm{dry}$ soil $\mathrm{h}^{-1}$. Under FC, homegardens red soils showed a mean of $58 \mathrm{mg} \mathrm{PNP} \mathrm{kg}{ }^{-1}$ dry soil $\mathrm{h}^{-1}$ whereas milpas red soils had $47 \mathrm{mg}$ PNP kg${ }^{-1}$ dry soil $\mathrm{h}^{-1}$. In contrast, forest red soil reached a mean of $123 \mathrm{mg}$ PNP kg-1 dry soil $\mathrm{h}^{-1}$.

The acid phosphatase activity was higher under $1 / 2$ FC (113 $\mathrm{mg}^{\mathrm{PNP}} \mathrm{kg}^{-1}$ dry soil $\left.\mathrm{h}^{-1}\right)$ than under FC (89 mg PNP kg ${ }^{-1}$ dry soil $\mathrm{h}^{-1}$ ) (p: 0.000) and similar to the results in the previous 
section, soil moisture significantly affected the acid phosphatase activity. This decreased around 1-32 \% under FC conditions in comparison with the soils under $1 / 2$ FC conditions and was significantly related to the moisture content ( $\mathrm{p}: 0.000$ ). Under $1 / 2$ FC and FC conditions positive correlation coefficients of 0.631 and 0.583 respectively, were reported (Table 4.4.c). It is well known that moisture has a high influence on the soil phosphatase activity (Rastin et al. 1988, Moscatelli et al. 2001, Boerner et al. 2005, Sardans et al. 2007) as well as the available P concentrations (Tarafdar and Claassen 1988, Häusling and Marschner 1989, Tadano et al. 1993). High level of moisture (FC) promoted a drop in the acid phosphatase activity due to the inhibition of the enzyme activity under high level of available P; keeping optimal moisture conditions (39 days of incubation), increases the P-availability, therefore the acid phosphatase activity decreases. This observation is in accordance with Aguila (2007) who reported higher phosphate concentration under full FC than under $1 / 2$ FC. High levels of phosphate under FC were attributed to the dependence of phosphate on soil moisture due to water content controls the $\mathrm{P}$ diffusion. To confirm our observation, correlation analysis showed that acid phosphatase under both $1 / 2$ FC and FC conditions correlated negatively with the $\mathrm{PO}_{4}{ }^{2}-\mathrm{P}$ demonstrating the influence of the available $\mathrm{P}$ on the acid phosphatase (Table 4.4.c).

Acid phosphatase had the highest activity in the forest soils compared to the other land uses. Forest soils reported a mean of the acid phosphatase activity around $164 \mathrm{mg} \mathrm{PNP} \mathrm{kg}^{-1}$ dry soil $\mathrm{h}^{-1}$, whereas enzyme activities in both milpa and homegardens soils were similar (74 and 65 mg PNP $\mathrm{kg}^{-1}$ dry soil $\mathrm{h}^{-1}$ in milpa and homegardens respectively). The results found in this assay are similar to those reported under field conditions (section 4.2), confirming the low availability of $\mathrm{P}$ in the forest ecosystems, where forest soils showed the highest phosphatase activity. Additionally, forest soils showed also high organic $\mathrm{C}$ contents from the accumulated litter on the soil surface, which provides a readily available supply of organic $\mathrm{P}$ for phosphatase to hydrolyse. Moreover, under laboratory condition, the litter accumulated produced an increase in the activity of the microbial communities. All of these factors might increase the mineralization of the organic matter with a consequent increase in the phosphatase activity. In line with our idea, George et al (2002) showed an enhancement in the phosphatase activities in agroforestry systems attributed to increase in the phosphatase production in the rhizosphere and the production of the enzyme by a stimulated microbial 
biomass on the addition of litterfall. The latter explanation confirms our observation, which suggests a relationship between the litterfall and phosphatase activity.

With regard to the soil types, black soils showed higher activity (119 mg PNP kg-1 dry soil h${ }^{-1}$ ) than the red soils ( $84 \mathrm{mg}$ PNP $\mathrm{kg}^{-1}$ dry soil $\mathrm{h}^{-1}$ ). Similar to section 4.2 , phosphatase activity was affected by the high organic matter content, confirming that organic matter plays an important role in protecting and maintaining phosphatase in their active form. To confirm the last observation, significant and positive correlation was obtained between acid phosphatase activity and organic $\mathrm{C}$. Furthermore microbial activity $\left(\mathrm{CO}_{2}-\mathrm{C}\right.$ evolved) under $1 / 2 \mathrm{FC}$ and $\mathrm{FC}$ (Table 4.4.c) also was correlated, indicating that the microbial activity influenced the activity of this enzyme. Microorganisms and plant roots produce acid phosphatase; in the present test, microorganisms exerted higher influence since stronger correlation with the microbial activity was reported. In contrast to our results, no significant correlation was obtained by Amador et al. (1997) and Wick et al. (2002), they attributed that the lack of significant correlation to phosphatase activity is not only affected by the SOM and related parameters (microbial biomass), but also by plant species composition, total root surface area or root morphology and phenology.

Table 4.4 a. Acid phosphatase activity (mg PNP kg ${ }^{-1}$ dry soil $^{-1}$ ) in black soils under different land uses by artificial wetting.

\begin{tabular}{|l|l|l|}
\hline Land Use & $1 / 2 \mathrm{FC}$ & $\mathrm{FC}$ \\
\hline Forest & $227 \pm 75$ & $155 \pm 57$ \\
\hline Milpa & $94 \pm 18$ & $90 \pm 21$ \\
\hline Homegardens & $84 \pm 54$ & $62 \pm 34$ \\
\hline FPLSD & 89 & 66 \\
\hline
\end{tabular}

Mean \pm 1 SD.

Within the same column, differences are significant when greater than FPLSD 
Table $4.4 \mathrm{~b}$. Acid phosphatase activity (mg PNP $\left.\mathrm{kg}^{-1} \mathrm{dry} \mathrm{soil}^{-1}\right)$ in red soils under different land uses by artificial wetting.

\begin{tabular}{|l|l|l|}
\hline Land Use & $1 / 2 \mathrm{FC}$ & $\mathrm{FC}$ \\
\hline Forest & $149 \pm 42$ & $123 \pm 53$ \\
\hline Milpa & $67 \pm 15$ & $47 \pm 17$ \\
\hline Homegardens & $59 \pm 30$ & $58 \pm 30$ \\
\hline FPLSD & 52 & 60 \\
\hline
\end{tabular}

Mean \pm 1 SD.

Within the same column, differences are significant when greater than FPLSD

\begin{tabular}{|l|l|}
\hline Factors and Interactions & $\mathbf{P}$ \\
\hline Land Use & 0.000 \\
\hline Soil Type & 0.000 \\
\hline Moisture & 0.000 \\
\hline Land Use x Soil Type & 0.030 \\
\hline Land Use x Moisture & 0.017 \\
\hline Soil Type x Moisture & 0.158 \\
\hline Land Use x Soil Type x Moisture & 0.139 \\
\hline
\end{tabular}

Table $4.4 \mathrm{c}$. Pearson's correlation coefficients of acid phosphatase activity (acP) after artificial wetting with organic $\mathrm{C}$, microbial activity $\left(\mathrm{C}-\mathrm{CO}_{2}\right)$ and phosphate.

\begin{tabular}{|l|l|l|}
\hline & acP $1 / 2 \mathrm{FC}$ & acP FC \\
\hline Moisture & $0.631 * *$ & $0.583^{* *}$ \\
\hline $\begin{array}{l}\text { Corg } \\
\left(\mathbf{D r y}^{1}\right)\end{array}$ & $0.520^{* *}$ & 0.447 \\
\hline $\begin{array}{l}\mathbf{C O}_{2}-\mathbf{C} \\
\left(1 / 2 \mathrm{FC}^{2}\right)\end{array}$ & $0.756^{* *}$ & $0.642^{* *}$ \\
\hline $\begin{array}{l}\mathbf{C O}_{2}-\mathbf{C} \\
\left(\mathrm{FC}^{3}\right)\end{array}$ & $0.738^{* *}$ & $0.613^{* *}$ \\
\hline $\begin{array}{l}\mathbf{P O}_{4}{ }^{2}-\mathbf{P} \\
\left(1 / 2 \mathrm{FC}^{2}\right)\end{array}$ & $-0.369^{* *}$ & $-0.369^{* *}$ \\
\hline $\begin{array}{l}\mathbf{P O}_{4}{ }^{2}-\mathbf{P} \\
\left(\mathrm{FC}^{3}\right)\end{array}$ & $-0.413^{* *}$ & $-0.419^{* *}$ \\
\hline
\end{tabular}

Pearson's correlation coefficients calculated from means of the acid phosphatase under $1 / 2$ FC and FC condition with determined parameters from all land uses. Corg: organic Carbon (Source: Aguila 2007), $\mathrm{CO}_{2}-\mathrm{C}$ : $\mathrm{CO}_{2}$ evolved in the incubation experiment, $\mathrm{PO}_{4}{ }^{2}-\mathrm{P}$ : available $\mathrm{P}$ in the incubation experiment (Source: Aguila 2007). $\mathrm{N}=90$.

** Correlation is significant at the 0.01 level (2-tailed)

acP: acid phosphatase

${ }^{1}$ Dry field conditions

2 under $1 / 2$ FC condition incubation experiment

${ }^{3}$ under FC condition incubation experiment 


\subsection{Alkaline Phosphatase activity upon artificial wetting}

The ranges in the alkaline phosphatase activities are shown in Table 4.5.a and 4.5.b. In black soils, the activities vary from 160-326 and 120-211 mg PNP kg${ }^{-1}$ dry soil h ${ }^{-1}$, under $1 / 2 \mathrm{FC}$ and FC conditions respectively. The red soils reported lower values than the black soils, within ranges of 116-159 and 76-107 $\mathrm{mg} \mathrm{PNP} \mathrm{kg}^{-1}$ dry soil $\mathrm{h}^{-1}$ under $1 / 2 \mathrm{FC}$ and FC respectively. Under $1 / 2$ FC conditions, the activity in the homegardens black soils was $160 \mathrm{mg}^{\mathrm{PNP} \mathrm{kg}^{-1}}$ dry soil $^{-1}$. In milpa, black soils reported activities of $165 \mathrm{mg} \mathrm{PNP} \mathrm{kg}^{-1} \mathrm{dry} \mathrm{soil} \mathrm{h}^{-1}$, whereas forest black soils presented the highest activity with a mean of $326 \mathrm{mg} \mathrm{PNP} \mathrm{kg}^{-1}$ dry soil h${ }^{-1}$. Red soils showed values of $116 \mathrm{mg}$ PNP $\mathrm{kg}^{-1}$ dry soil h${ }^{-1}$ in homegardens, $119 \mathrm{mg}^{\mathrm{PNP} \mathrm{kg}^{-1}}$ dry soil $\mathrm{h}^{-1}$ in milpas and $159 \mathrm{mg}$ PNP $\mathrm{kg}^{-1}$ dry soil $\mathrm{h}^{-1}$ in forest soils. Under FC conditions, alkaline phosphatase activity decreased, black soils had activities of $120 \mathrm{mg} \mathrm{PNP} \mathrm{kg}^{-1}$ dry soil $\mathrm{h}^{-1}$ in milpa, $126 \mathrm{mg} \mathrm{PNP} \mathrm{kg}^{-1}$ dry soil h $\mathrm{h}^{-1}$ in homegardens and $211 \mathrm{mg} \mathrm{PNP} \mathrm{kg}^{-1}$ dry soil h $\mathrm{h}^{-1}$ in forests. Red soils presented activities of $76 \mathrm{mg} \mathrm{PNP} \mathrm{kg}^{-1}$ dry soil $\mathrm{h}^{-1}$ in milpas, $78 \mathrm{mg} \mathrm{PNP} \mathrm{kg}{ }^{-1}$ dry soil $\mathrm{h}^{-1}$ in homegardens and $107 \mathrm{mg}$ PNP kg-1 dry soil $\mathrm{h}^{-1}$ in forest. During the wetting experiment, alkaline phosphatase was determined by the interaction land use $\mathrm{x}$ soil types.

Alkaline phosphatase activity was affected by the moisture effect under laboratory conditions. Paired-Samples T-Test analysis showed significant differences between $1 / 2$ FC (174 mg PNP $\mathrm{kg}^{-1}$ dry soil $\mathrm{h}^{-1}$ ) and FC (119 mg PNP $\mathrm{kg}^{-1}$ dry soil $\mathrm{h}^{-1}$ ). During the incubation experiment, positive correlation coefficients of 0.573 and 0.484 under $1 / 2$ FC and FC, respectively, were found between the alkaline phosphatase activity and moisture content (Table 4.5.c). In contrast to the results obtained in section 4.3, the artificial moisturizing influenced the activity of alkaline phosphatase. In this case, the variation of the alkaline activity might be attributed to prolonged incubation time under controlled conditions of moisture and temperature as well as to the states of the enzyme. Studies about changes of the alkaline phosphatase with moisture have been widely reported (Kraemer and Green 2000, Wick et al. 2002, Sardans et al. 2006); in general, these studies did not find changes in the activity with changes of the soil moisture. This is attributed to the stabilization of the enzyme by fresh organic matter in the soil fraction that is protected against decomposition (Busto and Perez-Mateos 1995). In contrast to the present test, these measurements have been carried out under moisture field conditions. 
Forest soils showed the highest alkaline phosphatase activity (201 mg PNP kg-1 dry soil h${ }^{-1}$ ), milpa (120 mg PNP kg ${ }^{-1}$ dry soil $\mathrm{h}^{-1}$ ) and homegardens (120 mg PNP kg ${ }^{-1}$ dry soil $\mathrm{h}^{-1}$ ) systems reported similar activities. Also, alkaline phosphatase activity showed differences between the different soil types. Black soils had higher activity (185 mg PNP kg-1 dry soil $\mathrm{h}^{-1}$ ) than red soils (109 mg PNP kg-1 dry soil h${ }^{-1}$ ). Similar to the results found in section 4.6, forest sites and black soils showed the highest activity, confirming the higher biological activity in these soils. The high leave input on the forest soils and the high organic matter content in black soils promotes high microbial activity and consequently the production of alkaline phosphatase is increased.

A strong and positive correlation of alkaline phosphatase activity with the organic $\mathrm{C}$ under dry field condition, $\mathrm{CO}_{2}-\mathrm{C}$ evolved under $\mathrm{FC}$ and $1 / 2 \mathrm{FC}$ conditions and $\mathrm{CO}_{2}-\mathrm{C}$ evolved with bacteria inhibition was reported (Table 4.5.c). As is expected, the alkaline phosphatase activity had a strong correlation with both, organic $\mathrm{C}$ and soil respiration as measure of microbial activity. Also, with bacteria inhibition (Str) the alkaline phosphatase was correlated, emphasizing the importance of the microbial activity and fungi as producers of the alkaline phosphatase (Dick and Tabatabai 1984, Tarafdar and Claassen 1988) and highly effective in the mineralization of organic P (Kucey 1983 in Wick et al. 2002). Studies carried out by Deng and Tabatabai (1997) and Wick et al. (2002) have also stated the correlation of alkaline phosphatase with soil organic $\mathrm{C}$ and microbial biomass. Additionally, alkaline phosphatase only under $1 / 2$ FC conditions correlated with the organic P under dry field conditions (Table 4.5.c). No correlation under FC conditions was found. It is important to highlight that in Yucatecan soils, the predominant fraction of organic $\mathrm{P}$ is $\mathrm{NaOH}-\mathrm{Po}$ (Aguila 2007), which is considered a resistant organic fraction (Agbenin and Tiessen 1994). The quality of the organic matter has a strong influence on phosphatase activity. In general, phosphatases are better associated with fresh organic matter in the larger soil fractions than with stable and humified organic matter (Rojo et al. 1990). Then, it is possible that these factors play an important role on the alkaline phosphatase activity and their production was strongly mediated by the microorganisms (higher correlation coefficient) than for the organic and inorganic $\mathrm{P}$ fractions. 
Table 4.5. a. Alkaline phosphatase activity by artificial wetting of black soils under different land uses (mg PNP $\mathrm{kg}^{-1}$ dry soil $\mathrm{h}^{-1}$ ).

\begin{tabular}{|l|l|l|}
\hline Land Use & $1 / 2 \mathrm{FC}$ & FC \\
\hline Forest & $326 \pm 112$ & $211 \pm 87$ \\
\hline Milpa & $165 \pm 46$ & $120 \pm 29$ \\
\hline Homegardens & $160 \pm 89$ & $126 \pm 48$ \\
\hline FPLSD & 143 & 99 \\
\hline
\end{tabular}

Mean \pm 1 SD.

Within the same column, differences are significant when greater than FPLSD

Table 4.5. b. Alkaline phosphatase activity by artificial wetting of red soils under different land uses (mg PNP kg ${ }^{-1}$ dry soil $\mathbf{h}^{-1}$ ).

\begin{tabular}{|l|l|l|}
\hline Land Use & $1 / 2$ FC & FC \\
\hline Forest & $159 \pm 50$ & $107 \pm 42$ \\
\hline Milpa & $119 \pm 27$ & $76 \pm 29$ \\
\hline Homegardens & $116 \pm 62$ & $78 \pm 39$ \\
\hline FPLSD & 80 & 61 \\
\hline
\end{tabular}

Mean \pm 1 SD.

Within the same column, differences are significant when greater than FPLSD

\begin{tabular}{|l|l|}
\hline Factors and Interactions & $\mathbf{P}$ \\
\hline Land Use & 0.000 \\
\hline Soil Type & 0.000 \\
\hline Moisture & 0.000 \\
\hline Land Use x Soil Type & 0.000 \\
\hline Land Use x Moisture & 0.071 \\
\hline Soil Type x Moisture & 0.270 \\
\hline Land Use x Soil Type x Moisture & 0.243 \\
\hline
\end{tabular}


Table 4.5. c. Pearson's correlation coefficients of alkaline phosphatase activity (alP) after artificial wetting with determined parameters.

\begin{tabular}{|l|l|l|}
\hline & alP $1 / 2 \mathrm{FC}$ & alP FC \\
\hline Moisture & $0.573^{* *}$ & $0.484^{* *}$ \\
\hline $\begin{array}{l}\mathbf{C O}_{2}-\mathbf{C} \\
\left.\mathbf{S t r}^{4}\right)\end{array}$ & $0.652^{* *}$ & $0.581^{* *}$ \\
\hline $\begin{array}{l}\mathbf{C O}_{2}-\mathbf{C} \\
\left(1 / 2 \mathrm{FC}^{2}\right)\end{array}$ & $0.723 * *$ & $0.659^{* *}$ \\
\hline $\begin{array}{l}\mathbf{C O}_{2}-\mathbf{C} \\
\left(\mathrm{FC}^{3}\right)\end{array}$ & $0.728^{* *}$ & $0.691^{* *}$ \\
\hline \begin{tabular}{l}
$\mathbf{C o r g}^{\left(\text {Dry }^{1}\right)}$ \\
\hline $\begin{array}{l}\text { Total Po } \\
(\text { Dry }\end{array}$
\end{tabular} & $0.574 * *$ & $0.584^{* *}$ \\
\hline
\end{tabular}

Pearson's correlation coefficients calculated from means of the alkaline phosphatase under $1 / 2$ FC and FC condition with determined parameters from all land uses. $\mathrm{CO}_{2}-\mathrm{C}: \mathrm{CO}_{2}$ evolved in the incubation experiment, Corg: organic Carbon (Source: Aguila 2007), Total Po: Total organic P (Po- $\left.\mathrm{HCO}_{3}+\mathrm{Po}-\mathrm{OH}+\mathrm{Po}-\mathrm{HClc}\right)$ (Source: Aguila 2007). N= 90.

** Correlation is significant at the 0.01 level (2-tailed)

alP: alkaline phosphatase

Str: Streptomycin

${ }^{1}$ Dry field conditions

${ }^{2}$ under $1 / 2$ FC condition incubation experiment

${ }^{3}$ under $\mathrm{FC}$ condition incubation experiment

${ }^{4}$ under $1 / 2$ FC condition and inhibition with Streptomycin

\subsection{Protease activity upon artificial wetting}

Protease activity varied around $67-228 \mathrm{mg} \mathrm{NH}_{4}{ }^{+} \mathrm{kg}^{-1}$ dry soil h${ }^{-1}$ in the black soils and $32-$ $92 \mathrm{mg} \mathrm{NH}_{4}{ }^{+} \mathrm{kg}^{-1}$ dry soil $\mathrm{h}^{-1}$ in the red soils under $1 / 2 \mathrm{FC}$ conditions (Table 4.6.a, 4.6.b). Under FC conditions, protease activity showed means of around $25-149 \mathrm{mg} \mathrm{NH}_{4}{ }^{+} \mathrm{kg}^{-1}$ dry soil h${ }^{-1}$ and $12-54 \mathrm{mg} \mathrm{NH}_{4}{ }^{+} \mathrm{kg}^{-1}$ dry soil $\mathrm{h}^{-1}$ in the black and red soils respectively (Table 4.6.a, 4.6.b). Protease activity was affected by interactions land use $\mathrm{x}$ wetting. Differences between $1 / 2$ FC and FC were reported. The values in the protease activity were significantly higher under $1 / 2 \mathrm{FC}\left(94 \mathrm{mg} \mathrm{NH}_{4}{ }^{+} \mathrm{kg}^{-1}\right.$ dry soil $\left.\mathrm{h}^{-1}\right)$ than under FC $\left(63 \mathrm{mg} \mathrm{NH}_{4}{ }^{+} \mathrm{kg}^{-1}\right.$ dry soil $\left.\mathrm{h}^{-1}\right)$. Protease activity under FC conditions decreased near to $35 \%$ to $68 \%$, compared with $1 / 2 \mathrm{FC}$ conditions. Regression analysis showed that protease activity was positive and significantly related with the moisture content under $1 / 2$ FC conditions (r: 0.585, p: 0.000) and FC conditions (r: 0.499, p: 0.000) (Table 4.6.c).

Higher conditions of moisture produced a drop in the protease activity. Normally, it has been described that soil moisture increases the protease activity. However, these studies were carried out under both field and in extreme conditions; normally they compared dry vs. rainy 
season (Watabane and Hayano 1995, Wick et al. 2002, Sardans and Peñuelas 2005, Bastidas et al. 2006b). Studies about enzyme activities carried out under laboratory conditions are few; up to date there are no data concerning to the protease activity measured under controlled conditions of laboratory. As was previously described, soil enzyme activities depend on several factors. Bastida et al. (2006a) argued that the enzymes don't follow a clear seasonal pattern, and the variations depend on multitude factors as: concentration of substrate in the medium, protective effect of the organic matter, and variations in the microbial biomass. In general, high fluctuations in the protease activity have been reported. In this assay, protease activity was measured after 39 days of soil incubation under controlled temperature and moisture conditions, might be under FC conditions the activity of the enzyme was repressed, due to formation of stable complexes between the protein with polyphenol complexes and high water content (Palm and Sanchez 1991).

Regarding land uses, protease reported the highest activity in the forest soils with a mean of $131 \mathrm{mg} \mathrm{NH}{ }_{4}^{+} \mathrm{kg}^{-1}$ dry soil $\mathrm{h}^{-1}$, whereas milpa and homegardens systems showed similar activities around 41 and $46 \mathrm{mg} \mathrm{NH}_{4}{ }^{+} \mathrm{kg}^{-1}$ dry soil $\mathrm{h}^{-1}$ respectively. Protease activity was determined by the interaction land use $\mathrm{x}$ soil type in the factorial ANOVA test, and pairedsamples T-Test reported significant differences between black and red soils. The black soils had higher activity (100 mg NH${ }_{4}^{+} \mathrm{kg}^{-1}$ dry soil h${ }^{-1}$ ) than the red soils (46 $\mathrm{mg} \mathrm{NH}_{4}{ }^{+} \mathrm{kg}^{-1}$ dry soil $\mathrm{h}^{-1}$ ). It is well known that quality and quantity of SOM play an important role on the protease activity (Tateno 1988, Bonmati et al. 1991, Palm and Sanchez 1991), therefore the higher activity in the forest and black soils, where the litter input is greater than the other ecosystems influenced on the protease activity. Other influencing factor on the high protease activity in forest is the high fungi activity of these soils. As was reported in the soil respiration experiment (Chapter III (3.7)) and similar to section 4.4, fungi exerted a high influence on the protease activity in forest. Since saprophytic fungi are the major decomposers and excrete enzymes like protease (Kandeler et al. 1999). Our observations are stated through correlation analysis, which reported high and significant correlation of the protease activity with the microbial biomass $\mathrm{N}$, microbial activity under contrasting moisture conditions and through the inhibition of bacteria $\left(\mathrm{CO}_{2}-\mathrm{C}\right.$ evolved), and also with the organic $\mathrm{C}$ under field dry conditions (Table 4.6.c). However, the stronger relation with the microbial activity suggests that protease is constrained by the microbial activity. 
Table 4.6. a. Protease activity by artificial wetting of black soils under different land uses $\left(\mathrm{mg} \mathrm{NH}_{4}{ }^{+} \mathrm{kg}^{-1}\right.$ dry soil $h^{-1}$ ).

\begin{tabular}{|l|l|l|}
\hline Land Use & $1 / 2 \mathrm{FC}$ & FC \\
\hline Forest & $228 \pm 53$ & $149 \pm 88$ \\
\hline Milpa & $67 \pm 31$ & $52 \pm 57$ \\
\hline Homegarden & $77 \pm 43$ & $25 \pm 9$ \\
\hline FPLSD & 72 & 100 \\
\hline
\end{tabular}

Mean \pm 1 SD.

Within the same column, differences are significant when greater than FPLSD

Table 4.6. b. Protease activity by artificial wetting of red soils under different land uses $\left(\mathrm{mg} \mathrm{NH} \mathrm{NH}^{+} \mathrm{kg}^{-1} \mathrm{dry}\right.$ soil $\mathbf{h}^{-1}$ ).

\begin{tabular}{|l|l|l|}
\hline Land Use & $1 / 2 \mathrm{FC}$ & FC \\
\hline Forest & $92 \pm 33$ & $54 \pm 15$ \\
\hline Milpa & $32 \pm 10$ & $12 \pm 8$ \\
\hline Homegarden & $67 \pm 45$ & $21 \pm 13$ \\
\hline FPLSD & 55 & 20 \\
\hline
\end{tabular}

Mean \pm 1 SD.

Within the same column, differences are significant when greater than FPLSD

\begin{tabular}{|l|l|}
\hline Factors and Significant Interactions & $\mathbf{P}$ \\
\hline Land Use & 0.000 \\
\hline Soil Type & 0.000 \\
\hline Moisture & 0.000 \\
\hline Land Use x Soil Type & 0.000 \\
\hline Land Use x Moisture & 0.021 \\
\hline Soil Type x Moisture & 0.189 \\
\hline Land Use x Soil Type x Moisture & 0.291 \\
\hline
\end{tabular}


Table 4.6. c. Pearson's correlation coefficients of protease activity after artificial wetting with determined parameters.

\begin{tabular}{|l|l|l|}
\hline & Protease $1 / 2 \mathrm{FC}$ & Protease FC \\
\hline Moisture & $0.585^{* *}$ & $0.499 * *$ \\
\hline $\begin{array}{l}\text { Nmic } \\
\left(1 / 2 \mathrm{FC}^{2}\right)\end{array}$ & $0.648^{* *}$ & $0.638^{* *}$ \\
\hline $\begin{array}{l}\text { Nmic } \\
\left(\mathrm{FC}^{3}\right)\end{array}$ & $0.698^{* *}$ & $0.610^{* *}$ \\
\hline $\begin{array}{l}\mathbf{C O}_{2}-\mathbf{C} \\
\left(1 / 2 \mathrm{FC}^{2}\right)\end{array}$ & $0.761^{* *}$ & $0.783^{* *}$ \\
\hline $\begin{array}{l}\mathbf{C O}_{2}-\mathbf{C} \\
\left(\mathrm{FC}^{3}\right)\end{array}$ & $0.786^{* *}$ & $0.768^{* *}$ \\
\hline $\begin{array}{l}\mathbf{C O}_{2}-\mathbf{C} \\
\left(\mathbf{S t r}^{2}\right)\end{array}$ & $0.706^{* *}$ & $0.707^{* *}$ \\
\hline $\begin{array}{l}\mathbf{C o r g} \\
(\text { Dry }\end{array}$ & $0.573^{* *}$ & $0.546^{* *}$ \\
\hline
\end{tabular}

Pearson's correlation coefficients calculated from means of the protease under $1 / 2$ FC and FC condition with determined parameters from all land uses. $\mathrm{N}$ mic: Microbial biomass $\mathrm{N}$ in the incubation experiment, $\mathrm{CO}_{2}-\mathrm{C}$ : $\mathrm{CO}_{2}$ evolved in the incubation experiment, Corg: organic Carbon (Source: Aguila 2007). N=90.

** Correlation is significant at the 0.01 level (2-tailed)

${ }^{1}$ Dry field conditions

${ }^{2}$ under $1 / 2$ FC condition incubation experiment

${ }^{3}$ under FC condition incubation experiment 
4.8 Synthesis: Effects of moisture conditions on enzymes involved in the $N$ and $P$ cycle - Potential effect on nutrient availability and comparison to microbial activities.

In the present chapter, it was stated that the moisture content affects biochemical processes in the soil. The soil moisture influenced each soil enzyme activity. Many activities are limited by the water content; also, some of them are constrained by nutrient content or microbial activity, which is strongly influenced by the fungi. For instance, under field conditions acid phosphatase was affected by the P-availability, but it was strongly constrained by the moisture content. Several studies have shown that root plants determine acid phosphatase activity. Nevertheless, in the laboratory experiment, microorganisms determined the activity of this enzyme. Interesting is also the results showed by the alkaline phosphatase activity, which did not show differences between dry and rainy season, but under laboratory conditions soil artificial moisturizing influenced their activity. Protease also was affected by moisture content; under field condition several factors influenced their activity (organic C, microbial biomass and activity by fungi), whereas under laboratory conditions microbial activity had a higher influence. Different trends of the effect of moisture on each enzyme activities could be due to differences in the states and conditions of measurements. Since they were measured once under field conditions, where plants' roots and field moisture possibly had an influence, and the other one was measured by long time under controlled conditions without the influence of vegetation.

Land uses and soil types are also an important factor affecting enzyme activities. Forest and black soils showed always higher activities under both field and laboratory conditions. In general, homegardens and milpa showed similar activities (with the exception of protease under field conditions). The high phosphatase activities in forest indicate available Pdeficiency, because phosphatases are considered as adaptive enzymes that are stimulated under low P availability. Regarding black soils, their high activities were attributed to organic matter content, which play an important role in the enzyme activity and consequently in the mineralization of nutrients. These results are in agreement with Aguila (2007), who reported lower available $\mathrm{P}$ in forest due to its reactions with carbonates, which formed complexes highly stable and delayed its mineralization. Protease showed higher activity in forests and black soils. Here, the organic matter content is also a factor associated to the enzyme activity, but microorganisms strongly determined their activity. The high activity in this ecosystem 
shows the high potential of $\mathrm{N}$ mineralization from the accumulated organic matter on the forest soils but a loss of potential in homegardens and milpa.

The results here are associated with those found in the previous chapter, where it was shown that microorganisms and organic matter determine the microbiological and biochemical processes in the nutrient cycle. In general, the findings show that the forest soils have the highest potential of nutrients and these might be liberated only under optimal soil moisture conditions in which fungi exert an important role in the decomposition and mineralization processes. However, milpa and homegardens showed a reduction in their potential of transformation due possibly to lack of adequate litter input.

In the karstic soils of Yucatan, the low $\mathrm{P}$ availability together with the decline in the organic matter is well correlated to the soil enzyme activity decline. The results are giving out the potential of transformation rates rather than in situ liberation rates. These show the negative effect of both long dry seasons and land uses (milpa and homegardens) on soil productivity capacity in Yucatan, through a decreased soil enzyme activity and thus a reduced potential transformation rate of organic matter. This effect shows the possible loss of fertility that low water availability and agricultural practices (homegardens and milpa) can have on the nutrient availability and productivity of the land uses in the karstic soils of Yucatan. 


\section{GENERAL CONCLUSIONS.}

In the present study, biological and biochemical parameters involved in nutrient cycling of calcareous soil in the Yucatan Peninsula were evaluated. The study was focussed in two principal chapters: the first was stressed on the global C-Cycle including the soil fauna effect on the decomposition, microbial biomass, microbial activity and the potential transformation of nutrient rate involved in the C-Cycle. And the second chapter was focussed on the potential transformation rates (through enzyme activities) of the limiting nutrients in the soils ( $\mathrm{N}$ and $\mathrm{P}$ ). Since water is a constraining factor in semi-arid soils, the moisture effect was assessed to evaluate their effect on the biological and biochemical processes. Soil biological and biochemical characteristics were evaluated under different land uses and soil types. Several indicators and methods were used to determine the soil moisture-, land uses- and the soil types- effect and it were chosen those indicators able to show changes that: first, reflect the major of processes and controlling factors involved in the cycling of $\mathrm{C}, \mathrm{N}$, and $\mathrm{P}$; second, be sensible to detect variations in moisture levels; and finally, be susceptible to changes of management and to differences in the soil types. These parameters were evaluated under two conditions: field conditions in two seasons of year and upon wetting and laboratory conditions at contrasting moisture levels. In general, it was concluded that:

- Rain strongly controls the decomposition process and many microbial and biochemical processes. An increase about $20 \%$ in the process at the beginning of the rainy season was reported. This effect was more pronounced in milpa systems, where around $80 \%$ and $40 \%$ mass loss in the big and medium mesh sizes, respectively, was found. The influence was higher than in forest due possibly to stronger effect of the radiation and temperature on the soil of this system as compared to forest.

- Mesofauna (soil fauna with body width $>250 \mu \mathrm{m}$ ) is the most abundant group of the soil fauna in Yucatecan soils. This group represented $77 \%$ of the soil fauna abundance in the land uses of Yucatan. Also, these organisms were involved in the decomposition process at the milpa and forests sites. Among the principal soil mesofauna groups, we found: Araneae(spiders), Coleoptera (beetles), Isoptera (termites) and Formicidae 
(ants). It was reported that termites and ants can have an important effect on the decomposition process due to they showed higher abundances. These groups represented about $22 \%$ (termites) and $30 \%$ (ants) of the total mesofauna abundance.

- In general, the soil fauna abundance reported in the present study is lower than other studies carried out in tropical regions. Soil fauna abundance have been reported around hundred to thousand individuals collected in several regions of the tropic. In the present study, the most abundant groups do not reach more than 250 ind. $\mathrm{m}^{2}$. In semiarid region the soil fauna abundance is low, however, it is recommended carry out studies more detailed about the soil fauna and their direct effect on the nutrient cycling, especially of ants and termites, as important groups that influence on the decomposition process in yucatecan soils.

- Microbial biomass reported a significant increase in the rainy season (45\%) compared to the dry season. The increase in the microbial biomass is attributed to higher source availability for the microorganisms in the rainy season that promoted their growth. Under artificial wetting after incubation experiment, $35 \%$ lower microbial biomass under FC compared to $1 / 2$ FC was found. This could indicate that higher level of moisture inhibit the microbial growth. In contrast, under FC, an increase in their activity was reported. The results show that high microbial biomass does not necessarily involved high microbial activity and vice versa.

- Under artificial wetting and incubation experiment, increase in the moisture levels stimulated the activity of the microorganisms. The highest microbial activities were reported under FC condition, which showed an increased 4-fold higher than the soil under dry field conditions. Furthermore, the activity was kept during the incubation time, indicating that the substrate is not limiting for the microbial activity. Str produced in part the inhibition of the microbial activity (6-17\%). This suggests higher fungi activity, principally in the forest. However, it deduces a dominance of bacterial population in the homegardens. The high activity of fungi, suggest a great immobilization of nutrients by these microorganisms in their biomass, which could delay the decomposition process and turnover of nutrients in these soils. 
- Both, season and artificial wetting also affected the potential transformation rates of $\mathrm{P}$ and $\mathrm{N}$. Increases in the phosphatase activities with the increase of the moisture were attributed to growth of plants and low P-availability. Under field conditions, acid phosphatase increase around 16-70\% during the rainy season compared to the dry season. However, after artificial wetting and incubation experiment, acid phosphatase activity declined about $23 \%$ under FC compared to $1 / 2$ FC due possibly to inhibition of the enzyme by increasing of available P. Protease also showed a significant decline in their activity under FC condition (55\%). High moisture and prolonged conditions produced a delayed in the enzyme activities and consequently in the mineralization. Mineralization rates depend on soil temperature, aeration, and soil moisture. Normally, the most rapid mineralization occurs in moist and well-aerated soils. Therefore, low enzyme activity under FC.

- In general, the moisture had a positive effect on the microbiological and biochemical characteristics of soil. All enzyme activities, microbial biomass, and microbial activity were positively correlated with the moisture content. This indicates the importance of the water content on the soil microbiological and biochemical processes. It is important to stress that in some cases, the results under field moisture conditions were less sensible than under artificial wetting as for example, alkaline phosphatase, and $\beta-$ glucosidase. Under field condition, the seasonal variation had not a significant effect on the activities of these enzymes but significant and higher activity under artifitial wetting was reported. This suggests that alkaline phosphatase and $\beta$-glucosidase are measurements of the potential of transformation rates due to under dry field conditions these enzymes showed low activity, whereas under medium and high moisture levels, the enzymes showed higher activity.

- The effect of the land uses was always detected on the microbiological and biochemical characteristics. It is important to highlight that both, under field and upon artificial wetting conditions, forest soils always showed the highest microbial biomass, microbial activity and enzyme activities compared to homegardens and milpa soils. This is attributed to the high soil organic $\mathrm{C}$ content present in this ecosystem. It is well 
known that microbial activity depends on $\mathrm{C}$, as substrate due to the most microbial population is heterotrophic. The result indicates the high potential of nutrients $(\mathrm{C}$ and $\mathrm{N}$ ) in forest, which suggests that these soils might be more fertile than milpa and homegardens. In general, milpa and homegardens showed similar microbial biomass and enzyme activities (phosphatases, proteases and $\beta$-glucosidase), despite high plant biodiversity in homegardens, the constant remove of plant material strongly affected their soil microbial and biochemical properties. In milpa, the maize leaves input is high, but maybe the high soil temperature influences on the microorganism's biomass and activity.

- Under field and laboratory conditions, microbial biomass (Nmic), microbial activity $\left(\mathrm{CO}_{2}-\mathrm{C}\right.$ evolved) and enzyme activities were higher in black soils than in red soils. This suggests the important role of the organic matter in these soils. Since the black soils have a high organic $\mathrm{C}$ content, biological and biochemical characteristics were correlated with this chemical parameter. Therefore, it is stated the importance of the organic matter as soil chemical property and their effect and relation with the biological and biochemical variables.

- In general, soil microbiological and biochemical characteristics were strongly related with soil chemical characteristics, as for example organic $\mathrm{C}$, nitrate, and available $\mathrm{P}$, which shows the link between the chemical and biological properties of the soils. However, it is important to stress that these relationships are constrained by soil moisture.

- Microbial biomass, acid phosphatase and protease activities were the most sensitive indicators to reflect the changes in the soil moisture, since they were susceptible in both, field and artificial wetting conditions. All the parameters reflect the effect of the land use and soil type with the exception of $\beta$-glucosidase activity that was not affected by the change in the soil types under field conditions.

The results show that under field condition these processes are strongly limited by the moisture, whereas under laboratory condition it can observe that there is potential of nutrients 
that only might be mineralise under optimal moisture conditions. Under optimal moisture conditions, many microorganisms are active and consequently they can transform the nutrients of organic to inorganic form that is available to the plants. However, the higher microbial activity by fungi, suggests that these organisms can retain nutrients in their biomass, which it is reflected normally in a low nutrient availability in the soils. Therefore the low nutrient availability $(\mathrm{P})$ in forest soils could be influenced by the high immobilization in fungi and the low availability of water. On the other hand, the low soil fauna abundance could also influence on the decomposition and consequently the soil mineralization processes, since they are considered as modifiers of the soil litter. A small group of soil fauna is adapted to the semiarid conditions of the yucatecan soils, where the dominant soil fauna are: ants and termites amongst others. They have high effect on the decomposition process; however, their direct influence on nutrient cycling is unclear.

Other important factor in this study was the land uses. In general, milpa and homegardens showed similar effect on the soil microbial and biochemical characteristics. The low organic input in homegardens, as well as the extreme soil conditions in milpa; it is reflected in a decrease of nutrient potential as well as in the microbial activity of these soils. However, forest soils showed a high potential transformation rates and high microbial biomass and activity. Apart from reduced litter input, removal and burning of organic matter may have a negative effect on the microbial biomass, microbial activity and enzyme activities and therefore on nutrient availability in homegardens. Consequently, the low litter input currently occurring and it is reflected in a negative effect on soil biological and biochemical processes and subsequently other negative effect on soil fertility separately from the direct one of low water availability, which in the future could be reflected in the productivity of these systems. 


\section{Summary}

The soils of the Yucatan Peninsula in Mexico, which are subject to diverse kinds of agricultural practices, have shown over time a decline in their fertility. The climate of the region (semi-arid) with scarce rainfall, rain in a concentrated short period, and a high mean temperature, play an important role in the soil processes and nutrient cycling. In addition, the high heterogeneity of the soils, where some of them present high organic matter content, does not allow a good diffusion of nutrients and limits their availability to the plants. Generally, in semi-arid ecosystems some nutrients are limiting and available to plant in short pulses following precipitation. Studies have shown that water input stimulates nutrient mineralization from accumulated organic mater. However, in a study carried out by Shang and Tiessen (2003) in Yucatan the hydrophobicity of some soil types with high organic matter content was observed, which affects water retention and consequently limits nutrient release.

This thesis was focussed on the evaluation of the soil's biological and biochemical characteristics involved in the nutrients transformation processes in the Yucatan Peninsula, which could contribute to understand the ecosystem functioning and to improve their management. Therefore, soil biological and biochemical indicators under different land uses systems and soil types were determined. Decomposition process, soil fauna (abundance and diversity), soil respiration, contribution of bacteria and fungi to the soil respiration, microbial biomass and enzyme activities were measured in order to evaluate the biological processes associated to the $\mathrm{C}$-cycle. The study was carried under field conditions and artificial wetting in laboratory to asses the seasonal effect and the influence of soil moisture, respectively. Additionally, it was performed an incubation experiment upon artificial wetting to evaluate the potential source of the nutrients $(\mathrm{N}, \mathrm{P})$ through measures of enzyme activities.

The main results of this research show that in general the rain and the moisture had a positive effect on the biological, microbiological and biochemical characteristics of soils. Decomposition process showed an increase and kept high rates during the rainy season, confirming that the rainfall has a strong effect. However, the soil fauna was another factor that determined the process, where termites and ants have high influence on it. Regarding biochemical characteristics, alkaline phosphatase and $\beta$-glucosidase were found as potential 
indicators of activity due to under optimal moisture levels these enzymes showed the highest capacity of source of nutrient in the soil.

The effect of the land uses was also detected on the microbiological and biochemical characteristics. It is important to highlight that both, field- and artificial wetting- conditions, the forest soils showed always the highest values compared to homegardens and milpa. Fungi play a greater role in the soil respiration, indicating that they could have a high influence on the decomposition processes in the different land uses but principally in the forests, where the litter input enriched the soil, and allow possibly an high immobilization of nutrients in their biomass. In general, milpa and homegardens showed similar characteristics and lower soil microbial biomass and activities in these systems were reported. The decrease in the microbial and biochemical parameters was attributed to the continuous remove of organic material in the soils. Thus, it is reflected in a negative effect on soil biological and biochemical processes that could be reflected in the productivity of these systems. Similarly, the black soils had higher values due to their high organic $\mathrm{C}$ content, which correlated with microbial and biochemical characteristics. Therefore, it stated the importance of the organic matter as soil chemical property and their effect and relationship with the biological and biochemical characteristics.

Finally, the results of the incubation experiment help to understand the soil biological processes considering the influence of the moisture and the impact of the different land uses in the peninsula, which show a potential of nutrient that might be liberated only when the moisture conditions are optimal. This could contribute to understanding the functioning of the systems and maybe to develop a better management based on the water control. 


\section{Zusammenfassung}

Die Böden der Yukatan-Halbinsel in Mexiko haben im Laufe der Zeit einen Rückgang der Fruchtbarkeit. Grund hierfür sind die landwirtschaftlichen Praktiken. Das Klima der Region (semi-ariden) mit einem konzentriert kurzen Regenzeitraum und eine hohe mittlere Temperatur spielen eine wichtige Rolle in den Bodenprozessen und dem Nährstoffkreislauf. Darüber hinaus gibt es Böden mit hoher Heterogenität, wovon einige von ihnen einen hohen Anteil an organischem Material besitzen. Diesen Böden ist es nicht möglich eine gute Diffusion von Nährstoffen den Pflanzen zur Verfügung zu stellen. Generell sind einige Nährstoffe durch die Verfügbarkeit und durch kurze Niederschlagsintervalle in semi-ariden Ökosystemen begrenzt.

Studien haben gezeigt, dass die Wasserzugabe die Nährstoff-Mineralisierung von organischem kumuliertem Material stimuliert. Doch in einer Studie, die von Shang und Tiessen (2003) in Yukatan, wurde die Hydrophobie von Bodenarten mit hohen organischen Stoffen, die Wasserretention und die Grenzen der Nährstoff-Freisetzung beobachtet.

Diese Arbeit konzentriert sich auf die Bewertung der Boden-biologischen und biochemischen Eigenschaften sowie Nährstoff-Transformationsprozesse. Sie sollen einen Beitrag zum Verständnis der Funktionsweise des Ökosystems der Yukatan-Halbinsel und zur Verbesserung deren Verwaltung dienen. Aus diesem Grund wurden im Boden biologische und biochemische Indikatoren unter Berücksichtigung verschiedenartiger Bodennutzungen und Bodentypen bestimmt. Zersetzung, Bodenfauna, Bodenatmung, Beitrag der Bakterien und Pilze im Bereich der Bodenatmung, mikrobielle Biomasse und Enzym-Aktivitäten wurden im Hinblick auf die Bewertung der biologischen Prozesse im Zusammenhang mit dem C-Kreislauf ebenso bestimmt. Die Studie wurde nacheinander unter Feldbedingungen und Befeuchtung im Labor durchgeführt, die die saisonalen Effekte und den Einfluss der Bodenfeuchte, darstellen. Darüber hinaus wurde durch ein Experiment die Inkubation der Befeuchtung, die potenzielle Quelle von Nährstoffen (N, P), durch Messung der Enzym-Aktivitäten bewertet. 
Die wichtigsten Ergebnisse dieser Forschung zeigen, dass im Allgemeinen der Regen und die Feuchtigkeit einen positiven Effekt auf die biologischen, mikrobiologische und biochemischen Eigenschaften der Böden hatten. Zersetzungsprozesse während der Regenzeit zeigten einen höheren Anstieg und, bestätigten, dass die Niederschläge eine starke Wirkung haben. Ein weiterer Faktor sind Termiten und Ameisen, die einen hohen Einfluss auf den Zersetzungsprozess haben. Im Rahmen der biochemischen Eigenschaften, der alkalischen Phosphatase und $\beta$-Glucosidase wurden diese als potenzielle Indikatoren ermittelt. Dabei wurde die höchste Kapazität der Quelle der Nährstoffgehalt im Boden durch Aktivität aufgrund von Feuchtigkeit unter optimalen Niveau dieser Enzyme aufgezeigt.

Der Effekt der Bodennutzung wurde auch bei den mikrobiologischen und biochemischen Eigenschaften festgestellt. Es ist wichtig zu betonen, dass die Waldböden bei Feld- sowie Befeuchtungsbedingungen die höchsten Werte im Vergleich zu homegardens und milpa zeigten. In den Wäldern spielen Pilze hauptsächlich eine größere Rolle in den Bodenatmung, was darauf hinweist, dass sie über einen hohen Einfluss auf den Zersetzungsprozess bei verschiedener Bodennutzung haben. Dabei dient der Streu-Input auf dem Boden als Nährstoff (Immobilisierung) für die Pilzbiomasse. Der Rückgang der mikrobiellen und biochemischen Parameter in milpa und homegardens war zurückzuführen auf das kontinuierliche Entfernen von organischem Material aus den Böden. Dies spiegelt sich in einem negativen Effekt in der Produktivität dieses Ökosystems wieder. Auch die schwarzen Böden hatten aufgrund ihrer hohen organischen C-Gehalte höhere Werte, die mit den mikrobiellen und biochemischen Eigenschaften korrelierte. Somit bestätigt sich die Wichtigkeit des organischen Materials bezüglich der chemischen Eigenschaften des Bodens und ihre Auswirkungen sowie die Beziehung zu den biologischen und biochemischen Eigenschaften.

Abschließend werden die Ergebnisse des Inkubations-Experiments zu verstehen helfen, dass durch die Optimierung der Bodenfeuchtigkeit ein Potenzial von Nährstoffen zur Bodennutzung in Yukatan zur Verfügung gestellt werden kann. Diese Wasserzugabe könnte dazu beitragen, ein Verständnis zur Funktionsweise des Ökosystems zu entwickeln, bei besserer Verwaltung der Wasserressourcen. 


\section{REFERENCES}

Acosta-Martínez V., Cruz L., Sotomayor-Ramírez D., Pérez-Alegría L., 2007. Enzyme activities as affected by soil properties and land use in a tropical watershed. Appl. Soil Ecol. 35, 35-45.

Acosta-Martinez V., Reicher Z., Bischoff M., Turco R.F., 1999. The role of tree leaf mulch and nitrogen fertilizer on turfgrass soil quality. Biol. Fertil. Soils 29, 55-61.

Acosta-Martinez V., Tabatabai M.A., 2000. Enzyme activities in a limed agricultural soil. Biol. Fertil. Soils 31, 8591.

Adams M.A., 1992. Phosphatase activity and phosphorus fractions in Karri (Eucaliptus diversicolor F. Muell.) forest soils. Biol. Fertil. Soils. 14, 200-204.

Adeoye G.O., Agboola A.A., 1983. Relationship between soil physical and chemical characteristics and ear-leaf concentration of $\mathrm{P}, \mathrm{K}, \mathrm{Mg}, \mathrm{Zn}, \mathrm{Fe}, \mathrm{Cu}, \mathrm{Mn}$ and relative yield of maize in soils derived from sedimentary rocks of South-Western Nigeria. Fertilizer Research 5, 109-119.

Adu J.K., Oades J.M., 1978. Utilization of organic materials in soil aggregates by bacteria and fungi. Soil Biol. Biochem. 10, 117-122.

Agbenin J.O., Tiessen H., 1994. Phosphorus transformation in a toposequence of Lithosols and Cambisols from semi-arid northeastern Brazil. Geoderma 62, 342-362.

Aguila Alcantara E., 2007. Nutrient availability in calcareous soils from México and Cuba. PhD Thesis, GeorgAugust University, Goettingen, Germany.

Ajwa H.A., Dell C.J., Rice C.W., 1999. Changes in enzymes activities and microbial biomass of tallgrass prairie soil as related to burning and nitrogen fertilitazion. Soil Biol. Biochem. 31, 769-777.

Alef K., Nannipieri P., Trazar Cepeda C., 1995. Phosphatase activity. In: Methods in Applied Soil Microbiology and Biochemestry. (K. Alef and P. Nannipieri Eds.) Harcout Brace \& Company, pp. 335-344.

Alexander M., 1980. Introducción a la microbiología del suelo. AGT editor, S.A. México, D.F. 491 pp.

Alphei J., Bonkowski M., Scheu S., 1995. Application of the selective inhibition method to determine bacterial: fungal rations in three beechwood soils rich in carbon - Optimization of inhibitor concentrations. Biol. Fertil. Soils 19, 173-176.

Amador J.A., Goerres J.H., Savin M.C., 2005. Role of soil water content in the carbon and nitrogen dynamics of Lumbricus terrestris L. burrow soil. Appl. Soil Ecol. 28, 15-22.

Amador J.A., Jones R.D., 1997. Response of carbon mineralization to combined changes in soil moisture and carbon-phosphorus ratio in a low-phosphorus Histosol. Soil Sci. 162, 275-282.

Amato M., Ladd J.N., 1988. Assay for microbial biomass based on ninhydrin-reactive nitrogen in extracts of fumigated soils. Soil Biol. Biochem. 20, 107-114.

Amato M., Ladd J.N., 1992. Decomposition of ${ }^{14}$ C-labelled glucose and legume material in soils: Properties influencing the accumulation of organic residue $\mathrm{C}$ and microbial biomass C. Soil Biol. Biochem. 24, 455464.

Anderson E.N., 1993. Gardens in tropical America and tropical Asia. Biotica 1, 81-102. 
Anderson J.M., 1988. Spatiotemporal effects of invertebrates on soil proceses. Biol. Fertil. Soils 6, 216-227.

Anderson J.M., 1991. The effects of climate change on decompostion processes in grassland and coniferous forests. Ecological Applications 1, 326-347.

Anderson J.M., Proctor J., Vallack H., 1983. Ecological studies in four contrasting lowland rain forest in Gunung Mulu National Park, Sarawak III. Decomposition processes and nutrient losses from leaf litter. J. Ecol. 71, 503-527.

Anderson J.P.E., Domsch K.H., 1973. Quantification of bacterial and fungal contributions to soil respiration. Arch. Mikrobiol. 93, 113-127.

Anderson J.P.E., Domsch K.H., 1975. Measurement of bacterial and fungal contributions to respiration of selected agricultural and forest soils. Can. J. Microbiol. 21, 314-322.

Andrist Y., 2003. Investigation of soils, vegetation and management of homegardens in the henequen region, Yucatan, Mexico. SLU Communications. Minor Field Studies No. 245. Swedish University of Agricultural Sciences.

Aon M.A., Cabello M.N., Sarena D.E., Colaneri A.C., Franco M.G., Burgos J.L., Cortassa S., 2001. I. Spatiotemporal patterns of soil microbial and enzymatic activities in an agricultural soil. App. Soil Ecol. 18, 239254.

Aon M.A., Colaneri A.C., 2001. II Temporal and spatial evolution of enzymatic activities and physico-chemical properties in an agricultural soil. Appl. Soil Ecol. 18, 255-270.

Asmar F., Eiland F., Nielsen N.E., 1994. Effect of extracellular-enzyme activities on solubilization rate of organic nitrogen. Biol. Fertil. Soils 17, 32-38.

Association of Official Analytical Chemist, 1970. Official Methods of Analysis Ed. 11: Washington D.C.

Austin A.T., Vitousek P., 2000. Precipitation, decomposition and litter decomposability of Metrosideros polymorpha in native forests on Hawaii. J. Ecol. 88, 129-138.

Austin A.T., Yahdjian L., Stark J.M., Belnap J., Porporato A., Norton U., Ravetta D., Schaeffer S.M., 2004. Water pulses and biogeochemical cycles in semi-arid ecosystems. Oecologia 141, 221-235.

Badalucco L., Kuikman P.J., Nannipieri P., 1996. Protease and deaminase activities wheat rhizosphere and their relation to bacterial and protozoan populations. Biol. Fertil. Soils 23, 99-104.

Badaluco, L., Pomaré F., Grego, S., Landi L., Nannipieri P., 1994. Activity and degradation of streptomycin and cycloheximid in soil. Biol. Fertil. Soils 18, 334-340.

Badiane N.N.Y., Chotte J.L., Pate E., Masse D., Rouland C., 2001. Use of soil enzymes to monitor soil quality in natural and improved fallows in semi-arid tropical regions. Appl. Soil Ecol. 18, 229-238.

Bailey V.L., Smith J.L., Bolton H., 2003. Novel antibiotics as inhibitors for the selective respiratory inhibition method of measuring fungal: bacterial ratios in soil. Biol. Fertil. Soils 38, 154-160.

Bandick A.K., Dick R.P., 1999. Field management effects on soil enzyme activities. Soil Biol. Biochem. 31, 14711479.

Bardgett R.D., Hobbs P.J., Frostegård Å., 1996. Changes in soil fungal: bacterial biomass ratios following reductions in the intensity of management of an upland grassland. Biol. Fertil. Soils 22, 261-264. 
Bardgett R.D., Lovell R.D., Hobbs P.J., Jarvis S.C., 1999. Seasonal changes in soil microbial biomass communities along a fertility gradient of temperate grasslands. Soil Biol. Biochem. 31, 1021-1030.

Bargali S.S., Singh S.P., Singh R.P., 1992. Patterns of weight loss and nutrient release from decomposing leaf litter in an age series of eucalypt plantations. Soil Biol. Biochem. 25, 1731-1738.

Barros E., Pashana B., Constantino R., Lavelle P., 2002. Effect of land-use on the soil macrofauna in western Brazilian Amazonia. Biol. Fertil. Soils 35, 338-347.

Bastida F., Moreno J.L., Hernandez T., Garcia C., 2006a. Microbiological activity in a soil 15 years after devegetation. Soil Biol. Biochem. 38, 2503-2507.

Bastidas F., Moreno J.L., Hernandez T., Garcia C., 2006b. Microbiological degradation index of soils in a semiarid climate. Soil Biol. Biochem. 38, 3463-3473.

Baum C., Leinweber P., Schlichting A., 2003. Effects of chemical conditions in re-wetted peats temporal variation in microbial biomass and acid phosphatase activity within the growing season. Appl. Soil Ecol. $22,167-174$.

Beare M.H., Blair J.M., Parmelee R.W., 1989. Resource quality and trophic response to simulated throughfall: effect on decomposition and nutrient flux in a no tillage agroecosystem. Soil Biol. Biochem. 21, 1027-1036.

Beare M.H., Coleman D.C., Crossley Jr. D.A., Hendrix P.F., Odum E.P., 1995. A hierarchical approach to evaluating the significance of soil biodiversity to biogeochemical cycling. Plant Soil 170, 5-22.

Beare M.H., Parmelee R., Hendrix P.F., Cheng W., Coleman D.C., Crossley A. Jr., 1992. Microbial and fauna interaction and effects on litter nitrogen and decomposition in Agroecosystems. Ecol. Monogr. 62, 569-591.

Beck L., Gasparotto L., Foerster B., Franklin E., Garcia M., Harada A., 1998. The role of the soil fauna in litter decomposition inprimary forest, secondary forest and a polyculture plantation in Amazonia (SHIFT Project ENV 52): Methodological considerations. Proceedings of the Third SHIFT-Workshop, Manaus, 15-19 March. BMBF, Bonn, Germany, pp. 471-481.

Benjamin T.J., 2000. Maya cultural practices in Yucatan homegardens: An ecophisiological perspective. PhD Thesis, Purdue University, Italy.

Benjamin T.J., Montañez P.I., Jimenez J.J.M., Gillespie A.R., 2001. Carbon, water and nutrient flux in Maya homegardens in the Yucatan peninsula of Mexico. Agroforestry Systems 53, 103-111.

Berg B., McClaugherty C., 2003. Plant Litter: Decomposition, Humus Formation, Carbon Sequestration [M]. Berlin: Springer-Verlag, 286p.

Bergstrom D.W., Monreal C.M., King D.J., 1998. Sensitivity of Soil Enzyme Actvities to Conservation Practices. Soil Sci. Soc. Am. J. 62, 1286-1295.

Billore S.K., Ohsawa M., Numata M., Okano S., 1995. Microbial biomass nitrogen pool in soils from a warm temperate grassland, and from deciduous and evergreen forests in Chiba, central Japan. Biol. Fertil. Soils $19,124-128$.

Birch H.F., 1958. The effect of soil drying on humus decomposition and nitrogen availability. Plant Soil 10, 9-31.

Blagodatskaya E.V., Anderson, T.-H., 1998. Interactive effects of $\mathrm{pH}$ and substrate quality on the fungal-bacterial ratio and of microbial communities in forest soils. Soil. Biol. Biochem. 30, 1269-1274. 
Bloem J., de Ruiter P.C., Koopman G.J., Lebbink G., Brussard L., 1992. Microbial numbers and activity in dried and rewetted arable soil under integrated and conventional management. Soil Biol. Biochem. 24, 655-665.

Bloem J., Lebbink G., Zwart K.B., Bouwman L.A., Burgers S.L.G.E., Vos J.A., de Ruiter P.C., 1994. Dynamics of microorganisms, microbivorous and nitrogen mineralization in winter wheat field under conventional and integrated management. Agric. Ecosyst. Environ. 51, 129-143.

Boehme L., Boehme F., Langer U., 2004. Spatial variability of enzyme activities in a 100-year old long-term field experiment. Biol. Fertil. Soils 40, 153-156.

Boerner R.E.J., Brinkman J.A., Smith A., 2005. Seasonal variation in enzyme activity and organic carbon in soil of a burned and unburned hardwood forest. Soil Biol. Biochem. 37, 1419-1426.

Bolton H., Smith J.L., Link S.O., 1993. Soil microbial biomass and activity of disturbed and undisturbed shrubsteppe ecosystem. Soil Biol. Biochem 25, 545-552.

Bolton Jr H., Elliot L.F., Papendick R.I., Bezdicek D.F., 1985. Soil microbial biomass and selected soil enzyme activities: effect of fertilization and cropping practices. Soil Biol. Biochem. 17, 297-302.

Bonde T.A., Schnurer J., Rosswall T., 1988. Microbial biomass as a fraction of potentially mineralizable nitrogen in soils from long-term field experiments. Soil Biol. Biochem. 20, 447-452.

Bonmati M., Ceccanti B., Nanniepieri P., 1991. Spatial variability of phosphatase, urease, proteasem organic carbon and total nitrogen in soil. Soil Biol. Biochem. 23, 391-396.

Bonmati M., Ceccanti B., Nannipieri P., 1998. Protease extraction from soil by sodium pyrophosphatase and chemical characterizationof the extracts. Soil Biol. Biochem. 30, 2113-2125.

Bottner P., 1985. Response of microbial biomass to alternate moist and dry conditions in a soil incubated with ${ }^{14}$ $\mathrm{C}$ and ${ }^{15} \mathrm{~N}$-labelled plant material. Soil Biol. Biochem. 17, 329-337.

Boulton A.M. Amberman K., 2006. How ant nests increase soil biota richness and abundance: a field experiment. Biodiversity and Conservation 15, 69-82.

Brady N.C., 1990. The nature and properties of soil. Macmillan Publishing Company, NY, USA.

Brookes P.C., 1995. The use of microbial parameters in monitoring soil pollution by heavy metals. Biol. Fertil. Soils 19, 69-79.

Brookes P.C., Landman A., Pruden G., Jenkinson D.S., 1985. Chloroform fumigation and the release of soil nitrogen: A rapid direct extraction method for measuring microbial biomass nitrogen in soil. Soil Biol. Biochem. 17, 837-842.

Burns R.G., 1978. Soil Enzymes. Academics Press, London.

Burns R.G., 1982. Enzyme activity in soil: location and a possible role in microbial ecology. Soil Biol. Biochem. $14,423-427$.

Busto M.D., Perez-Mateos M., 1995. Extraction of humic- $\beta$-glucosidasefractions from soils. Biol. Fertil. Soils 20, 77-82.

Busto M.D., Perez-Mateos M., 2000. Characterization of $\beta$-D-glucosidase extracted from soil fractions. Eur. J. Soil Sci. 51, 193-200.

Caldwell B.A., Griffiths R.P., Sollins P., 1999. Soil enzyme response to vegetation disturbance in two lowland Costa Rican soils. Soil Biol. Biochem. 31, 1603-1608. 
Campo J., Jaramillo V.J., Maass J.M., 1998. Pulses of soil phosphorus availability in a tropical dry forest: effect of seasonality and level of wetting. Oecologia 115, 167-172.

Caravaca F., Masciandro G., Ceccanti B., 2002. Land use in relation to soil chemical and biochemical properties in a semiarid Mediterranean environment. Soil Till. Res. 68, 23-30.

Carpenter-Boggs L., Stahl P.D., Lindstrom M.J., Shumacher T.E., Soil microbial properties under permanent grass, conventional tillage, and no-till-managements in South Dakota. Soil Till. Res. 71, 15-23.

Caterino M.S., 2007. Species richness and complementarity of beetle faunas in a Mediterranean-type biodiversity hotspot. Biodiversity and Conservation 16, 3993-4007.

Ceccon E., Olmsted I., Vasquez-Llanes C., Campo-Alves J., 2002. Vegetation and soil properties in two tropical dry forests of differing regeneration status in Yucatan. Agrociencia 36, 621-631.

Chacón N., Dezzeo N., 2007. Litter decomposition in primary forest and adjacent fire-disturbed forest in the Gran Sabana, southern Venezuela. Short Communication in Biol. Fertil. Soils.

Chander K., Goyal S., Mundra M.C., Kapoor K.K., 1997. Organic matter, microbial biomass and enzyme activity of soils under different crop rotations in the tropics. Biol. Fertil. Soils 4, 306-310.

Chhonkar P.K., Tarafdar J.C., 1984. Accumulation of phosphatases in soils. J. Indian Soc. Soil Sci. 32, 266-272.

Clarholm M., 1993. Microbial biomass P, labile P, and acid phosphatase activity in the humus layer of a spruce forest after repeat additions of fertilizers. Biol. Fertil. Soils 16, 287-292.

Conant R., Klopatek J.M., Klopatek C.C., 2000. Environmental factors controlling soil respiration in three semiarid ecosystems. Soil Sci. Soc. Am. J. 64, 383-390.

Conesa A., Punt P.J., van den Hondel C., 2002. Fungal peroxidases: molecular aspects and applications. J. Biotechnol. 93, 143-158.

Cortet J., Joffre R., Elmholt S., Hennig Krogh P., 2003. Increasing species and trophic diversity of mesofauna affects fungal biomass, mesofauna community structure and organic matter decomposition processes. Bio. Fertil. Soils 37, 302-312.

Couteaux M.M., Bottner P., Berg B., 1995. Litter decomposition, climate and litter quality. Tree 10, 63-66.

Cragg R.G., Bardgett R.D., 2001. How changes in soil faunal diversity and composition within a trophic group influence decomposition processes. Soil Biol. Biochem. 33, 2073-2081.

Cuevas E., Medina E., 1986. Nutrient dynamics within Amazonian forest ecosystems. I. Nutrient flux in the litter fall and efficiency of nutrient utilization. Oecologia 68, 466-472.

Cui, M.Y., Caldwell, M.M., 1997. A large ephemeral release of nitrogen upon wetting of dry soil and corresponding root responses in the field. Plant and Soil 191, 291-299.Dalal R.C., 1977. Soil organic phosphorus. Adv Agron. 29, 83-117.

Curry J.P., 1987. The invertebrate fauna of grassland and its influence on productivity. 1. The composition of the fauna. Grass For. Sci. 42, 103-120.

Danin A., Yom-Tov, Y., 1990. Ant nests as primary habitats of Silybum marianum (Compositae). Plant Syst. Evol. 169, 209-217.

Dannenmann M., Gasche R., Ledebuhr A, Papen H., 2006. Effect of forest management on soil N cycling in beech forests stocking on calcareous soils. Plant Soil 287, 279-300. 
Dash M.C., Guru C.B., 1980. Distribution and seasonal variation in numbers of testacea (protozoa) in some Indian soils. Pedobiologia 20, 325-342.

De la Paz Jimenez M., de la Horra A.M., Pruzzo L., Palma R.M., 2002. Soil quality: a new index based on microbiological and biochemical parameters. Biol. Fertil. Soils 35, 302-306.

Dean W.R.J., Yeaton R.I., 1993. The influence of harvester ant Messor capensis nest mounds on the productivity and distribution of some plant species in the southern Karoo, South Africa. Vegetatio 106, 21-35.

De Luca T.H., Keeney D.R., 1993. Soluble anthrone-reactive carbon in soils: effect of carbon and nitrogen amendments. Soil Sci. Soc. Am. J. 57, 1296-1300.

Deng S.P., Tabatabai M.A., 1996. Effect of tillage and residue management on enzyme activities in soils: II. Glycosidase. Biol. Fertl. Soils, 22, 208-213.

Deng S.P., Tabatabai M.A., 1997. Effect of tillage and residue management on enzyme activities in soils: III. Phosphatases and arysulfatase. Biol. Fertl. Soils, 24, 141-146.

Dick R.P., 1992. A review: long effects of agricultural systems on soil biochemical and microbial parameters. Agric. Ecosys. Environ. 40, 25-36.

Dick R.P., 1994. Soil enzymes as indicators of soil quality. In: Doran J.W., Coleman D.C., Bezdicek D.F., Stewart B.A., (eds.) Defining soil quality for a sustainable environment. SSSA special publication No. 35. Madison, Wis. pp. 107-124.

Dick R.P., Breakwell D.P., Turco R.F., 1996. Soil enzyme activities and biodiversity measurements as integrative microbiological indicators, Methods for Assessing Soil Quality, vol. 9. Soil Science Society of America, Madison, WI pp. 9-17.

Dick R.P., Rasmussen P.E., Kerle E.A., 1987. Kinetic parameters of enzyme activities as influenced by organic residues and $\mathrm{N}$ fertilizer management. In: Agronomy Abstracts. $79^{\text {th }}$ Annual Meeting (Atlanta, GA, 1987). American Society of Agronomy, Madison, WI.

Dick R.P., Rasmussen P.E., Kerle E.A., 1988. Influence of long-term residue management on soil enzyme activity in relation to soil chemical properties of a wheat-fallow system. Biol. Fertil. Soils 6, 159-164.

Dick R.P., Sandor J.A., Eash N.S., 1994. Soil enzyme activities after 1500 years of terrace agriculture in the Colca Valley, Peru. Agric. Eco. Environ. 50, 123-131.

Dick W.A., 1984. Influence of long-term tillage and crop rotation combinations on soil enzyme activities. Soil Sci. Soc. Am. J. 48, 569-574.

Dick W.A., Tabatabai M.A., 1984. Kinetic parameters phosphatases in soils and organic-waste materials. Soil Sci. 137, 7-15.

Dixon M., Webb E.C., 1979. Enzymes, 3rd edn. Longman, London.

Doormaar J.F., Johnston A., Smoliak S., 1984. Seasonal changes in carbon content, and dehydrogenase, phosphatase and urease activities in mixed prairie and fescue grassland Ah Horizons. J. Range Manag. 37, 31-35.

Doran J.W., 1980. Soil microbial and biochemical changes associated to reduced tillage. Soil Sci. Soc. Am. 44, 765771. 
Dormaar J.F., Johnston A., Smoliak S., 1984. Seasonal changes in carbon content and dehydrogenase, phosphatase and urease activities in mixed prairie and fescue grassland Ah horizons. J. Ran. Manag. 37, 31-35.

Duch G, J., 1988. La conformación territorial del estado de Yucatán. Los componentes del medio físico. Universidad Autónoma de Chapingo, México. pp 29-34.

Duch G.J., 1991. Fisiografía del estado de Yucatán. Su relación con la agricultura. Universidad Autónoma de Chapingo, México.

Duch G.J., 1994. Los suelos, la agricultura y vegetación en Yucatán. pp. 97-107. In: E. Hernandez X, et al. (ed.) La milpa en Yucatán: Un sistema de producción agrícola tradicional. Vol. 1. Colegio de Posgraduado, México.

Dumontet S., Mazzatura A., Casucci C., Perucci P., 2001. Effectiveness of microbial indexes in discriminating interactive effects of tillage and crop roattions in a Vertic Ustirthens. Biol. Fertil. Soils 34, 411-416.

Dyer M.L., Meentemeyer V., Berg B., 1990. Apparent controls of mass loss rate of leaf litter on a regional scale. Scan. J. Forest Res. 5, 311-323.

Eggleton P., Homathevi R., Jeeva D., Jones D., Davis R.G., Maryati M., 1997. The species richness and composition of termites (Isoptera) in primary and regenerating lowland dipterocarp forest in Sabah, East Malaysia. Ecotropica 3, 119-128.

Ehlers W., Goss M., 2003. Water Dynamics in Plant Production. pp 16-19.

Einsenbeis G., Lenz R., Dogan H., Schüler G., 1996. Biologische Aktivität von Nadelwaldböden: Messungen der tierischen Fraßaktivität mit dem Köderstreifentest sowie Bestimmung von Streueabbauraten mit dem Minicontainert. Verh. Ges. Ökol. 26, 305-312.

Eivazi F., Bayan M.R., 1996. Effects of long-term prescribed burning on the activity of selected soil enzymes in an oak-hickory forest. Cana. J. For. Res. 26, pp. 1799-1804.

Eivazi F., Tabatabai M. A. 1990. Factors affecting glucosidase and galactosidase activities in soils. Soil Biol. Biochem. 22, 891-897.

Eivazi F., Tabatabai M.A., 1988. Glucosidase and galactosidases in soils. Soil Biol. Biochem. 20, 601-605.

Elkins N., Whitford W., 1982. The role of microarthropods and nematodes in decomposition in a semi-arid ecosystem. Oecologia 55, 303-310.

Elliot E.T., Anderson R.V., Coleman D.C., Cole C.V., 1980. Habitable pore space and microbial trophic interactions. Oikos 35, 327-335.

Emmett B.A., Beire C., Estiarte M., Tietema A., Kristensen H., Williams D., Peñuela J., Schmidt I., Sowerby A., 2004. The response of soil processes to climate change: Results for manipulation studies of shrublands across an environmental gradient. Ecosystems 7, 625-637.

Esen A., 1993. $\beta$-Glucosidases: overview, in: Esen, A. (Ed.), $\beta$-Glucosidases: biochemistry and molecular biology. American Chemical Society, Washington, DC, pp. 1-14.

Estrada H., 2000. Caracterización and cartografia del recurso suelo del municipio de Hocaba, Yucatán. MSc Thesis. Universidad Autánoma de Yucatán, Mexico.

Evans R.D., Ehleringer J.R., 1994. Water and nitrogen dynamics in an arid woodland. Oecologia 99, 233-242.

Fierer N., Schimel J.P., 2002. Effects of drying-rewetting frequency on soil carbon and nitrogen transformations. Soil Biol. Biochem. 34, 777-787. 
Filip Z., 2002. International approach to assessing soil quality by ecologically-related biological parameters. Agriculture, Ecosystems and Environment 88, 169-174.

Filser J., 2002. The role of Collembola in carbon and nitrogen cycling in soil. Pedobiologia 46, 234-245.

Filser J., Dette A., Fromm H., Lang A., Mebes K-H., Munch J.C., Nagel R., Winter K., Beese F., 1999. Reactions of soil organisms to site-specific management: the first long-term study at the landscape scale. In: Windhorst, W., Enckell, P.H. (Eds.), Proceedings of the Conference Sustainable Landuse Management The Challenge of Ecosystem Protection. 28.9.-1.10.99. Salzau Federal Cultural Center, Organizers: University of Kiel/European Ecological Federation EcoSys Supplementband, 28, pp. 139-147.

Filser J., Fromm H., Nagel R.F., Winter K., 1995. Effects of previous intensive agricultural management on microorganisms and the biodiversity of soil fauna. Plant Soil 170, 123-129.

Fitzpatrick E.A., 1996. Introducción a la ciencia de los suelos. Trillas Ed. México.

Flores S.J., Espejel C.I., 1994. Tipos de vegetacián de la Peninsula de Yucatan. Vol. 3: Sostenibilidad Maya. Universidad Autónoma de Yucatán, Mexico.

Floret C.R., Pontainer R., Rambal S., 1982. Measurenment and modelling of primary production and water use in a south Tunisian steppe. J. Arid Environ. 5, 77-90.

Fox R.H., Myers R.J.K., Vallis I., 1990. The nitrogen mineralization rate of legume residues in soil as influencedby their polyphenol, lignin, and nitrogen content. Plant Soil 129, 251-259.

Frankenberger W.T. Jr., Dick W.A., 1983. Relationships between enzyme activities and microbial growth and activity indices in soil. Soil Sci. Ame. J. 47: 945-951.

Frankland J.C., 1998. Fungal succession-unravelling the unpredictable. Mycol. Res. 102, 1-15.

Friedel J.K, Munch J.C, Fischer W.R., 1996. Soil microbial properties and the assessment of available soil organic matter in a haplic luvisol after several years of different cultivation and crop rotation. Soil Biol. Biochem. 8, 479-488.

Fromm H., Winter K., Filser J., Hantschel R.E., Beese F., 1993. The influence of soil type and cultivation system on the spatial distributions of the soil fauna and microorganisms and their interactions. Geoderma 60, 109118.

Gaillard V., Chenu C., Recous S., Richards G., 1999. Carbon, nitrogen and microbial gradients induced by plantresidues decomposing in soil. Eur. J. Soil Sci. 50, 567-578.

Gallardo A., Schlesinger W.H., 1995. Factors determining soil microbial biomass and nutrient immobilization in desert soils. Biogeochemistry 28, 55-68.

Garcia C., Hernandez T., Costa F., 1994. Microbial activity in soils under Mediterranean environmental conditions. Soil Biol. Biochem. 26, 1185-1191.

Garcia C., Hernandez T., Roldan A., Albaladejo J., 1997. Biological and biochemical quality of a semiarid soil alter induced devegetation. J. Environ. Qual. 26, 1116-1122.

Geissen V., Brümmer G.W., 1999. Decomposition rates and feeding activities of soil fauna in deciduous forest soils in relation to soil chemical parameters following liming and fertilization. Biol. Fertil. Soils 29, 335-342.

George T.S., Gregory P.J., Robinson J.S., Buresh R.J., Jama B., 2002. Utilization of organic P by agroforestry and crop species in the field, western Kenya. Plant Soil 246, 53-63. 
Gholz H.L., Wedin D.A., Smitherman S.M., Harmon M.E. Parton W.J., 2000. Long-term dynamics of pine and hardwood litter in contrasting environments: toward and global model of decomposition. Glob. Change Biol. 6, 751-765.

Gianfreda L., Rao M.A., Piotrowska A., Palumbo G., Colombo C., 2005. Soil enzyme activities as affected by anthropogenic alterations: intensive agricultural practices and organic pollution. Scie. Total Environm. 341, 265-279.

Gil-Sotres F., Trasar-Cepeda C., Leirós M.C., Seoane S., 2005. Different approaches to evaluating soil quality using biochemical properties. Soil Biol. Biochem. 37, 877-887.

Goerres J.H., Savin M.C., Neher D.H., Weicht T.R., Amador J.A., 1999. Grazing in a porous environment: I. The effect of pore structure on C and N mineralization. Plant Soil 212, 75-83.

Goldstein A.H., Baertlein D.A.S., McDaniel R.G., 1988. Phosphatate starvation inducible metabolism in Lycopersicum esculentum. Part I. Excretion of acid phosphatase by tomato plants and suspension-cultured cells. Plant Physiology 87, 711-715.

González G., Ley R.E., Schmidt S.K., Zou X., Seastedt T.R., 2001. Social ecological interactios: comparisons between tropical and subalpine forests. Oecologia 128, 549-556.

Graefe S., 2003. Crop and soil variability in traditional and modern Mayan maize cultivation of Yucatan, México. In: Journal of Agricultural and Rural Development in the Tropics and Subtropics. Beiheft 75, Kassel University press $\mathrm{GmbH}$.

Greenstone M.H., 2001. Spiders in wheat: first quantitative data for North America. BioControl 46, 439-454.

Gunapala N., Venette R.C., Ferris H., Scow K.M., 1998. Effect of soil management hystory on the rate of organic matter decomposition. Soil Biol. Biochem. 30, 1917-1927.

Gupta S.R., Singh J.S., 1981. The effect of plant species, weather variables and chemical composition of plant material on decomposition in a tropical grassland. Plant and Soil 59, 99-117.

Harris R.F., 1981. Effect of water potential on microbial growth and activity. In: Parr J.F., Gardner W.R., Elliot L.F. (eds) Water potential relations in soil microbiology. Soil Science Society of America Madison, Wis.

Harrison A..F., Pearce T., 1979. Seasonal variation of phosphatase activity in woodland soils. Soil Biol. Biochem. $11,405-410$.

Harrison A.F., 1983. Relationship between intensity of phosphatase activity and physico-chemical properties in woodland soils. Soil Biol. Biochem. 15, 93-99.

Harte J., Kinzig A.P., 1993. Mutualism and competition between plants and decomposers -implications for nutrient allocation in ecosystems. Am. Nat. 141, 829-846.

Hassink J., Bouwman L.A., Zwart K.B., Brussart L., 1993. Relationships between habitable pore space, soil biota and mineralization rates in grassland soils. Soil Biol. Biochem. 25, 47-55.

Häussling M., Marschner H., 1989. Organic and inorganic soil phosphatase activity in the rhizosphere of 80-yearold Norway spruce. Bio. Fertil. Soils 8, 128-133.

Hawksworth D.L., 1991. The fungal dimension of biodiversity: Magnitude, significance, and conservation. Mycol. Res. 95, 641-655. 
Hayano K., 1996. Characterization and origin of protease activity in cultivated soils. Jap. Agric. Res. Quart. 30, 79-84.

Hayano K., Tubaki K., 1985. Origin and properties of ß-glucosidase activity of tomato-field soil. Soil Biol. Biochem. 17, 553-557.

Hayano K., Watanabe K., 1990. Characterization of extracellular protease in paddy field soils. $14^{\text {th }}$ International Congress of Soil Science, Kyoto, Japan, pp. 270-271.

Haynes R.J., 1987. The use of polyethylene mulches to change soil microclimate as revealed by enzyme activity and biomass nitrogen, sulphur and phosphorus. Biol. Ferl. Soils. 5, 235-240.

Hector A., Schmid B., Beierkuhnlein C., Caldeira M.C., Diemer M., Dimitrakopoulos P.G., Finn J.A., Freitas H., Giller P.S.,Good J.,Harris R.,Hoegberg P., Huss-Danell K., Joshi J., Jumpponen A., Koerner C., Leadley P.W., Loreau M., Minns A., Mulder C.P.H., O ’Donovan G., Otway S.J., Pereira J.S., Prinz A., Read D.J., Scherer-Lorenzen M., Schulze E.D., Siamantziouras A.S.D., Spehn E.M., Terry A.C., Troumbis A.Y., Woodward F.I., Yachi S., Lawton J.H., 1999. Plant diversity and productivity experiments in European grasslands. Science 286, 1123-1127.

Heim A., Frey B., 2004. Early stage litter decomposition rates for Swiss forest. Biogeochemestry 70, 299-313.

Hendrickson O.Q., 1985. Variation in the C: N ratio of substrate mineralized during forest humus decomposition. Soil Biol. Biochem. 17, 435-440.

Hendrix P.F., Parmelee R.W., Crossley D.A. Jr., Coleman D.C., Odum E.P., Groffman P.M., 1986. Detritus food webs in conventional and no-tillage agroecosystems. BioScience 36, 374-380.

Herbien S.A., Neal J.L., 1990. Soil pH and phosphatase activity. Comm. Soil Scie. Plant Anal. 21, 439-456.

Hernández T., Garcia C., Reinhardt I., 1997. Short-term of wildfire on the chemical, biochemical and microbiological properties of Mediterranean pine forest soils. Biol. Fertil. Soils, 25, 109-116.

Hernández X. E., 1959. La agricultura. In E. Beltram (ed.) Los recursos naturales del sureste y su aprovechamiento. Volumen 3. pp. 3-57. Instituto Mexicano de Recursos Naturales Renovables, A.C., México.

Hernández X. E., Levy Tacher E. S., Bello Baltazar E., 1994. La roza-tumba-quema en Yucatán. In E. Hernández X., et al. (ed.) La milpa en Yucatán: Un sistema de producción agrícola tradicional. Volumen 1. pp. 36-86. Colegio de Postgraduados, México.

Hillel D., 1971. Soil and Water: Physical Principles and Processes. In: Kozlowski T.T (Eds.), Physiological Ecology. pp.185-187.

Höfer H., Hanagarth W., Garcia M., Martius C., Franklin E., Roembke J., Beck L., 2001. Structure and function of soil fauna communities in Amazonian anthropogenic and natural ecosystems. Eur. J. Soil Biol. 37, 229235.

Höfer H., Martius C., Beck L., 1996. Decomposition in an Amazonian rain forest after experimental litter addition in small plots. Pedobiol. 40, 570-576.

Höfer H., Martius C., Hanagarth W., Garcia M., Franklin E., Römbke J., Beck L., 2000. Soil fauna and litter decomposition in primary and secondary forest and a mixed culture system in Amazonia. Final report of SHIFT project ENV 52. BMBF, Bonn, Germany. 
Holland E.A., Coleman D.C., 1987. Litter placement effects on microbial and organic matter dynamis in an agroecosystems. Ecology 68, 425-433.

Holt F.D., 1987. Carbon mineralisation in semi-arid nort eastern Australia: the role of termites. J. Trop. Ecol. 3, 255-263.

Holt J.A., Mayer R.J., 1998. Changes in microbial biomass and protease activities of soil associated with longterm sugar cane monoculture. Bio. Fertil. Soils 27, 127-131.

Horwath W.R., Paul E.A., 1994. Microbial biomass. In: Weaver RW, Angel GS, Bottomley PS (eds) Methods of soil analysis, part 2. Book Series No. 5. SSSA, Madison, Wis., pp 753-773.

Hossain A.K.M.A., Raison R.J., Khanna P.K., 1995. Effect of fertilizer application and fire regime on soil microbial biomass carbon and nitrogen, and nitrogen mineralization in an Australian subalpine eucalypt forest. Biol. Fertl. Soil 19, 246-252.

House G.J., Brust G.E., 1989. Soil arthropods from weed and crop roots of an agroecosystem in a wheat-soybeancorn rotation: impact of tillage and herbicides. Agric. Ecosystems Environ. 25, 233-244.

Howard D.M., Howard P.J.A., 1993. Relationships between $\mathrm{CO}_{2}$ evolution, moisture content and temperature for a range of soil types. Soil Biol. Biochem. 25, 1537-1546.

Huhta V. 1971. Succession in the spider communities of the forest floor after clear-cutting and prescribed burning. Ann. Zool. Fenn. 8, 483-542.

Huston M.A., Aarssen L.W., Austin M.P., Cade B.S., Fridley J.D., Garnier E., Grime J.P., Hodgson J., Lauenroth W.K., Thompson K., Vandermeer J.H., Wardle D.A., 2000. No consistent effect of plant diversity on productivity. Science 289, 1255.

INEGI, 1995. Anuario estadístico del Estado de Yucatán. Gobierno del Estado de Yucatán.

Ingham E.R., Trofymow J.R., Armes R.N., Hunt H.W., Morley C.R., Moore J.C., Coleman D.C., 1986. Trophic interactions and nitrogen cycling in a semi-arid grassland soil II. System responses to removal of different groups of soil microbes or fauna. J. App. Ecol. 23, 615-630.

Ingham R.E., Trofymow J.A., Ingham E.R., Coleman D.C., 1985. Interactions of bacteria, fungi, and their nematode grazers: effects of nutrient cycling and plant growth. Ecol. Monog. 55, 119-140.

Insam H., 1990. Are the soil microbial biomass and basal respiration governed by the climatic regime? Soil Biol. Biochem. 22, 525-532.

IPCC, 2001. Climate change 2001: the scientific basis. In: Houghton J.T., Dung Y., Noguer M., Van der Linden P.J., Dui X., Maskell K.,Johson C.A. (eds.) Contribution of working group I. Third assessment report of intergovernmental panel on climate change. Cambrige Universoty Press, Cambrige, pp. 881.

James J.J., Richards J.H., 2006. Plan nitrogen capture in pulse-driven systems: interaction between root responses and soil processes. J. Ecol. 94, 765-777.

James J.J., Richards J.H., 2007. Influence of temporal heterogeneity in nitrogen supply on competitive interactions in a desert shrub community. Oecologia 152, 721-727.

Jastrow J.D., Amonette J.E., Bailey V.L., 2007. Mechanisms controlling soil carbon turnover and their potential application for enhancing carbon sequestration. Climatic Change 80, 5-23. 
Jenkinson D.S., Ladd J.N., 1981; Microbial biomass in soil: measurement and turnover. In: Paul, E.A., Ladd, J.N. (Eds.), Soil Biochemistry, vol. 5. Marcel Dekker, New York, pp. 415-471.

Joergensen R.G., 1995. Die quantitative Bestimmung der mikrobiellen Biomasse in Böden mit der ChloroformFumigations-Extraktions-Methode. In: Meyer B. (ed) Göttinger Boden-kundliche Berichte, Vol 104. Justus von Liebig, Göttingen, pp. 1-229.

Joergensen R.G., Brookes P.C., 1990. Ninhydrin-reactive measurement of microbial biomass in $0.5 \mathrm{M} \mathrm{K}_{2} \mathrm{SO}_{4}$ soil extracts. Soil Biol. Biochem. 22, 1023-1027.

Joffre R., Ågren G., 2001. From plant to soil: litter production and decomposition. In: Roy J, Saugier B, Mooney HA (eds) Global territrial productivity: past, present, future. Academic Press, San Diego, Calif., pp. 83-99.

Joner E.J., Magid J., Gahoonia T.S., Jakobsen I., 1995. Depletion and activity of phosphatases in the rhizosphere of mycorrhizal and non-mycorrhizal cucumber (Cucumis sativus L.). Soil Biol. Biochem. 27, 1145-1151.

Jones J.A., 1990. Termites, soil fertility and carbon cycling in dry tropical Africa: a hypothesis. J. Trop. Ecol. 6, 291-305.

Jordan D., Kremer R.J., Bergfield W.A., Kim K.Y, Cacnio V.N., 1995. Evaluation of microbial methods as potential indicator of soil quality in historical agricultural fields. Bio. Fertil. Soil 19, 297-302.

Juma N.G., Tabatabai M.A., 1978. Distribution of phosphomonoesterases in soils. Soil Sci. 126, 101-108.

Kandeler E., Gerber H., 1988. Short-term assay of soil urease activity using colorimetric determination of ammonium. Biol. Fertil. Soils 6, 68-72.

Kandeler E., Kampichler C., Horak O., 1996. Influence of heavy metals on the functional diversity of soil communities. Biol. Fertil. Soils 23, 299-306.

Kandeler E., Palli S., Stemmer M., Gerzabeck M., 1999. Tillage changes microbial biomass and enzyme activities in particle-size fractions of Haplic Chernozem. Soil Biol. Biochem. 31, 1253-1264.

Kandeler E., Tscherko D., Bruce K.D., Stemmer M., Hobbs P.J., Bardgett R.D., Amelung W., 2000. Structure and function of the soil microbial community in microhabitats of a heavy metal polluted soil. Soil Biol. Biochem. 32, 390-400.

Ke X., Winter K., Filser J., 2005. Effect of soil mesofauna and farming management on decomposition of clover litter: microcosm experiment. Soil Biol. Biochem. 37, 731-738.

Kennedy A.C., Papendick R.I., 1995. Microbial characteristics of soil quality. J. Soil Water Cons. 50: $243-248$.

Kieft T.L., Soroker E., Firestone M.K., 1987. Microbial biomass response to a rapid increase in water potential when dry soil is rewetted. Soil Biol. Biochem. 19, 119-126.

Knight T., Dick R.P., 2004. Differentiating microbial and stabilized B-glucosidase activity relative to soil quality. Soil Biol. Biochem. 36, 2089-2096.

Kraemer S., Green D.M., 2000. Acid and alkaline phosphatase dynamics and their relationship to soil microclimate in a semiarid woodland. Soil Biol Biochem. 32, 179-188.

Kuikman P.J., Jansen A.G., Van Veen J.A., Zehnder A.J.B., 1990. Protozoan predation and the turnover of soil organic carbon and nitrogen in the presence of plants, Biol. Fertil. Soils 10, 22-28.

Kurzatkowski D., Martius C., Höfer H., Garcia M., 2004. Litter decomposition, microbial biomass and activity of soil organisms in three agroforestry sites in central Amazonia. Nutr. Cycling Agroecosyst. 69, 257-267. 
Ladd J.N., 1978. Origin and range of enzymes in soil. In: Soil Enzymes. Burns RG (Eds.) Academics Pressn New York, pp. 51-96.

Ladd J.N., 1985. Soil enzymes. In: Soil Organic Matter and Biological Activity (Vaughan, D., Malcom, R.E. Eds.), Boston, pp. 175-221.

Ladd J.N., Paul E.A., 1973. Changes in enzymatic activity and distribution of acid-soluble, amino acid-nitrogen in soil during nitrogen immobilization and mineralization. Soil Biol. Biochem. 5, 825-840.

Lajtha K., Schlesinger W.H., 1988. Factors affecting phosphate sorption and phosphate retention in a desert soil ecosystem, Soil Sci. 146, 160-167.

Lal R., 1988. Effect of macrofauna on soil properites in tropical ecosystems. Agric. Ecosys. Environm. 24, 101116.

Lal R., 2002. Soil carbon dynamics in cropland and rageland. Environ. Poll. 116, 353-362.

Landi L., Renella G., Moreno J.L., Falchini L., Nannipieri P., 2000. Influence of cadmium on the metabolic quotient, L-D-glutamic acid respiration ratio and enzyme activity: microbial biomass ratio under laboratory conditions. Biol. Fertil. Soils 32, 8-16.

Lassau S.A., Hochuli D.F., Cassis G., Reid C.A.M., 2005. Effects of habitat complexity on forest beetle diversity: do functional groups respond consistently?. Divers. Distrib. 11, 73-82.

Lavelle P., 2002. Functional domains in soils. Ecol. Res. 17, 441-450.

Lavelle P., Barros E., Blanchart E., Brown G., Desjardins T., Mariani L., Rossi J-P., 2001. SOM management in the tropics: Why feeding the soil macrofauna? Nut. Cyc. Agroeco. 61, 53-61.

Lavelle P., Blanchart E., Martin S., 1993. A hierarchical model for decomposition in terrestrial ecosystems: application to soils of the humid tropics. Biotropica 25, 130-150.

Law B.A., 1980. Transport and utilization of proteins by bacteria. In: J.W. Payne (ed.). Microorganisms and Nitrogen Sources, John Wiley and Sons, London, pp. 341-409.

Leprince F., Quiquampoix H., 1996. Extracellular enzyme activity in soil: effect of $\mathrm{pH}$ and ionic strength on the interaction with montmorillonite of two acid phosphatases secreted by the ectomycorrhizal fungus Hebeloma cylindrosporum. Eur. J. Soil Sci. 47, 511-522.

Li X., Chen Z., 2004. Soil microbial biomass $\mathrm{C}$ and $\mathrm{N}$ along a climatic transect in the Mongolian steppe. Biol. Fertil. Soils 39, 344-351.

Li X., Sarah P., 2003. Enzyme activities along a climatic transect in the Judean Desert. Catena 53, 349-363.

Lindenmann W.C., Lindsey D.L., Fresquez P.R., 1984. Amendment of mine spoil to increase the number and activity of microorganisms. Soil Sci. Soc. Am. J. 48, 574-578.

Lobry de Bruyn L.A., Conacher A.J., 1990. The role of termites and Ants in soil modification: A review. Aust. J. Soil Res. 28, 55-93.

Lodge D.J., Mc Dowell W.H., Mc Swiney C.P., 1994. The importance of nutrients pulses in tropical forest. Trend. Ecol. 9, 384-387.

Loll M.J., Bollag J.M., 1983. Protein transformation in soil. Adv. Agron. 36, 351-382.

Luettge U., 1977. Physiological ecology of tropical plants. Springer-Verlag, Saladruck Berlin, Germany. 384 pp. 
Luizão F.J., Proctor J., Thompson J., Luizão R.C.C., Marrs R.H., Scott D.A. Viana, V., 1998. Rain forest on Maracá Island, Roraima, Brazil: soil and litter process response to artificial gaps. For. Ecol. Manag. 102, 291-303.

Lund V., Gorkscryr J., 1980. Effects of water fluctuations on microbial mass and activity in soil. Micro. Ecol. $6,115-123$.

Lundquist E.J., Jackson L.E., Scow K.M., 1999a. Wet-dry cycles affect dissolved organic carbon in two California agricultural soils. Soil Biol. Biochem. 31, 1031-1038.

Lundquist E.J., Scow K.M., Jackson L.E., Uesugi S.L., Johnson C.R., 1999b. Rapid response of soil microbial communities from conventional, low input, and organic farming systems to a wet/dry cycle. Soil Biol. Biochem. 31, 1661-1675.

Lussenhop J., 1996. Collembola as mediators of microbial symbiont effects upon soybean. Soil Biol. Biochem. 28, 363-369.

Magid J., Kjaergaard C., Gorissen A., Kuikman P.J., 1999. Drying and rewetting of a loamy sand soil did not increase the turnover of native organic matter, but retarded the decomposition of ${ }^{14} \mathrm{C}$-labelled plant material. Soil Biol. Biochem. 31, 595-602.

Magnan N., Lynch J.M., 1986. Water potential, growth and cellulolysis of fungi involved in decomposition of cereal residues. J. Gen. Microbiol. 132, 1181-1187.

Marinissen J.Y.C., deRuiter, P.C., 1993. Contribution of earthworms to carbon and nitrogen cycling in agroecosystems. Agric. Ecosyst. Environ. 47, 59-74.

Martin A., 1991. Short- and long-term effects of the endogeic earthworm Millsonia anomala (Omodeo) (Megascolecidae, Oligochaeta) of tropical savanna, on soil organic matter. Bio. Fertil. Soil 11, 234-238,

Martius C., 1994. Diversity and ecology of termites in Amazonian forests. Pedobiologia 38, 407-428.

Marumoto T., Anderson J.P.E., Domsch K.H., 1982. Mineralization of nutrients from soil microbial biomass. Soil Biol. Biochem. 14, 469-475.

Marumoto T., Anderson J.P.E., Domsch K.H., 1982. Mineralization of nutrients for soil microbial biomass. Soil Biol. Biochem. 14, 469-475.

Mayor X., Belmonte R., Rodrigo A., Rodà F., Piñol J., 1994. Crecimiento diametral de la encina (Quercus ilex L.) en un año de abundante precipitación estival: efecto de la irrigación previa y de la fertilización. Orsis 9, 13-23.

Mazzarino M.J., Oliva L., Abril A., Acosta M., 1991. Factors affecting dynamics in a semiarid woodland (Dry Chaco, Argentina), Plant and Soil 138, 85-98.

McGill W.B., Cannon K.R., Robertson J.A., Cook F.D. 1986. Dynamics of soil microbial biomass and watersoluble organic $\mathrm{C}$ in Breton L after 50 years of cropping to two rotations. Can. J. Soil Sci. 66, 1-19.

McGill W.B., Cole C.V. 1981. Comparative aspects of C, N, S and P cycling through soil organic matter during pedogenesis. Geoderma 26, 267-286.

McIver J.D., Parsons G.L., Moldenke A.R., 1992. Litter spider succession after clear-cutting in a western coniferous forest. Can. J. Forest Res. 22, 984-992. 
Mebes K.-H., Filser, J., 1998. Does the species composition of Collembola affect nitrogen turnover? App. Soil Ecol. 9, 241-247.

Methods of Soils Analysis. Part 1: Physical and Mineralogical Methods. Arnold Klute Ed. American Society of Agronomy, Inc. Soil Science Society of America, Inc.1986. Madison, Wisconsin USA..

Misra A., Tyler R.J., 1999. Influence of the soil moisture and soil solution chemistry and concentration of minerals in the calcicoles Phleum phleoides and Veronica spicata grown on a limestone soil. Annals of Botany 84, 401-410.

Mitscherlich A., 1949. Bodenkunde für Landwirte, Forstwirte und Gärtner. (5. Auflage). Max Nieneyer Verlag Halle (Saale). pp. 79-80.

Montañez P., 1998. Producción de hojarasca y aporte de nutrimentos en los huertos familiares de Hocabá y Sacabá, Yucatan, México. Master Thesis. FMVZ, Universidad Autónoma de Yucatan.

Moore J.C., Walter D.E., Hunt H.W., 1988. Arthropod regulation of micro- and mesobiota in below-ground detrital food webs. Ann. Rev. Entomol. 33, 419-439.

Moore J.M., Klose S., Tabatabai M.A., 2000. Soil microbial biomass carbon and nitrogen as affected by cropping systems. Biol. Fértil. Soils 31, 200-210.

Moscatelli M.C., Fonck M., De Angelis P., Larbi H., Macuz A., Rambelli A., Grego S., 2001. Mediterranean natural forest living at elevated carbon dioxide : soil biologiacal properties and plant biomass growth. Soil Manage. 17, 195-202.

Motaña C., Ezcurra E., Carrillo A., Delhoume J.P., 1988. The decomposition of litter in grasslands of northern Mexico: a comparison between arid and non-arid environments. J. Arid Environ. 14, 55-60.

Moya García X., Caamal A., Ku Ku B., Chan Xool E., Armendariz I., Flores J., Moguel J., Noh Poot M., Rosales M., Xool Domínguez J., 2003. La agricultura campesina de los mayas en Yucatán. LEISA. Edición especial pp.7-17.

Mueller T., Joergensen R.G., Meyer B., 1992. Estimation of soil microbial biomass C in the presence of living roots by fumigation-extraction. Soil Biol. Biochem. 24, 179-181.

Nadeau J.A., Qualls R.G., Nowak R.S., Blank R.R., 2007. The potential bioavailability of organic C, N, and P through enzyme hydrolysis in soils of Mojave Desert. Biogeochemestry 82, 305-320.

Nagel R.F., Frmm H., Beese, F., 1995. The influence of earthworms and soil mesofauna on the $\mathrm{C}$ and $\mathrm{N}$ mineralisation in agricultural soils-a microcosm study. Acta Zoo. Fenn. 196, 22-26.

Nakas J.P., Gould W.D., Klein D.A., 1987. Origin and expression of phosphatase activity in a semi-arid grassland soil. Soil Biol. Biochem. 19, 13-18.

Nakas J.P., Klein D.A., 1980. Mineralization capacityof bacteria and fungi rhizosphere-rhizosphere of semiarid grassland. Appl. Environ. Microbiol. 39, 113-117.

Nannipieri P., 1994. The potential use of soil enzyme as indicators of productivity, sustainability and pollution, in: Pankhurst, C.E., Double, B.M., Gupta, V.V.S.R., Grace, P.R. (Eds.), Soil Biota: Management in Suitainable Farming Systems. CSIRO, Melbourne, pp. 238-244.

Nannipieri P., Ascher J., Ceccherini MT., Landi L., Pietramellara G., Renella G., 2003. Microbial diversity and soil functions. Euro. J. Soil Sci. 54, 655-670. 
Nannipieri P., Grego S., Ceccanti B., 1990. Ecological significance of the biological activity in soil. In: Soil Biochemestry, Vol. 6 (eds. J.M. Bollag \& G. Stotzky), Marcel Dekker, New York, pp. 293-355.

Nannipieri P., Johnson R.L., Paul E.A., 1978. Criteria for measurement of microbial growth and activity in soil. Soil Biol. Biochem. 10, 223-229.

Nannipieri P., Kandeler E., Ruggiero P., 2002. Enzyme activities and microbiological and biochemical processes in soil. In: Enzymes in the Environment. Activity, Ecology and Applications, (Burns, R.G., Dick, R.P. Eds.), Marcel Dekker, New York, pp. 1-33.

Nannipieri P., Muccini L., Ciardi C., 1983. Microbial biomass and enzyme activities: production and persistence. Soil Biol. Biochem. 15, 679-685.

Nannipieri P., Sequi P., Fusi P., 1996. Humus and enzyme activity. In:Piccolo A (ed) Humic substances in terrestrial ecosystems. El sevier, New York, pp 293-328.

Ndiaye D., Lepage M., Sall C.E., Brauman A., 2004. Nitrogen transformation associated with termite biogenic structure in dry savanna ecosystem. Plant and Soil 265, 189-196.

Ndiaye E.L., Sandeno J.M., McGrath D., Dick R.P., 2000. Integrative biological indicators for detecting change in soil quality. Am. J. Alt. Agric. 15, 26-36.

Neher D.A., Campbell C.L., 1994. Nematodes communities and microbial biomass in soil with annual and perennial crops. Appl. Soil Ecol. 1, 17-28.

Newell K., 1984. Interactions between two decomposer Basidiomycetes and a collembolan under Sitka spruce: distribution, abundance and selective grazing. Soil Biol. Biochem. 16, 235-239.

Niemi R.M., Vepsäläinen M., Wallenius K., Simpanen S., Alakukku L., Pietola L., 2005. Temporal and soil depth-related variation in soil enzyme activities and in root growth of red clover (Trifolium pratense) and timothy (Phleum pratense) in the field. Appl. Soil Ecol. 30, 113-125.

Noble J.C., Whitford W.G., Kaliszweski M., 1996. Soil and litter microarthropod populations from two contrasting ecosystems in semi-arid eastern Australia. J. Arid Environ. 32, 329-346.

Ocio J.A., Brookes P.C., 1990. An evaluation of methods for measuring the microbial biomass in soils following recent additions of wheat straw and the characterization on the biomass that develops. Soil Biol. and Biochem. 22, 685-694.

Orchad V.A. Cook F.J., 1983. Relationship between soil respiration and soil moisture. Soil Biol. Biochem. 15, 447453.

Ostfeld R.S., Keesing F., 2000. Pulsed resources and community dynamics of consumers in terrestrial ecosystems. Trends Ecol. Evol. 15, 232-237.

Palm C.A., Sanchez P.A., 1991. Nitrogen release for the leaves of some tropical legumes as affected by their lignin and polyphenolic content. Soil Biol. Biochem. 23, 83-88.

Paul E.A., Clark F.E., 1989. Soil microbiology and Biochemistry. Academic Press, San Diego, California, E.U. 275.

Paul E.A., Clark F.E., 1996. Soil microbiology and biochesmetry. Academic Press, San Diego, 368 pp.

Payne J.W., 1980. Microorganisms and nitrogen sources. Wiley, New York, pp 381-411.

Payne J.W., 1981. Denitrification. Wiley Press, New York. 
Perez Z.O., Uribe V.G., Navarrete O.R., 1981. The "Milpa", an ancient agricultural system of Yucatan Mexico. Agronomy Abstracts, $73^{\text {rd }}$ Annu. Meeting Am. Soc. Agron. 44-45.

Peterjohn W.T., 1991. Denitrification: enzyme content and activity in desert soils. Soil Biol. Biochem. 23, 845855.

Piao H.C., Hong Y.T., Yuan Z.Y., 2000. Seasonal changes of microbial biomass carbon related to climatic factors in soils from karst areas of southwest China. Biol. Fertil. Soils 30, 294-297.

Poesen J., Lavee H., 1994. Rock fragments in top soils: significance and processes. Catena 23, 1-28.

Pool N.L., 1986. Experimentación en producción milpera bajo roza-tumba-quema en Yaxcabá, Yucatán, México. Tesis de Licenciatura, Departamento de Ciencias del Suelo, UACH, Chapingo, México.

Powlson D.S., Jenkinson D.S., 1976. The effect of biocidal treatments on metabolism in soil. V.A method for measuring soil biomass. Soil Biol. Biochem. 8, 209-213.

Prasad P., Basu S., Behera N., 1994. A comparative account of the microbial characteristics of soils under natural forest, grassland and crop field from Eastern India. Plant and Soil 175, 85-91.

Rao A.V., Tarafdar J.C., 1992. Seasonal changes in available phosphorus and different enzyme activities in arid soil. Annals Arid Zone 31, 185-189.

Rastin N., Rosenplaenter K., Huettermann A., 1988. Seasonal variation of enzyme activity and their dependence on certain soil factors in a beech soil. Soil Biol. Biochem. 20, 637-642.

Reid D.S., 1980. Water activity as the criterion of water availability. In: Ellwood D.C., Hedger J.N., Latham M.J., Lynch J.M., Slater J.H. (eds) Microbial Ecology. Academic Press, London.

Robertson L.N., Kettle B.A., Simpson G.B., 1994. The influence of tillage practice on soil macrofauna in a semiarid agroecosystem in nirtheastern Australia. Agric. Ecosystems Environ. 48, 149-156.

Rojo M,J., Carcedo S.G. Mateos M.P., 1990. Distribution and characterization of phosphatase and organic phosphorus in soil fractions. Soil Biol. Biochem. 22, 169-174.

Romanyà J., Casals P., Cortina J., Bottner P., Coûteaux M-M., Vallejo V.R. 2000. $\mathrm{CO}_{2}$ efflux from a Mediterranean semi-arid forest soil. II. Effects of soil fauna and surface stoniness. Biogeochemistry 48, 283-306.

Ross D.J. Speir T.W. Kettles H.A., Mackay A.D., 1995. Soil microbial biomass, C and N mineralization and enzyme activities in hill pasture: influence of season and slow-release P and S fertilizer. Soil Biol. Biochem. 27, 1431-1443.

Ross D.J., 1987. Soil microbial biomass estimated by fumigation-incubation procedure: seasonal fluctuations and influence of the soil moisture content. Soil Biol. Biochem. 19, 397-404.

Ross D.J., 1988. Modifications of the fumigation procedure to measure microbial biomass $\mathrm{C}$ in wet soils under pasture: Influence on estimates of seasonal fluctuations in the soil biomass. Soil Biol. Biochem. 20, 377388.

Ross D.J., 1990. Estimation of soil microbial C by a fumigation extraction method: Influence of seasons, soils and calibration with fumigation incubation procedure. Soil Biol. Biochem. 22, 295-300.

Sakamoto K., Oba Y., 1994. Effect of fungal of bacterial biomass ratio on the relationship between $\mathrm{CO}_{2}$ evolution and total soil microbial biomass. Biol. Fertl. Soils 17, 39-44. 
Salinas Garcia J.R., Hons F.M., Matocha J.E., 1997. Long-term effects of tillage and fertilization on soil organic matter dynamics. Soil Sci. Soc. Am. J. 61, 152-159.

Santos P.F. Whitford W., 1981. The effect of microarthropods on litter decomposition in a Chihuahuan dessert ecosystem. Ecology 63, 654-663.

Sardans J., Panuelas J., 2005. Drought decrease soil enzyme activity in a Mediterranean Quercus ilex L. forest, Soil Biol. Biochem. 37, 455-461.

Sardans J., Pañuelas J., Estiarte M., 2006.Warming and drought alter soil phosphatase activity and soil P availability in a Mediterranean shrubland. Plant Soil 289, 227-238.

Sardans J., Pañuelas J., Estiarte M., 2007. Seasonal pattern of root-surface phosphatase activities in a Mediterranean shrubland. Response to experimantal warming and drought. Biol. Fertil. Soils 43, 779-786.

Savin M.C., Goerres J.H., Neher D.H., Amador J.A., 2001. Biogeophysical factors influencing soil respiration and mineral nitrogen content in an old field soil. Soil. Biol. Biochem. 33, 429-438.

Saynes V., Hidalgo C., Etchevers J.D., Campo J., 2005. Soil C and N dynamics in primary and secondary seasonally dry forest in México. Appl. Soil Ecol. 282-289.

Schimel J.P., Firestone M.K., Killham K., 1984 Identification of heterotrophic nitrification in a Sierra forest soil.

Appl. Environ. Microbiol. 48, 802-806.

Schmidt G., Laskowski M. Sr., 1961. Phosphate ester cleavage (Survey). In: Boyer PD, et al. (eds) The enzymes, $2^{\text {nd }}$ edn. Academic Press, New York, pp. 3-35.

Schwinning S., Sala O., Hierarchy of responses to resource pulses in arid and semi-arid ecosystems. Oecologia 141, 211-220.

Seastedt T.R., 1984. The role of microarthropods in decomposition and mineralization processes. Ann. Rev. Entomol. 29, 25-46.

Senthilkumar K., Manian S., Udaiyan K., 1997. The effect of burning on soil enzyme in natural grasslands in southern India. Ecol. Res. 12, 21-25.

Shang C., Tiessen H., 2003. Soil organic C sequestration and stabilization in karstic soils of Yucatan. Biogeochemistry 62, 177-196.

Shewale J.G., 1982. $\beta$-Glucosidase: Its role in cellulase synthesis and hydrolyses of cellulose. Int. J. Biochem. 14, 435-443.

Shi W., Dell E., Bowman D., Iyyemperumal K., 2006. Soil enzyme activities and organic matter composition in a turfgrass chronosequence. Plant Soil 288, 285-296.

Sileshi G., Mafongoya P.L., 2007. Quantity and quality of organic inputs from coppicing leguminous trees influence abundance of soil macrofauna in maize crops in eastern Zambia. Biol. Fertil. Soils 43, 333-340.

Sinegani A.A.S., Hossainpour A., Nazarizadeh F., 2006. Spatial Variation in Soil Phosphomonoesterase in Irrigated and Dry Farmlands. Eur. Soil Sci. 39, 507-511.

Singh H., Singh K.E., 1993. Effect of residue placement and chemical fertilizer on soil microbial biomass under tropical dryland cultivation. Biol. Fertil. Soils 16, 275-281.

Singh J.S., Gupta S.R., 1977. Plant decomposition and soil respiration in terrestrial ecosystems. Botanical review 43, 449-528. 
Singh J.S., Raghubanshi A.S., Singh R.S., Srivastava S.C., 1989. Microbial biomass acts as a source of plant nutrients in dry tropical forest and savanna. Nature 338, 499-500.

Sinsabaugh R.L., 1994. Enzymatic analysis of microbial pattern and process. Biol. Fertil. Soils 17, 69-74.

Sinsabaugh R.L., Antibus R.K., Linkins A.E., 1991. An enzymic approach to the analysis of microbial activity during plant litter decomposition. Agric. Ecosyst. Environ. 34, 43-54.

Sinsabaugh R.L., Antibus R.K., Linkins A.E., McClaugherty C.A., Rayburn L., Weiland T., 1993. Wood decomposition: nitrogen and phosphorus dynamics in relation to extracellular enzyme activity. Ecology 74, 1586-1593.

Sinsabaugh R.L., Antibus R.K., Linkins A.E., Rayburn L.Repert D., Weiland T., 1992. Wood decomposition in a first order watershed: mass loss as a function of exoenzyme activity. Soil Biol. Biochem. 24, 743-749.

Skopp J., Dawson M.D., Doran J.W., 1990. Steady-state aerobic microbial activity as a function of soil water content. Soil Sci. Soc. Am. J. 54, 1619-1625.

Skujins J., 1976. Extracellular enzymes in soil. CRC Crit. Rev. Microbiol. 4, 383-421.

Smith J.L, Paul E.A., 1990. The significance of soil biomass estimates. In Soil Biochememestry. Vol. 6 (J.M. Bollag and G. Stotsky, Eds), Dekker, New York. pp. 357-396.

Smith J.L., Papendick R.I., Bezdicek D.F., Lynch J.M., 1993. Soil organic matter dynamic and crop residue management. In: Soil Microbial Ecology, (F. Blaines Metting, Jr. Eds.). Marcel Dekker, New York, pp. 65-93.

Smolander A., Barnette L., Kitunen V., Lumme I., 2005. N and C transformations in long-term N fertilized forest soils in response to seasonal drought. Appl. Soil Ecol. 29, 225-235.

Sorensen L.H., 1974. Rate of decomposition of organic matter in soil as influenced by repeated air dryingrewetting and repeated additions of organic material. Soil Biol. Biochem. 6, 287-292.

Sowerby A., Emmett B., Beier C., Tietema A., Peñuelas J., Estiarte M., Van Meeteren M.J.M., Hughes S., Freeman C., Microbial community changes in heathland soil communities along a geographical gradient: interaction with climate change manipulations. Soil Biol. Biochem. 37, 1805-1813.

Sparling G.P., West A., 1989. Importance of soil water content when estimating soil microbial C, N, and P by the fumigation-extraction methods. Soil Biol. Biochem. 21, 245-253.

Spedding T.A., Hamel C., Mehuys G.R., Madramootoo C.A., 2004. Soil microbial dynamics in maize-growing soil under different tillage and residue management systems. Soil Biol. Biochem. 36, 499-512.

Speir T.W., Cowling J.C., 1991. Phosphatase activities of pasture plants and soils: relationship with plat productivity and soil P fertility indices. Biol. Fertl. Soils 12, 189-194.

Speir T.W., Lee R., Pansier E.A., Cairns A., 1980. A comparison of sulphatase, urease and protease activities in planted and fallow soils. Soil Biol. Biochem. 12, 281-291.

Sppeding T.A., Hamel C., Mehuys G.R. Madramootoo C.A., 2004. Soil microbial dynamics in maize-growing soil under different tillage and residue management systems. Soil Biol. Biochem. 36, 499-512.

Srivastava S.C., 1992. Microbial biomass C, N, and P in tropical soils: Seasonal changes influence of soil moisture. Soil Biol. Biochem. 24,711-714. 
Staaf H., Berg B., 1981. Plant litter input to soil. In: Clark F.E., Roswall T. (eds.) Terrestrial nnitrogen cycles: processes ecosystem strategies and management impacts. Ecological Bulletin, Stockholm, pp. 147-167.

Staaf H., Berg B., 1982. Accumulation and release of plant nutrients in decomposing Scots pine needle litter. II. Long-term decomposition in a Scots pine forest [J]. Can. J. Bot. 60, 1561-1568.

Staddon W.J., Duchesne L.C., Trevors J.T., 1998. Acid phosphatase, alkaline phosphatase and arylsulfatase activities in soils from a jack pine (Pinus banksiana Lamb.) ecosystem after clear-cutting, prescribed burning, and scarification. Biol Fertil Soils 27, 1-4.

Stamatiadis S., Doran J.W., Ingham E.R., 1990. Use of staining and inhibitors to separate fungal and bacterial activity in soil. Soil Biol. Biochem. 22, 81-88.

Stark C., Condron L.M., Stewart A., Di H.J., O’Callaghan M., 2007. Influence of organic and mineral amendments on microbial soil properties and processes. Appl. Soil Ecol. 35, 79-93.

Steenwerth K.L., Jackson L.E., Calderón F.J., StrombergM.R., Scow K.M., 2003. Soil microbial community composition and land use history in cultivated and grassland ecosystems in coastal California. Soil Biol. Biochem. 35, 489-500.

Stinner B.R., House G.J., 1990. Arthropods and other invertebrates in conservation-tillage agriculture. Ann. Rev. Entomol. 35, 299-318.

Stryer L., 1988. Biochemestry, $3^{\text {rd }}$ edn. Freeman and Company, New York.

Sunderland K., Samu F., 2000. Effects of agricultural diversification on the abundance, distribution, and pest control potential of spiders: a review. Ento. Exp. App. 95, 1-13.

Susilo F.X., Neutel A.M., van Noordwijk M., Hairiah K., Brown G., Swift M., 2004. Soil biodiversity and food web. In: van Noordwijjk, M., Cadish G., Ong C.K., (eds.), Below-ground Interactions in Tropical Agroecosystems. CAB International, pp. 285-307.

Swift M.J., Anderson J.M., 1989. Decomposition. In: Ecosystems of the world. 14B. Tropical rain forest ecosystems; biogeographical and ecological studies. Lieth, H. y M.J.A. Werger (eds.). Elservier, Amsterdam.

Swift M.J., Heal O.W., Anderson J.M., 1979. Descomposition in terrestrial ecosystems. (Studies in ecology, Vol. 5) Balckwell Scientific Publication, Oxford, England.

Swift M.J., Russel-Smith A., Perfect T.J., 1981. Decomposition and mineral-nutrient dynamics of plant litter in a regenerating bush-fallow in sub-humid tropical Nigeria. J. Ecol. 69, 981-995.

Swift M.J., van der Meer J., Ramakrishnan P.S., Anderson J.M., Ong C.K., Hawkins B.A., 1996. Biodiversity and agroecosystem function. In: Mooney H.A., Hall Cushman J., Medina E., Sala O.E., Schulze E.D., (Eds.), Functional Roles of Biodiversity: a Global Perspective. John Wiley and Sons, Chichester, pp. 261298.

Tabatabai M.A., Bremner J.M., 1969. Use of p-nitrophenylphosphate for assay of soil phosphatase activity. Soil Biol. Biochem, 1, 301-307.

Tabatabai M.A.,1994. Soil enzymes. In: Methods of Soil Analysis. American Society of Agronomy, (Page, A.L., Miller, R.H., Keeny, D.R. Eds.), Madison, pp. 775-833. 
Tadano T., Ozawa K., Sakai H., Osaki M., Matsui H., 1993. Secretion of acid phosphatase by the rotos of crop plants under phosphorus-deficient conditions and some properties of the enzyme secreted by lupin rotos. Plant Soil 155/156, 95-98.

Tarafdar J.C., Claassen N., 1988. Organic phosphorus compounds a phosphorus source for higher plant through the activity of phosphatase produced by plant roots and microorganisms. Biol. Fertil Soils 5, 308-312.

Tarafdar J.C., Jungk A. 1987. Phosphatase activity in the rhizosphere and its relation to the depletion of soil organic phosphorus. Biol. Fertil. Soils 3, 199-204.

Tarafdar J.C., Kiran B., Rao A.V., 1989. Phosphatase activity and distribution of phosphorous in arid soil profiles under different land use pattern. J. Arid Environ. 16, 29-34.

Tarafdar J.C., Rao A.V., Bala K., 1988. Production of phosphatases by fungi isolated from desert soils. Folia Microbiol 33, 453-457.

Tarafdar J.C.,Chhonkar P.K., 1979. Phosphatase production by microorganisms isolated from diverse types of soils. Entralbl Mikrobiol 134, 119-122.

Tateno M., 1988. Limitation of available substrate for the expression of cellulase and protease activities in soil. Soil Biol Biochem, 20, 117-118.

Templer P.H., Groffman P.M., Flecker A.S., Power A.G., 2005. Land use change and soil nutrient transformations in the Los Haitises region of the Dominican Republic. Soil Biol. Biochem. 37, 215-225.

Ten Have R., Teunissen P.J.M., 2001. Oxidative mechanisms involved in lignin degradation by white-rot fungi. Chem. Rev. 101, 3397-3413.

Teran S., Rasmussen C.H., 1992. La Milpa de los Mayas (La agricultura de los Mayas prehispánicos y actuales en el noreste de Yucatan). Gobierno del Estado de Yucatan y DANIDA, Yucatan, Mexico.

Tian G., Kang B.T., Brussard L., 1992. Biological effects of plant residues with contrasting chemical composition under humid tropical conditions - decomposition and nutrient release. Soil Biol. Biochem. 24, 1051-1060.

Tiessen H., Bettany J.R., Stewart J.W.B., 1981. An improved method for the determination of carbon in soils and soil extracts by dry combustion. Commun. in Soil Science and Plant Analysis. 12, 211-218.

Trasar Cepeda C., Leirós C., Gil Sotres F., Seoane S., 1998. Towards a biochemical quality index for soils: an expression relating several biological and biochemical properties. Biol. Fertil. Soils 6, 100-106.

Turner B.L., Cade-Menum B.J., Westermann D.T., 2003. Organic phosphorus composition and potential bioavailability in semi-arid arable soils of western United States. Soil Sci. Soc. Am. J. 67, 1168- 1179.

Turner B.L., Hopkins D.W., Haygarth P.M., Ostle N., 2002. $\beta$-Glucosidase activity in pasture soils. Appl. Soil Ecol. 20, 157-162.

Van Gestel M., Ladd J.N., Amato M., 1991. Carbon and nitrogen mineralization from two soils of contrasting texture and microaggregate stability: influence of sequential fumigation, drying and storage. Soil Biol. Biochem. 23, 313-322.

Van Gestel M., Merckx R., Vlassak K., 1993. Microbial biomass responses to soil drying and rewetting: the fate of fast- and slow-growing microorganisms in soils from different climates. Soil Biol. Biochem. 25, 109123. 
Van Gestel M., Merckx R., Vlassak K., 1996. Spatial distribution of microbial biomass in microaggregates of a silty loam soil and the relation with the resistance of microorganisms to soil drying. Soil Biol. Biochem. 28, 503-510.

Van Veen J.A., Merckx R., Van de Geijn S.C., 1989. Plant- and soil related controls of the flow of carbon from roots through the soil microbial biomass. Plant Soil 115, 179-188.

Vanlauwe B., Vanlangenhove G., Merckx R., 1995. Impact of rainfall on the decomposition of leaf litter with contrasting quality under subhumid tropical conditions. Biol. Fertil. Soils 20, 8-16.

Verhoef H.A., Brussaard L., 1990. Decomposition and nitrogen mineralization in natural and agroecosystems: the contribution of the soil animals. Biogeochemistry 11, 175-211.

Vincent G., Reza Shahriari A., Lucot E., Badot P.M., Epron D., 2006. Spatial and seasonal variations in soil respiration in a temperate deciduous forest with fluctuating water table. Soil Biol. Biochem. 38, 2527-2535.

Visser S., Parkinson D., 1992. Soil biological criteria as indicators of soil quality: soil microorganisms. Am. J. Alternative Agriculture 7, 33-37.

Vitousek P.M., Turner D.R., Parton W.J., Sanford R.L., 1994. Litter decomposition on the Mauna Loamatrix: patterns, mechanisms, and models. Ecology 75, 418-429.

Von Lützow M., Zelles L., Scheunert I., Ottow J.C.G., 1992. Seasonal effects of liming, irrigation, and acid precipitation on microbial biomasss $\mathrm{N}$ in a spruce (Picea abies L.) forest soil. Biol. Fertil. Soils 13, 130134.

Wainwright M., 1992. The impact of fungi on environmental biogeochemistry. In The Fungal Community, Its Organization and Role, in the Ecosystem. Eds. G.C Carroll and D T Wicklow. pp. 601-618. Marcel Dekker, Inc., New York.

Waldrop M.P., Balser T.C., Firestone M.K., 2000. Linking microbial community composition to function in a tropical soil. Soil Biol. Biochem. 32,1837-1846.

Wardle D.A., Giller K., 1996. The quest for a contemporary ecological dimension to soil biology - discussion. Soil Biol. Biochem, 28, 1549-1554.

Wardle D.A., Lavelle P., 1997. Linkage between soil biota, plant litter quality and decomposition. In: Giller K.E, Cadish G. (eds.) Driven by Nature - plant litter quality and decomposition CAB International, Wallingford, pp. 107-124.

Wardle D.A., Parkinson D., 1990. Interactions between microclimatic variables and the soil microbial biomass. Biol. Fertil. Soils 9, 73-80.

Watabane K., Hayano K., 1995. Seasonal variation of soil protease activities and their relation to proteolitic bacteria and Bacillus spp in paddy field soil. Soil Biol. Biochem. 27, 197-203.

Watabane K., Hayano K., 1996. Seasonal variation in extracted proteases and relationship to overall soil protease and exchangeable ammonia in paddy soils. Biol Fertil Soils 21, 89-94.

Weisbach C., Tiessen H., Jimenez-Osornio J., 2002. Soil fertility during shifting cultivation in the tropical Karst of Yucatan. Agronomie 22, 253-263.

West A.W., 1986. Improvement of the selective respiratory inhibition technique to measure eukaryote: prokaryote ratios in soils. J. Microbiol. Meth. 5, 125-138. 
West A.W., Sparling G.P., 1986. Modifications to the substrate-induced respiration method to permit measurement of microbial biomass in soils of different water content. J. Microbiol. Meth. 37, 686-692.

West A.W., Sparling G.P., Feltham C.W., Reynolds J., 1992. Microbial activity and survival in soil dried at different rates. Aust. J. Soil Res. 30, 209-222.

West A.W., Sparling G.P., Speir T.W., Wood J.M., 1988. Dynamic of microbial C, N-flush and ATP and enzyme activities of gradually dried soils from a climosequence. Aust. J. Soil Res. 26, 519-530.

Whitford W.G., 1978. Structure and seasonal activity of Chihuhu Desert ant communities. Ins. Soc. 79-88.

Whitford W.G., 1989. Abiotic controls on the functional structure of soil food webs. Biol. Fertil. Soils 8, 1-6.

Whitford W.G., 1996. The importance of the biodiversity of soil biota in arid ecosystems. Biodiv. Conserv. 5, 185-195.

Whitford W.G., Freckman D.W., Elkins N.Z., Parker L.W., Parmalee R., Phillips J., Tucker S., 1981. Diurnal migration and responses to simulated rainfall in desert soil: Microarthrops and nematodes. Soil Biol. Biochem. 13, 417-425.

Wick B., Kuehne R.F., Vielhauer K., Vlek P.L.G., 2002. Temporal variability of selected soil microbiological and biological indicators under different soil quality conditions in south-western Nigeria. Biol Fertil Soils, $35,155-167$.

Wick B., Kuehne R.F., Vlek P.L.G., 1998. Soil microbiological parameters as indicators of soil quality under improved fallow management systems in south-western Nigeria. Plant and Soil 202: 97-107.

Wick B., Tiessen H., Menezes R.S.C. 2000. Land quality changes following the conversion of the natural vegetation into silvo-pastoral systems in semi-arid NE Brazil. Plant Soil 222, 59-70.

Wieder R.K., Lang G.E., 1982. A critique of the analytical methods used in examining decomposition data obtained from litter bags. Ecology 63, 1636-1642.

Wilson E.M., 1980. Physical geography of the Yucatan Peninsula. In: A world apart: Yucatan (E.H. Moseley and E.D. Terry Eds.). The University of Alabama Press, Alabama, U.S.A, pp. 5-40.

Wise D.H., Schaefer M., 1994. Decomposition of leaf litter in a mull beech forest: comparison between canopy and herbaceous species. Pedobiologia 38, 269-288.

Wolters V., 2000. Invertebrate control on soil organic matter stability. Biol. Fertil. Soils 31, 1-19.

Wolters V., Joergensen R.G., 1992. Microbial carbon turnover in beech forest soils worked by Aporrectodea caliginosa (Savigny) (Oligochaeta, Lumbricidae). Soils Biol. Biochem. 24, 171-177.

Xu X-N., Shibata H., Enoki T., 2006. Decomposition patterns of leaf litter of seven common canopy species in a subtropical forest: dynamics of mineral nutrients. J. For. Res. 17, 1-6.

Xuluc F., 1995. Caracterización del componente vegetal de los solares de la comunidad de Sahcabá, Yucatán, México. Tesis de Licenciatura. FMVZ-UADY. Mérida, Yucatán, México, 55 pp.

Xuluc-Tolosa F.J., Vester H.F.M., Ramirez-Marcial N., Castellanos-Albores J., Lawerence D., 2003. Leaf litter decomposition of tree species in three sucesional phases of tropical dry secondary forest in Campeche, Mexico. For. Ecol. Manage. 174, 401-412.

Yamashita T., Takeda H., 1998. Decomposition and nutrient dynamics of leaf litter in litter bags of two mesh sizes set in two dipterocarp forest sites in Peninsular Malasya, Pedobiologia 42, 11-21. 


\section{References}

York A., 1999. Lon-Term effect of frequent low-intensity burning on the abundance of litter-dwelling invertebrates in coastal blackbutt forests of southeastern Australia. J. Insect Conserv. 3, 191-199.

Zaman M., Cameron K.C., Di H.J., Noonan M.J., 1998. Nitrogen mineralisation rates from soil amended with dairy pond waste. Aust. J. Soil Res. 36, 217-230.

Zaman M., Chang S.X., 2004. Substrate type, temperature, and moisture content affect gross and net N mineralization and nitrification rates in agroforestry systems. Biol. Fertil, Soils 39, 269-279.

Zaman M., Di H.J., Cameron K.C., Frampton C.M., 1999. Gross nitrogen mineralization and nitrification rates and their relationships to enzyme activities and the soil microbial biomass in soils treated with dairy shed effluent and ammonium fertilizer at different water potentials. Biol. Fertil. Soils 29, 178-186.

Zech W., Drechsel P., Neugebauer B., 1991. Mineral deficiencies of forest trees in Yucatan (Mexico) and consequences for land-use, Turrialba 41, 230-236.

Zelles L., Rackwitz R., Bai Q.Y., Beck T., Beese F., 1995. Discrimination of microbial diversity by fatty acid profiles of phospholipids and lipopolysacharides in differently cultivated soils. Plant Soil 170, 115-122.

Zhang P., Li L., Pan G., Ren J., 2006. Soil quality changes in land degradation as indicated by soil chemical, biochemical and microbiological properties in a karst area of southwest Guizhou, China. Environ. Geol. 51, 609-619. 
IV. Appendix

IX. Appendix 
Table A. 1. Individual number (ind. $\mathrm{m}^{-2}$ ) according classification by width body of the litterbags under land uses and soil types in the dry season.

\begin{tabular}{|c|c|c|c|c|c|c|c|}
\hline $\begin{array}{l}\text { Classification } \\
\text { by Wide Size }\end{array}$ & Order & $\begin{array}{l}\text { Black Forest } \\
\text { Soils }\end{array}$ & Red Forest Soils & Total Forest & $\begin{array}{l}\text { Black Milpa } \\
\text { Soils }\end{array}$ & Red Milpa Soils & Total Milpa \\
\hline Big & Araneae & 20 & 9 & 29 & 13 & 21 & 34 \\
\hline Big & Blattoptera & 0 & 1 & 1 & 0 & 1 & 1 \\
\hline Big & Caelifera & 0 & 1 & 1 & 0 & 0 & 0 \\
\hline Big & Carabidae/Coccinelli & 1 & 0 & 1 & 0 & 0 & 0 \\
\hline Big & Coleoptera & 23 & 10 & 33 & 6 & 10 & 16 \\
\hline Big & Coleoptera Larve & 7 & 8 & 15 & 0 & 1 & 1 \\
\hline Big & Dermaptera & 0 & 0 & 0 & 0 & 2 & 2 \\
\hline Big & Diplopoda & 8 & 10 & 18 & 0 & 8 & 8 \\
\hline Big & Diptera & 0 & 1 & 1 & 0 & 4 & 4 \\
\hline Big & Embioptera & 0 & 1 & 1 & 0 & 0 & 0 \\
\hline Big & Formicidae & 6 & 36 & 42 & 4 & 4 & 8 \\
\hline Big & Gastropoda & 1 & 0 & 1 & 0 & 2 & 2 \\
\hline Big & Hemiptera & 0 & 0 & 0 & 1 & 1 & 2 \\
\hline Big & Heteroptera & 0 & 0 & 0 & 0 & 5 & 5 \\
\hline Big & Isopoda & 0 & 1 & 1 & 0 & 0 & 0 \\
\hline Big & Isoptera: Termite & 7 & 4 & 11 & 35 & 83 & 118 \\
\hline Big & Lepidoptera & 0 & 6 & 6 & 0 & 0 & 0 \\
\hline Big & Lumbricidae & 0 & 0 & 0 & 0 & 1 & 1 \\
\hline Big & Oribatida & 1 & 0 & 1 & 0 & 0 & 0 \\
\hline Big & Pseudoscorpionida & 2 & 4 & 6 & 4 & 6 & 10 \\
\hline Big & Pupa Insect & 0 & 0 & 0 & 0 & 1 & 1 \\
\hline Big & Scarabaeidae & 3 & 0 & 3 & 0 & 1 & 1 \\
\hline Big & Siphonaptera & 0 & 0 & 0 & 0 & 6 & 6 \\
\hline Medium & Acari & 3 & 0 & 3 & 8 & 2 & 10 \\
\hline Medium & Diplura & 3 & 4 & 7 & 3 & 3 & 6 \\
\hline Medium & Myriapoda & 6 & 3 & 9 & 1 & 4 & 5 \\
\hline
\end{tabular}


Table A. 2. Individual number (ind. ${ }^{-2}$ ) according classification by width body of the litterbags under land uses and soil types in the dry season.

\begin{tabular}{|c|c|c|c|c|c|c|c|}
\hline $\begin{array}{l}\text { Classification } \\
\text { by Wide Size }\end{array}$ & Order & $\begin{array}{|ll|}\text { Black } & \text { Forest } \\
\text { Soils } & \end{array}$ & Red Forest Soils & Total Forest & \begin{tabular}{ll|} 
Black & Milpa \\
Soils &
\end{tabular} & Red Milpa Soils & Total Milpa \\
\hline Big & Araneae & 10 & 8 & 18 & 5 & 2 & 7 \\
\hline$\overline{B i g}$ & Blattoptera & 2 & 0 & 2 & 0 & 0 & 0 \\
\hline Big & Coleoptera & 5 & 2 & 7 & $\mathbf{0}$ & 1 & 1 \\
\hline Big & Coleoptera Larve & 3 & 19 & 22 & 6 & 8 & 14 \\
\hline Big & Diplopoda & 11 & 8 & 19 & 1 & 0 & 1 \\
\hline Big & Diptera Larve & 3 & 0 & 3 & 2 & 3 & 5 \\
\hline Big & Formicidae & 20 & 84 & 104 & 8 & 5 & 13 \\
\hline Big & Heteroptera & 0 & 0 & 0 & 1 & 0 & 1 \\
\hline Big & Isopoda & 0 & 0 & 0 & 0 & 0 & 0 \\
\hline Big & Isoptera: Termite & $\mathbf{0}$ & 103 & 103 & $\mathbf{0}$ & 0 & 0 \\
\hline Big & Lepidoptera & 1 & 1 & 2 & 0 & 1 & 1 \\
\hline Big & Lumbricidae & 27 & 7 & 34 & 4 & 6 & 10 \\
\hline Big & Pseudoscorpionida & 0 & 0 & 0 & 1 & 1 & 2 \\
\hline Big & Scorpion & 1 & 0 & 1 & 0 & 0 & 0 \\
\hline Medium & Acari & 0 & 0 & 0 & 4 & 5 & 9 \\
\hline Medium & Diplura & 19 & 84 & 103 & 21 & 13 & 34 \\
\hline Medium & Myriapoda & 6 & 11 & 17 & 0 & 4 & 4 \\
\hline
\end{tabular}


Table A. 3. Individual number (ind. $\mathrm{m}^{-2}$ ) according classification by width body of the litterbags under land uses and soil types in the rainy season.

\begin{tabular}{|c|c|c|c|c|c|c|c|c|c|c|}
\hline $\begin{array}{l}\text { Functional } \\
\text { Group }\end{array}$ & Order & $\begin{array}{l}\text { Black } \\
\text { Forest Soils }\end{array}$ & $\begin{array}{l}\text { Red Forest } \\
\text { Soils }\end{array}$ & $\begin{array}{l}\text { Total } \\
\text { Forest }\end{array}$ & $\begin{array}{l}\text { Black } \\
\text { Milpa Soils }\end{array}$ & $\begin{array}{ll}\text { Red } & \text { Milpa } \\
\text { Soils } & \end{array}$ & $\begin{array}{l}\text { Total } \\
\text { Milpa }\end{array}$ & $\begin{array}{l}\text { Black } \quad \text { HG } \\
\text { Soils }\end{array}$ & $\begin{array}{ll}\text { Red } & \text { HG } \\
\text { Soils } & \end{array}$ & Total HG \\
\hline Mesofauna & Acari & 3 & 0 & 3 & 8 & 2 & 10 & 3 & 3 & 6 \\
\hline Mesofauna & Araneae & 20 & 9 & 29 & 13 & 21 & 34 & 20 & 13 & 33 \\
\hline Mesofauna & Blattoptera & 0 & 1 & 1 & 0 & 1 & 1 & 2 & 0 & 2 \\
\hline Macrofauna & Caelifera & 0 & 1 & 1 & 0 & 0 & 0 & 0 & 0 & 0 \\
\hline Macrofauna & Carabidae/Coccinelli & 1 & 0 & 1 & 0 & 0 & 0 & 0 & 0 & 0 \\
\hline Macrofauna & Coleoptera Larve & 7 & 8 & 15 & 0 & 1 & 1 & 10 & 6 & 16 \\
\hline Macrofauna & Coleoptera & 23 & 10 & 33 & 6 & 10 & 16 & 12 & 21 & 33 \\
\hline Mesofauna & Dermaptera & 0 & 0 & 0 & 0 & 2 & 2 & 0 & 0 & 0 \\
\hline Mesofauna & Diplopoda & 8 & 10 & 18 & 0 & 8 & 8 & 2 & 36 & 38 \\
\hline Mesofauna & Diplura & 3 & 4 & 7 & 3 & 3 & 6 & 11 & 10 & 21 \\
\hline Mesofauna & Diptera - Larve & 0 & 0 & 0 & 0 & 0 & 0 & 0 & 9 & 9 \\
\hline Mesofauna & Diptera & 0 & 1 & 1 & 0 & 4 & 4 & 0 & 0 & 0 \\
\hline Mesofauna & Embioptera & 0 & 1 & 1 & 0 & 0 & 0 & 0 & 1 & 1 \\
\hline Mesofauna & Formicidae & 6 & 36 & 42 & 4 & 4 & 8 & 109 & 71 & 180 \\
\hline Macrofauna & Gastropoda & 1 & 0 & 1 & 0 & 2 & 2 & 0 & 0 & 0 \\
\hline Mesofauna & Hemiptera & 0 & 0 & 0 & 1 & 1 & 2 & 0 & 0 & 0 \\
\hline Macrofauna & Heteroptera & 0 & 0 & 0 & 0 & 5 & 5 & 1 & 0 & 1 \\
\hline Mesofauna & Isopoda & 7 & 4 & 11 & 0 & 0 & 0 & 50 & 69 & 119 \\
\hline \multirow[t]{2}{*}{ Mesofauna } & $\begin{array}{lll}\begin{array}{l}\text { Isoptera } \\
\text { Termite }\end{array} & - \text { Neoptera: } \\
\end{array}$ & 7 & 4 & 11 & 35 & 83 & 118 & 2 & 0 & 2 \\
\hline & Larve & 0 & 1 & 1 & 1 & 2 & 3 & 0 & 0 & 0 \\
\hline Macrofauna & Lepidoptera & 0 & 6 & 6 & 0 & 0 & 0 & 0 & 0 & 0 \\
\hline Mesofauna & Lumbricidae & 0 & 0 & 0 & 0 & 1 & 1 & 0 & 2 & 2 \\
\hline Mesofauna & Myriapoda & 6 & 3 & 9 & 1 & 4 & 5 & 0 & 7 & 7 \\
\hline Mesofauna & Oribatida & 1 & 0 & 1 & 0 & 0 & 0 & 0 & 1 & 1 \\
\hline Mesofauna & Pseudoscorpionida & 2 & 4 & 6 & 4 & 6 & 10 & 1 & 0 & 1 \\
\hline Mesofauna & Pupa Insect & 0 & 0 & 0 & 0 & 1 & 1 & 0 & 0 & 0 \\
\hline
\end{tabular}




\begin{tabular}{|l|l|l|l|l|l|l|l|l|l|l|}
\hline $\begin{array}{l}\text { Functional } \\
\text { Group }\end{array}$ & Order & $\begin{array}{l}\text { Black } \\
\text { Forest Soils }\end{array}$ & $\begin{array}{l}\text { Red Forest } \\
\text { Soils }\end{array}$ & $\begin{array}{l}\text { Total } \\
\text { Forest }\end{array}$ & $\begin{array}{l}\text { Black } \\
\text { Milpa Soils }\end{array}$ & $\begin{array}{l}\text { Red Milpa } \\
\text { Soils }\end{array}$ & $\begin{array}{l}\text { Total } \\
\text { Milpa }\end{array}$ & $\begin{array}{l}\text { Black } \\
\text { Soils }\end{array}$ & $\begin{array}{l}\text { HG } \\
\text { Red } \\
\text { Soils }\end{array}$ & HG \\
\hline Macrofauna & Scarabaeidae & 3 & 0 & 3 & 0 & 1 & 1 & 0 & 1 \\
\hline Macrofauna & Scorpion & 0 & 0 & 0 & 0 & 0 & 0 & 0 & 0 \\
\hline Mesofauna & Siphonaptera & 0 & 0 & 0 & 0 & 6 & 6 & 1 & 0 \\
\hline
\end{tabular}


Table A. 4. Individual number (ind. $\mathrm{m}^{-2}$ ) according classification by functional groups under land uses and soil types in the dry season.

\begin{tabular}{|c|c|c|c|c|c|c|c|c|c|c|c|}
\hline $\begin{array}{l}\text { Functional } \\
\text { Group }\end{array}$ & Order & \begin{tabular}{|l|} 
Black \\
Forest Soils
\end{tabular} & $\begin{array}{l}\text { Red Forest } \\
\text { Soils }\end{array}$ & \begin{tabular}{|l} 
Total \\
Forest
\end{tabular} & $\begin{array}{l}\text { Black } \\
\text { Milpa Soils }\end{array}$ & $\begin{array}{ll}\text { Red } & \text { Milpa } \\
\text { Soils }\end{array}$ & $\begin{array}{l}\text { Total } \\
\text { Milpa }\end{array}$ & $\begin{array}{l}\text { Black } \\
\text { Soils }\end{array}$ & HG & $\begin{array}{ll}\text { Red } & \text { HG } \\
\text { Soils } & \end{array}$ & Total HG \\
\hline Mesofauna & Acari & 0 & 0 & 0 & 4 & 5 & 9 & 1 & & 3 & 4 \\
\hline Mesofauna & Araneae & 10 & 8 & 18 & 5 & 2 & 7 & 16 & & 2 & 18 \\
\hline Mesofauna & Blattoptera & 2 & 0 & 2 & 0 & 0 & 0 & 3 & & 1 & 4 \\
\hline Macrofauna & Caelifera & 0 & 0 & 0 & 0 & 0 & 0 & 2 & & 0 & 2 \\
\hline Macrofauna & Carabidae/Coccinelli & 0 & 0 & 0 & 0 & 0 & 0 & 0 & & 0 & 0 \\
\hline Macrofauna & Coleoptera & 5 & 2 & 7 & 0 & 1 & 1 & 8 & & 7 & 15 \\
\hline Macrofauna & Coleoptera Larve & 3 & 19 & 22 & 6 & 8 & 14 & 4 & & 6 & 10 \\
\hline Mesofauna & Dermaptera & 0 & 0 & 0 & 0 & 0 & 0 & 0 & & 2 & 2 \\
\hline Mesofauna & Diplopoda & 11 & 8 & 19 & 1 & 0 & 1 & 16 & & 9 & 25 \\
\hline Mesofauna & Diplura & 19 & 84 & 103 & 21 & 13 & 34 & 33 & & 19 & 52 \\
\hline Mesofauna & Diptera & 0 & 0 & 0 & 0 & 0 & 0 & 0 & & 0 & 0 \\
\hline Mesofauna & Diptera Larve & 3 & 0 & 3 & 2 & 3 & 5 & 6 & & 3 & 9 \\
\hline Mesofauna & Embioptera & 0 & 0 & 0 & 0 & 0 & 0 & 0 & & 0 & 0 \\
\hline Macrofauna & Formicidae & 20 & 84 & 104 & 8 & 5 & 13 & 30 & & 13 & 43 \\
\hline Mesofauna & Gastropoda & 0 & 0 & 0 & 0 & 0 & 0 & 0 & & 0 & 0 \\
\hline Macrofauna & Heteroptera & 0 & 0 & 0 & 1 & 0 & 1 & 6 & & 0 & 6 \\
\hline Mesofauna & Isopoda & 0 & 0 & 0 & 0 & 0 & 0 & 33 & & 10 & 43 \\
\hline \multirow[t]{2}{*}{ Mesofauna } & \begin{tabular}{|lll}
$\begin{array}{l}\text { Isoptera } \\
\text { Termite }\end{array}$ & Neoptera: \\
\end{tabular} & 0 & 103 & 103 & 0 & 0 & 0 & 55 & & 4 & 59 \\
\hline & Larve & 0 & 0 & 0 & 0 & 0 & 0 & 0 & & 0 & 0 \\
\hline Macrofauna & Lepidoptera & 1 & 1 & 2 & 0 & 1 & 1 & 1 & & 0 & 1 \\
\hline Mesofauna & Lumbricidae & 27 & 7 & 34 & 4 & 6 & 10 & 1 & & 1 & 2 \\
\hline Mesofauna & Myriapoda & 6 & 11 & 17 & 0 & 4 & 4 & 4 & & 3 & 7 \\
\hline Mesofauna & Oribatida & 0 & 0 & 0 & 0 & 0 & 0 & 0 & & 0 & 0 \\
\hline Mesofauna & Pseudoscorpionida & 0 & 0 & 0 & 1 & 1 & 2 & 0 & & 0 & 0 \\
\hline Mesofauna & Pupa Insect & 0 & 0 & 0 & 0 & 0 & 0 & 0 & & 0 & 0 \\
\hline Macrofauna & Scarabaeidae & 0 & 0 & 0 & 1 & 0 & 1 & 0 & & 2 & 2 \\
\hline
\end{tabular}




\begin{tabular}{|l|l|l|l|l|l|l|l|l|l|l|l|}
\hline $\begin{array}{l}\text { Functional } \\
\text { Group }\end{array}$ & Order & $\begin{array}{l}\text { Black } \\
\text { Forest Soils }\end{array}$ & $\begin{array}{l}\text { Red Forest } \\
\text { Soils }\end{array}$ & $\begin{array}{l}\text { Total } \\
\text { Forest }\end{array}$ & $\begin{array}{l}\text { Black } \\
\text { Milpa Soils }\end{array}$ & $\begin{array}{l}\text { Red Milpa } \\
\text { Soils }\end{array}$ & $\begin{array}{l}\text { Total } \\
\text { Milpa }\end{array}$ & $\begin{array}{l}\text { Black } \\
\text { Soils }\end{array}$ & $\begin{array}{l}\text { HG } \\
\text { Soils }\end{array}$ & $\begin{array}{l}\text { HG } \\
\text { Total HG }\end{array}$ \\
\hline Macrofauna & Scorpion & 1 & 0 & 1 & 0 & 0 & 0 & 0 & 0 \\
\hline Mesofauna & Siphonaptera & 0 & 0 & 0 & 0 & 0 & 0 & 0 & 0 \\
\hline
\end{tabular}


Table A. 5.Univariate Analysis of Variance for Araneae group.

\begin{tabular}{|l|l|}
\hline Factors and Interactions & P \\
\hline Land Use & 0.779 \\
\hline Soil Type & 0.130 \\
\hline Season & 0.008 \\
\hline Land Use x Soil Type & 0.269 \\
\hline Land Use x Season & 0.576 \\
\hline Soil Type x Season & 0.638 \\
\hline Land Use x Soil Type x Season & 0.466 \\
\hline
\end{tabular}

Table A. 6.Univariate Analysis of Variance for Coleoptera Group.

\begin{tabular}{|l|l|}
\hline Factors and Interactions & P \\
\hline Land Use & 0.003 \\
\hline Soil Type & 0.861 \\
\hline Season & 0.000 \\
\hline Land Use x Soil Type & 0.029 \\
\hline Land Use x Season & 0.546 \\
\hline Soil Type x Season & 0.726 \\
\hline Land Use x Soil Type x Season & 0.122 \\
\hline
\end{tabular}

Table A. 7. Univariate Analysis of Variance for Formicidae Group.

\begin{tabular}{|l|l|}
\hline Factors and Interactions & P \\
\hline Land Use & 0.116 \\
\hline Soil Type & 0.782 \\
\hline Season & 0.541 \\
\hline Land Use x Soil Type & 0.317 \\
\hline Land Use x Season & 0.118 \\
\hline Soil Type x Season & 0.669 \\
\hline Land Use x Soil Type x Season & 0.932 \\
\hline
\end{tabular}

Table A. 8. Univariate Analysis of Variance for Termites Group.

\begin{tabular}{|l|l|}
\hline Factors and Interactions & P \\
\hline Land Use & 0.781 \\
\hline Soil Type & 0.330 \\
\hline Season & 0.663 \\
\hline Land Use x Soil Type & 0.142 \\
\hline Land Use x Season & 0.018 \\
\hline Soil Type x Season & 0.967 \\
\hline Land Use x Soil Type x Season & 0.102 \\
\hline
\end{tabular}


Table A. 9. Remaining weight in litterbags in the forest soils.

\begin{tabular}{|l|l|l|l|l|l|l|}
\hline Mesh Size & Soil Type & Time (days) & $\begin{array}{l}\text { Average Mass } \\
\text { Loss (g) }\end{array}$ & SD & $\begin{array}{l}\text { Average } \\
\text { Remaining } \\
\text { Weight (\%) }\end{array}$ & SD \\
\hline 250 micro & Red & 30 & 1,96 & 0,66 & 77 & 6 \\
\hline 250 micro & Red & 75 & 1,56 & 0,48 & 80 & 6 \\
\hline 250 micro & Red & 135 & 1,66 & 1,03 & 81 & 11 \\
\hline 250 micro & Red & 180 & 3,19 & 0,11 & 66 & 1 \\
\hline 250 micro & Red & 225 & 5,25 & 1,27 & 39 & 9 \\
\hline 250 micro & Black & 30 & 1,70 & 0,44 & 80 & 3 \\
\hline 250 micro & Black & 75 & 1,78 & 0,61 & 82 & 6 \\
\hline 250 micro & Black & 135 & 1,85 & 0,32 & 78 & 3 \\
\hline 250 micro & Black & 180 & 3,00 & 0,16 & 67 & 4 \\
\hline 250 micro & Black & 225 & 5,01 & 0,79 & 41 & 7 \\
\hline $1 \mathrm{~cm}$ & Red & 30 & 1,40 & 0,46 & 81 & 6 \\
\hline $1 \mathrm{~cm}$ & Red & 75 & 1,56 & 0,47 & 82 & 6 \\
\hline $1 \mathrm{~cm}$ & Red & 135 & 2,34 & 0,37 & 75 & 2 \\
\hline $1 \mathrm{~cm}$ & Red & 180 & 3,06 & 0,45 & 64 & 5 \\
\hline $1 \mathrm{~cm}$ & Red & 225 & 5,58 & 1,10 & 29 & 10 \\
\hline $1 \mathrm{~cm}$ & Black & 30 & 2,04 & 0,46 & 73 & 7 \\
\hline $1 \mathrm{~cm}$ & Black & 75 & 2,12 & 0,64 & 76 & 8 \\
\hline $1 \mathrm{~cm}$ & Black & 135 & 2,56 & 0,38 & 70 & 4 \\
\hline $1 \mathrm{~cm}$ & Black & 180 & 3,21 & 0,31 & 63 & 2 \\
\hline $1 \mathrm{~cm}$ & Black & 225 & 5,54 & 0,62 & 35 & 8 \\
\hline
\end{tabular}


Table A. 10. Remaining weight in litterbags in the milpa soils.

\begin{tabular}{|l|l|l|l|l|l|l|}
\hline Mesh Size & Soil Type & Time (days) & $\begin{array}{l}\text { Average } \\
\text { Mass Loss } \\
\text { (g) }\end{array}$ & SD & $\begin{array}{l}\text { Average } \\
\text { Remaining } \\
\text { Weight (\%) }\end{array}$ & SD \\
\hline 250 micro & Red & 30 & 0,93 & 0,39 & 89 & 3 \\
\hline 250 micro & Red & 75 & 1,43 & 0,30 & 81 & 5 \\
\hline 250 micro & Red & 135 & 1,13 & 0,41 & 85 & 6 \\
\hline 250 micro & Red & 180 & 2,50 & 1,53 & 72 & 14 \\
\hline 250 micro & Red & 225 & 2,34 & 1,17 & 74 & 10 \\
\hline 250 micro & Black & 30 & 2,08 & 0,78 & 73 & 4 \\
\hline 250 micro & Black & 75 & 2,39 & 0,81 & 69 & 1 \\
\hline 250 micro & Black & 135 & 2,75 & 0,23 & 70 & 2 \\
\hline 250 micro & Black & 180 & 4,16 & 0,53 & 57 & 5 \\
\hline 250 micro & Black & 225 & 3,33 & 1,29 & 62 & 9 \\
\hline $1 \mathrm{~cm}$ & Red & 30 & 1,38 & 0,72 & 85 & 8 \\
\hline $1 \mathrm{~cm}$ & Red & 75 & 1,43 & 0,43 & 82 & 6 \\
\hline $1 \mathrm{~cm}$ & Red & 135 & 3,07 & 0,29 & 68 & 3 \\
\hline $1 \mathrm{~cm}$ & Red & 180 & 4,46 & 0,63 & 51 & 5 \\
\hline $1 \mathrm{~cm}$ & Red & 225 & 6,26 & 1,03 & 33 & 9 \\
\hline $1 \mathrm{~cm}$ & Black & 30 & 2,74 & 0,88 & 69 & 10 \\
\hline $1 \mathrm{~cm}$ & Black & 75 & 2,46 & 0,91 & 69 & 11 \\
\hline $1 \mathrm{~cm}$ & Black & 135 & 3,08 & 0,48 & 66 & 1 \\
\hline $1 \mathrm{~cm}$ & Black & 180 & 5,09 & 0,61 & 48 & 2 \\
\hline $1 \mathrm{~cm}$ & Black & 225 & 7,46 & 1,55 & 18 & 14 \\
\hline
\end{tabular}

Table A. 11. N, P Concentrations $\left({\left.\mathrm{g} . \mathrm{kg}^{-1}\right)}^{-1}\right.$ in the maize leaves at the beginning of the litterbags experiment.

\begin{tabular}{|l|l|l|l|l|}
\hline Land Use & $\mathbf{N} \pm \mathbf{S D}$ & $\mathbf{P} \pm$ SD & $\mathbf{C : N}$ & $\mathbf{C : P}$ \\
\hline Forest & $0.31 \pm 0.037$ & $0.05 \pm 0.004$ & 14 & 91 \\
\hline Milpa & $0.32 \pm 0.047$ & $0.05 \pm 0.006$ & 15 & 84 \\
\hline
\end{tabular}




\section{Aknowledments}

I would like to thanks to my supervisor Prof. Dr. Holm Tiessen, for his guidance, advices, and patience, throught this work. Also, I am very grateful to Prof. Dr. Juan Jimenez Osornio from Universidad Autonoma de Yucatan in Mexico, for his support during the fieldwork and for his comments and suggestions. Thanks to Dr. Martin Worbes for his cooperation throughout the process of the presentation and publication of this work.

I am very very much indebted to Dr. Barbara Wick, who gave me a lot of advises, who taugh me some techniques to carry out the measures in the laboratory, for her unreserved assistance throughout the course of this study. Her critical comments and suggestions were invaluable in the developing this thesis.

I want to express my gratitude to Dr. Francisco Herrera, who was my support during the fieldwork, for his ideas, comments and especially for his advises during the difficult moments.

In Mexico, many people help me during the fieldwork; I am very gratefull to Don Alfonso Castillo, Raul Hernandez, and Maria Concepcion Barreras (Conchis) for their assitance. Also, all Protropic's members for their friendship and collaboration. In Germany, the people of the Section of Agronomy in the Tropics were like being in the Tropico!! I wish to thanks Ute Ronsöhr for excellent assistance, support, and cooperation in the laboratory. Naturally, to Dr. Ronald Kühne, for his statistical advises.

This research would not have materialized without the support of many people in others institutes. I would, therefore; like to express my gratitude: in the Soil Science Institute, to Dr. Christian Ahl, Dr. Klaus-Wenzel Becker; also to Karin Schmidt for her assitance and cooperation in the laboratory. At the Faculty of Forestry and Forest Ecology to Anita Kriegel, Christine Brüggemann, and Edith Nadai for their support and assistance during the development of some experiments. I am also very grateful to the Dr. Christian Platner at the Ecology Department in the Faculty of Biology for his help and cooperation in the identification of the soil fauna. 
The extraordinary support of Holger, for his help during the experiments in others institutes, by loading the samples and material. And of course for his incredible patience, moral support, thanks because when the things were wrong, he was always at my side.

I thank to all my friends by their affecting support, for being with me in good and bad times. I don't want to give names; it is not a good idea because I can forget somebody. Everybody know who were with me during these moments...

To Harald and Karin Meyer, for their emotional support. Also, their financial support is of course invaluable. Without their help I would not have been able to complete my studies.

My sincere thankfulness to my family for their moral support. To "Mi Cora" for being with me and tolerate my bad mood. Also, I would like to thanks my mother, who was with me in the last days of the thesis, thanks for her patience. 


\section{CURRICULUM VITAE}

\section{Personal}

Name: Adriana José Campos González

Sex: Female

Date of Birth: 20.01.1974

Place of Birth: Carúpano, Sucre State, Venezuela

Nationality: Venezuelan

\section{Current Address}

Am Weendespring 24

37077 Goettingen

Germany

\section{Permanent Address}

Av. Rio Caroni, Edif. Floresal, Apto. 43, Urb. Cumbres de Curumo

1080 Caracas - Venezuela

e-mail: adrianajcampos@yahoo.es

\section{Education Training}

2002-2004: University of Kassel, Kassel, Germany.

MSc. in Ecological Agriculture.

1990-1999: Central University of Venezuela (Sp. Universidad Central de Venezuela) Caracas, Venezuela.

Diploma: Biologist.

Focus: Ecology.

\section{Professional career}

2000-2001: Assistant to the Research.

Ecology Department, Venezuelan Institute for Scientific Research (Sp. Instituto Venezolano de Investigaciones Cientificas). Km 11 Carretera Panamericana, Urb. Altos de pipe, San Antonio, Miranda State, Venezuela.

1996-1999 : Assistant teaching, Department of Ecology, Biology, Science Faculty Central University of Venezuela (Sp. Universidad Central de Venezuela), Caracas Venezuela. 